\title{
EXAMINATION OF \\ STATEMENTS OF SERVICE PERFORMANCE OF \\ NEW ZEALAND LOCAL AUTHORITIES: \\ THE CASE OF WASTEWATER SERVICES
}

BY

PRAE KEERASUNTONPONG

\begin{abstract}
A thesis
submitted to the Victoria University of Wellington

in fulfillment of the requirements for the degree of

Doctor of Philosophy

in Accounting
\end{abstract}

Victoria University of Wellington

(2011) 


\section{Abstract}

The provision of statements of service performance (SSPs) by local government in New Zealand is a product of the economic reforms carried out in the late 1980s. A statement of service performance is regarded as an important document of New Zealand local government reporting. It is statutorily required by the Local Government Act 2002 and complemented by accounting guidance provided by the New Zealand Institute of Chartered Accountants (NZICA), with the objective of strengthening accountability obligations (Local Government Act 2002, s. 98; NZICA, 2002).

In spite of twenty years' experience in preparing statements of service performance, the Office of the Auditor-General (OAG) (2008) criticised that the quality of SSPs prepared by local authorities (and other public-sector entities) was poor. A fundamental problem of statements of service performance reporting is the lack of comprehensive authoritative requirements on their preparation and presentation (Office of the Auditor-General, 2008). Arguably, the present authoritative requirements have been written to cater for the needs of large, profitoriented entities in the private-sector rather than for the public-sector's specific needs for performance reporting and pitched at a higher or more conceptual level than is typically required for financial reporting standards (Office of the AuditorGeneral, 2008, Webster, 2007). This may be due to the fact that the current authoritative requirements, developed in early 1990s, have been influenced by the economic framework highlighting the decision-usefulness purpose of privatesector reporting, which is not suitable for public-sector reporting (Mack, 2003; 
Parker \& Gould, 1999). Responding to the need for more adequate guidance for non-financial performance reporting of public-sector entities, the OAG and the International Public Sector Accounting Standards Board (IPSASB) are working on improving accounting guidance applicable for the preparation for SSP reporting by public-sector entities (Office of the Auditor-General, 2010; International Public Sector Accounting Standard Board, 2010).

Pallot (1992) points out that accountability is the preferred purpose for publicsector reporting since the nature of the relationship between providers and users of government is non-voluntary. Past theoretical literature has attempted to define the possible components of accountability that would be suitable for public-sector entities to adequately discharge their accountability. Among them, Stewart (1984) has developed accountability bases, which provide a platform for understanding accountability expectations and, hence desirable characteristics of any accountability documents provided by public-sector entities for the public. It is possible that accountability documents pertaining to these accountability expectations will enable the public-sector entities to adequately discharge their accountability.

New Zealand local government is the important second tier of New Zealand government sector. Among the wide range of community services provided by New Zealand local authorities, wastewater services represent one of the most crucial services. New Zealand constituents could be expected to be concerned not only about the performance of wastewater services provided by their local authorities, but also with the disclosures about that performance. However, the 
research on SSP wastewater disclosures by New Zealand local authorities is limited (Smith \& Coy, 2000). Given the criticism on the usefulness of authoritative requirements for SSP reporting and the recognition of accountability expectations by the literature, the first two objectives of this study are to examine the consistency of SSP disclosures, regarding wastewater services provided by New Zealand local authorities, with the existing authoritative requirements, and the accountability expectations, using the disclosure index as a measurement tool. To understand possible explanations for the cross-sectional differences on the extent of disclosures, according to the authoritative requirements and accountability expectations, the third objective of this study is to examine the influential factors of the disclosures, using multiple regression analysis.

The study finds that the performance disclosures made by the local authorities have low levels of correspondence with the index that is based on the authoritative requirements. The result also provides evidence that the current authoritative requirements are focused on financial information reporting and pitched at a high conceptual level. This supports the view that the existing authoritative pronouncements are not providing sufficient guidance for local authorities. The index based on accountability expectations has relatively greater correspondence with the disclosures made. This identifies that local authorities are providing information consistent with accountability expectations. The study suggests that accountability expectations provide a model suitable for SSP reporting guidance. According to the multiple regression analysis, the result shows that only size is significantly related to the extent of the disclosures. Larger local authorities report more corresponding information. 
The findings of this study provide three immediate implications which should be useful to: (i) accounting standard-setters for their current work on improving accounting guidance for SSP reporting; (ii) the Office of the Auditor-General for providing more insightful comments in the audit statement for SSP reporting; and (iii) regulators for increased attention on some special local authorities. By doing so, it is expected that New Zealand local authorities may lead the world in providing comprehensive SSPs, which enable them to adequately discharge their accountability and, hence in reaching a reform principle for greater accountability. 
This doctoral thesis is dedicated to my mother,

Dr Narasri Vivanichakul, who has supported me

by all means, to become a full scholar. 


\section{Acknowledgements}

First and foremost I want to thank my principal supervisor, Professor Keitha Dunstan. It has been a privilege to have her as my supervisor. She taught me how to think more critically and understand research, by use of analogies, particularly the jigsaw example. I appreciate her belief in me, time, advice, encouragement, and patience, which have been so motivational. She has set an excellent example as a lovely, knowledgeable professor.

I am deeply grateful to my secondary supervisor, Dr Bhagwan Khanna. He has guided me in a non-threatening, empathetic way on my research path, assisting me with compliance of administrative requirements, and offering timely words of encouragement and advice.

I am indebted to Adjunct Professor Kevin Simpkins who helped me patiently to cultivate my understanding of the public-sector reforms in New Zealand and accounting guidance environment.

I am also thankful to Professor Brenda Porter, my principal supervisor (retired), for a period of time meticulously editing my writing.

I am very grateful to those who provided funding resources to help me pursue my $\mathrm{PhD}$ study. I was granted full scholarships from Chulalongkorn University for my first four years. My research work was also supported by the New Zealand Institute of Chartered Accountants, and Victoria University of Wellington.

I owe my sincere gratitude to my friend, Dr Carolyn Cordery, who met me on my first day at Victoria University of Wellington. She has always been helpful and encouraging, and showing much kindness during difficult moments in my study.

During my study I have received generous assistance - notably from Prof Judy Brown, Mr Tony Dale, Dr Thu Phuong Truong, Ms Kamy Ooi and Mr Andy Bruere - and constant encouragement from many friends at the School of Accounting and Commercial Law at Victoria University of Wellington, Faculty of Commerce and Accountancy at Chulalongkorn University, and family friends (especially Dr Churaiporn Klaijamlang, and Mrs Pansy Wee). I extend my warm and grateful thanks to them all.

I owe loving thanks to my family for all their care, encouragement and support, particularly my parents, Dr Narasri Vivanichakul and Dr Ittipon Padungcheewit, who, by their example, raised me to become a full scholar, and supported me in all my pursuits. Most of all I thank my loving and patient husband, Tanin Keerasuntonpong, whose rocksolid support throughout my $\mathrm{PhD}$ study has been of such value that words cannot adequately describe it. I also thank my dear sons, Prin and Pratt Keerasuntonpong, for their good behaviour and dedication shown in pursuit of their own dreams, which has been an ongoing source of inspiration to me. Above all, I thank God for the blessings witnessed through these people who have assisted me in the course of my PhD study. 


\section{Table of Contents}

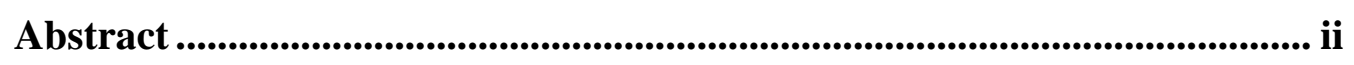

Acknowledgements ................................................................................... vii

Table of Contents...................................................................................................... viii

List of Tables..................................................................................................... xii

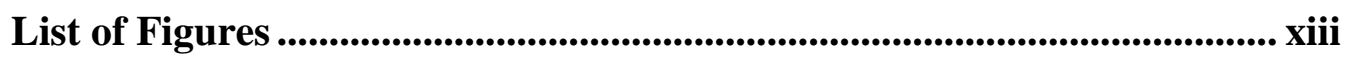

List of Abbreviations................................................................................... xiv

Statement of Originality ............................................................................................

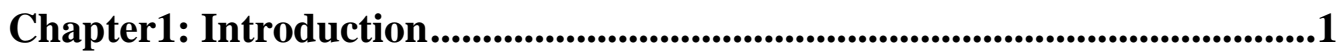

1.1 Study motivations, objectives, and contribution .................................. 1

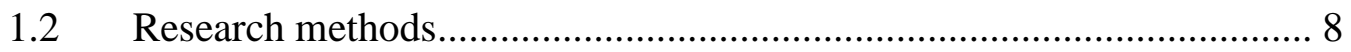

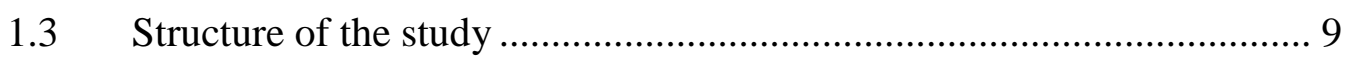

Chapter 2: Service Performance Reporting Requirements for New Zealand Local Authorities .......................................................................................11

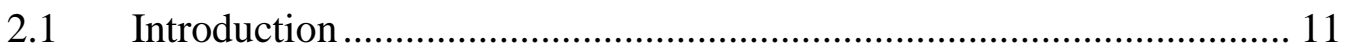

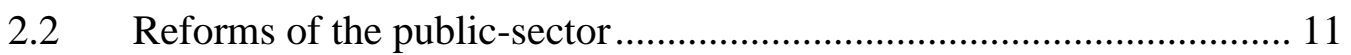

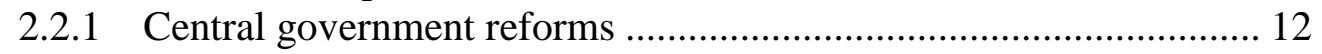

2.2.2 Local government reforms ......................................................... 16

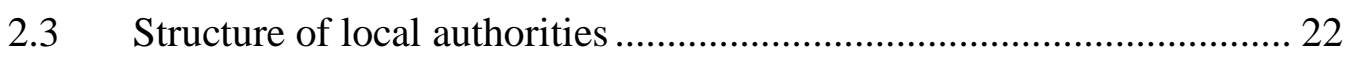

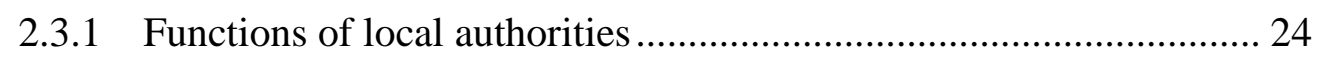

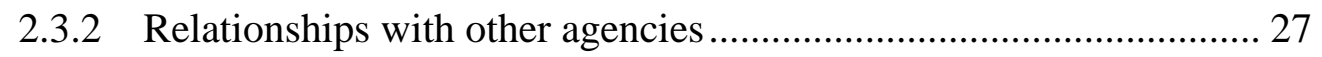

2.4 Financial management of local authorities ...................................... 30

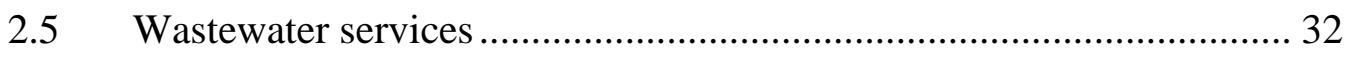

2.6 Accountability mechanisms for local authorities ............................... 37

2.6.1 Long-term council community plans ................................................ 39

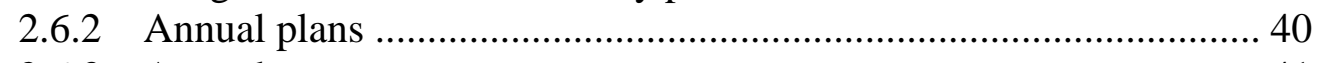

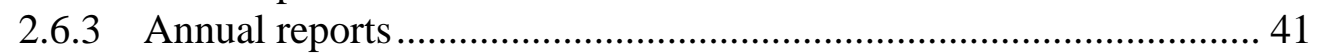

2.7 Authoritative requirements for SSP reporting ….............................. 42

2.7.1 Statutory requirements for SSP reporting .................................... 42

2.7.2 GAAP relevant to SSP reporting …................................................... 43

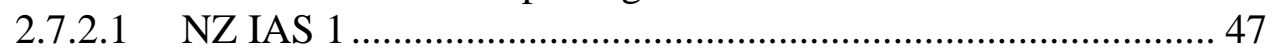

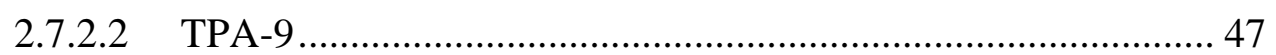

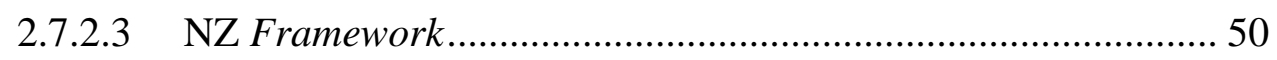

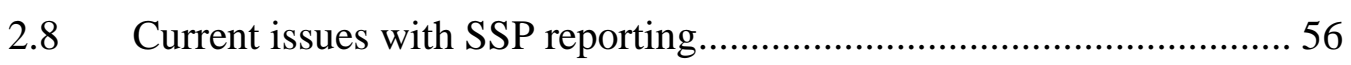

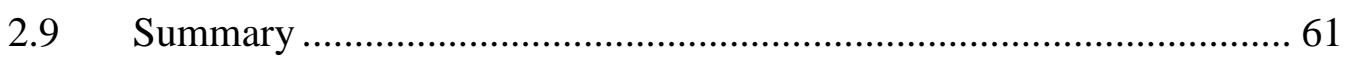


Chapter 3: Accountability and Statements of Service Performance as an Accountability Tool ..................................................................................................63

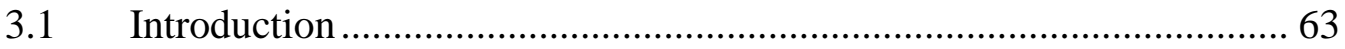

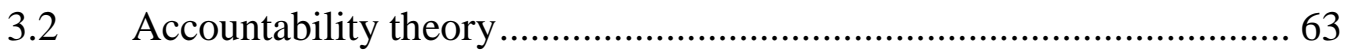

3.3 Types of accountability …………………………………………..... 70

3.3.1 Types of accountability based on 'to whom' an acceptor is

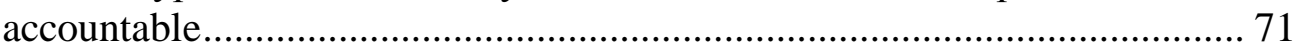

3.3.2 Types of accountability based on 'for what' an acceptor is accountable to the public............................................................................ 75

3.4 Accountability expectations for wastewater services .......................... 80

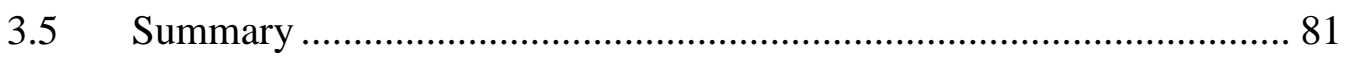

\section{Chapter 4: Review of Empirical Work on Statements of Service}

Performance...................................................................................................83

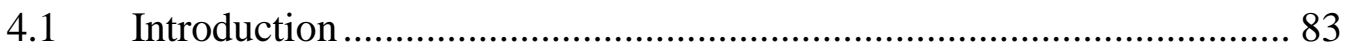

4.2 Prior research on service performance reporting ……………………. 83

4.2.1 Research using authoritative requirements ...................................... 88

4.2.2 Research using accountability expectations ...................................... 89

4.3 Prior research on incentives for service performance reporting ........... 90

4.3.1 The public's demand for information: .............................................. 91

4.3.2 The agent's awareness of political costs ......................................... 94

4.3.3 The agent's capability ................................................................. 95

4.3.4 The agent's awareness of funding benefits ....................................... 97

4.4 Incentives applicable for wastewater disclosures …………………….... 99

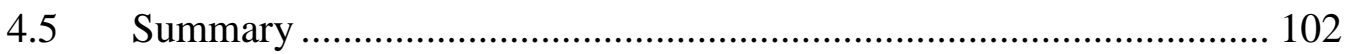

Chapter 5: Methodology for Examining Statements of Service Performance..................................................................................................104

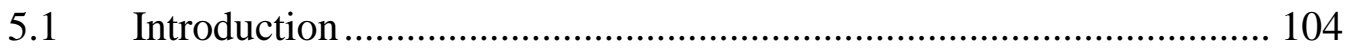

5.2 The methods of analysis.................................................................. 104

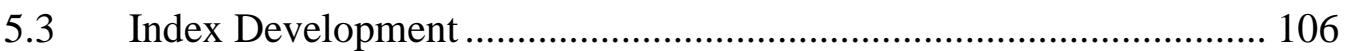

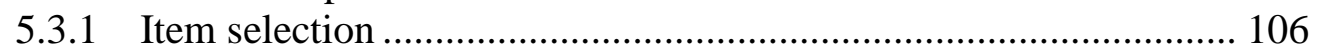

5.3.1.1 Authoritative Requirement (AR) index items ........................ 107

5.3.1.2 Accountability Expectation (AE) index items ........................ 113

5.3.2 Weights determination ............................................................... 116

5.3.3 Scoring development..................................................................... 117

5.4 Independent variables for multiple regression analysis ...................... 120

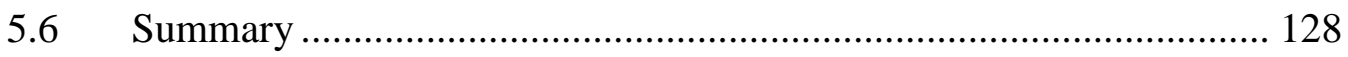




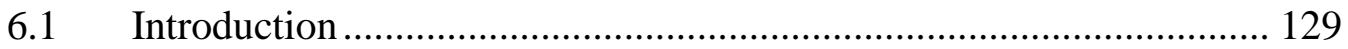

6.2 Form and content of wastewater disclosures ................................... 129

6.3 Authoritative requirement index ….............................................. 132

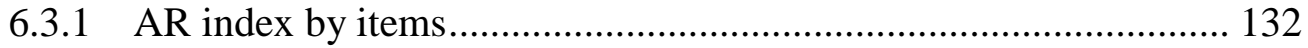

6.3.2 AR Index by local authorities .................................................. 139

6.4 Accountability expectation index..................................................... 141

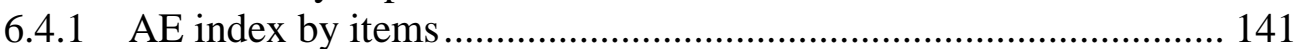

6.4.2 AE index by local authorities .............................................. 145

6.5 Comparing $\mathrm{AR}$ and $\mathrm{AE}$ indices..................................................... 147

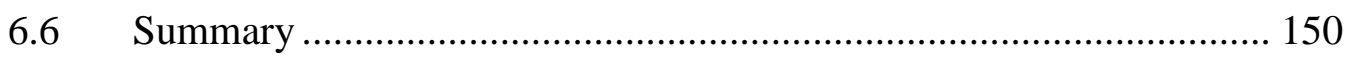

Chapter 7: Results and Analysis of the Factors Influencing Disclosures.153

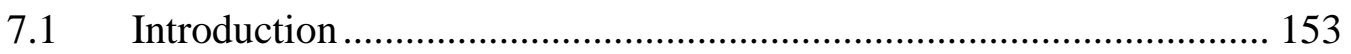

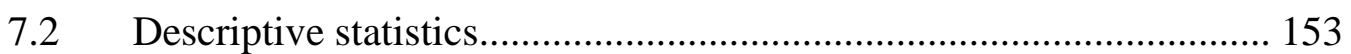

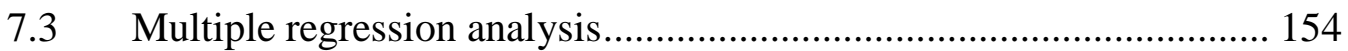

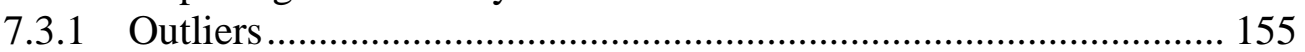

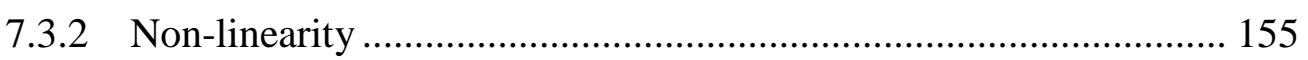

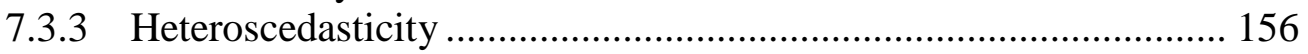

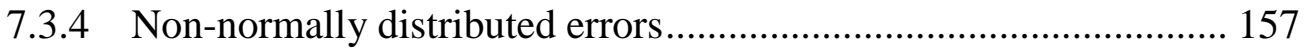

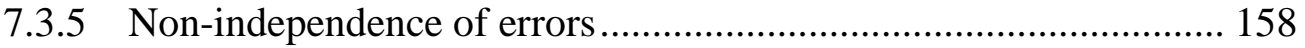

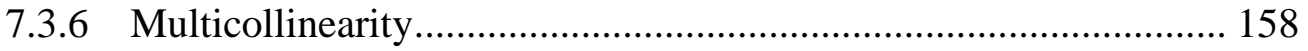

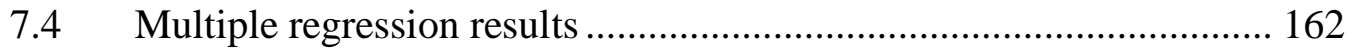

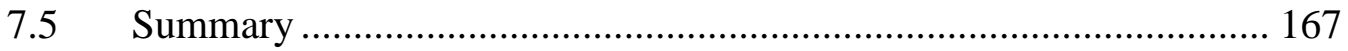

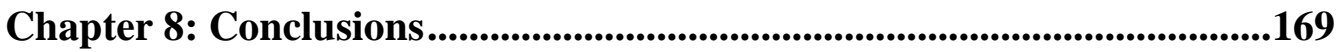

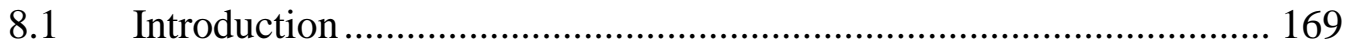

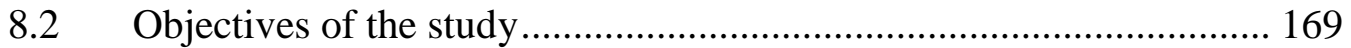

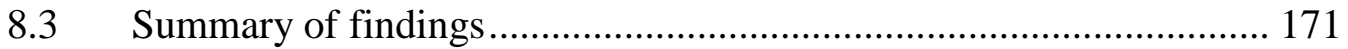

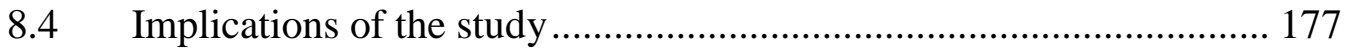

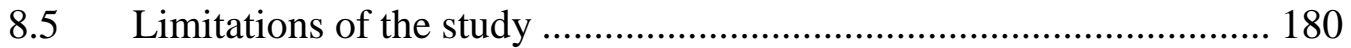

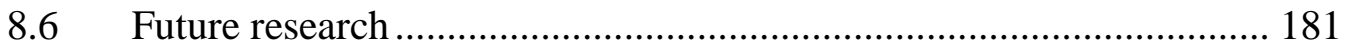


References:

Appendices:

Appendix A: Local authorities' profile between 2004-2008

Appendix B: Examples of prior studies using disclosure indices

Appendix C: Standardised residual and Cook's Distance values for the AR index scores

Appendix D: Standardised residual and Cook's Distance values for the AE index scores

Appendix E: The scatterplot of standardised residuals against standardised predicted value for the AR index

Appendix F: The scatterplot of standardised residuals against standardised predicted value for the AE index

Appendix G: Histogram of standardised residuals for the AR index 203

Appendix H: Histogram of standardised residuals for the AE index 204

Appendix I: Standardised residual and Cook's Distance value of the logarithmic transformed AR index scores

Appendix J: Standardised residual and Cook's Distance value of the logarithmic transformed AE index scores 


\section{List of Tables}

Table 2.1: Sources of operating revenue and items of operating expenditure of local authorities by percentage for the years $2007 / 2008$ and 2008/2009.

Table 2.2: Purpose and content of long-term council community plans, annual plans, and annual reports.

Table 2.3: Example of performance measures and their targets for each dimension of wastewater services.

Table 3.1: Prior researchers' explanations of the term 'accountability'

Table 4.1: Disclosure incentives and their influential factors of publicsector entities.

Table 4.2: SSPs wastewater disclosure incentives and influential factors of New Zealand local authorities.

Table 5.1: Categories and items of the AR index.

Table 5.2: Categories and items of the AE index.

Table 5.3: Summary of empirical results of influential factors affecting disclosures

Table 5.4: Variables used to proxy influential factors for wastewater disclosures

Table 5.5: Independent variables and the data sources

Table 6.1: AR index scores by categories and items

Table 6.2: AR index scores by local authorities.

Table 6.3: AE index scores by categories and items.

Table 6.4: AE index scores by local authorities.

Table 6.5: Statistical descriptives of the AR and AE indices of 73 local authorities.

Table 7.1: Statistical descriptives of dependent and independent variables of 73 local authorities.

Table 7.2: Kendall's tau_b correlation coefficient among independent variables.

Table 7.3: Multiple regression results for the AR index

Table 7.4: Multiple regression results for the AE index 


\section{List of Figures}

Figure 2.1: Connection of components of authoritative requirements in the context of wastewater disclosures.

Figure 3.1: Procedures involved in a simple accountability

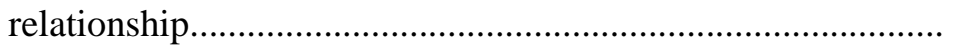

Figure 3.2: Directional accountability of an acceptor within and outside a hierarchical structure............................................................... $\quad 72$

Figure 6.1: Histogram of the AR index...................................................... 140

Figure 6.2: Histogram of the AE index....................................................... 146

Figure 6.3: Box plot for the AR and AE indices............................................ 149 


\section{List of Abbreviations}

$\mathrm{AE}$

AR

$\mathrm{CC}$

DC

FRS-2

GAAP

LTCCP

NPM

NZ Framework

NZ IAS 1

NZICA

OAG

SOC

SSP

TPA-9

VIF
Accountability expectation

Authoritative requirement

City Council

District Council

Financial Reporting Standard 2: Presentation of Financial Reports

Generally accepted accounting practice

Long-term council community plans

New public management

the New Zealand Equivalent to the International Accounting Standard Board Framework for the Preparation and Presentation of Financial Statements

New Zealand Equivalent to International Accounting Standard 1: Presentation of Financial Statements

New Zealand Institute of Chartered Accountants

Office of the Auditor-General

Statement of Concepts for General Purpose Financial Reporting

Statement of Service Performance

Technical Practice Aid No. 9: Service Performance Reporting

Variance Inflation Factor 


\section{Statement of Originality}

This is to certify that the work contained in this thesis has never previously been submitted for a degree or diploma in any university and that, to the best of my knowledge and belief, the thesis contains no material previously published or written by another person except where due reference is made in the thesis itself.

Prae Keerasuntonpong

Date 


\section{Chapter1: Introduction}

\subsection{Study motivations, objectives, and contribution}

The provision of service performance information by local government in New Zealand is a product of the economic reforms carried out in the late 1980s. The New Zealand public-sector has been subject to extensive reforms since 1985 . These reforms, commonly referred to as New Public Management (NPM) ${ }^{1}$ (Pallot, 1998; Whitecombe, 2008), are similar to reforms undertaken in the United Kingdom, Australia, and many other Western European countries (Olson, Guthrie, \& Humphery, 1998; Parker \& Gould, 1999). Adoption of private-sector practices, pursuit of efficiency and effectiveness of service delivery, and development of explicit performance targets and measures, thereby leading to greater accountability to consumers, are the three major principles of NPM (Glynn \& Perkins, 1997; Parker \& Gould, 1999). As a result, commercialisation, privatisation, outsourcing, and downsizing characterised the pattern of reforms (Parker \& Gould, 1999). Performance measurement in the public-sector, which had traditionally focused on inputs, shifted to outputs and outcomes (J. Dixon, Kouzmin, \& Korac-Kakabadse, 1998). Today, public-sector entities are formally held accountable for outputs (Parker \& Gould, 1999).

New Zealand embraced the reforms suggested by NPM paradigm, within an economic framework primarily based on agency theory and public choice to develop principles that were used to guide wide reaching public-sector reform in

\footnotetext{
${ }^{1}$ In Western democracies, these reform efforts have also been referred to as managerialism and marketisation (Guthrie \& Parker, 1998; Ryan, Stanley, \& Nelson, 2002).
} 
New Zealand (Pallot, 1998). Based on an economic notion of accountability, those principles were enhanced transparency, distancing of politicians from dayto-day administration, performance specification and monitoring, and devolution of activities from central government to local government, Crown entities or the private-sector (Pallot, 1998). In the area of performance specification and monitoring, New Zealand public-sector entities led the world in producing output performance reporting statements, known as "statements of service performance" (SSPs) (Neale \& Pallot, 2001). SSPs present non-financial information about the performance of entities in providing goods and services (outputs), with the stated objective of strengthening accountability to the public (Local Government Act 2002, s. 98; NZICA, 2002, para 1.10; 2004, para. 126.2). Statements of service performance provide a comparison between actual service performances and the targets of service performance (as set out in the plan), with reasons given for any significant variances (Local Government Act 2002, Schedule 10; Public Finance Act 1989 , s. 45A). They need to be prepared in compliance with generally accepted accounting practice (GAAP) ${ }^{2}$ and audited by the Auditor-General (Local Government Act 2002, s. 99; Public Finance Act 1989, s. 45D).

Parallel with the reform, accounting guidance for SSP reporting was developed and devolved with insignificant change over time with prevailing economic emphasis. The current GAAP relevant to SSP reporting comprises the New

\footnotetext{
${ }^{2}$ In the context of local authorities' financial reports (which may contain both financial and nonfinancial information) GAAP refers to financial reporting standards approved by the Accounting Standards Review Board. For matters where there is no approved financial reporting standard, GAAP requires compliance with accounting standards promulgated by the New Zealand Institute of Chartered Accountants (NZICA) and international financial reporting standards that are appropriate and have authoritative support within New Zealand (Local Government Act 2002, s. $5)$.
} 
Zealand Equivalent to International Accounting Standard 1: Presentation of Financial Statements (NZ IAS 1), ${ }^{3}$ the New Zealand Equivalent to the International Accounting Standard Board Framework for the Preparation and Presentation of Financial Statements (NZ Framework) ${ }^{4}$, and Technical Practice Aid No. 9 (TPA-9): Service Performance Reporting ${ }^{5}$.

In spite of twenty years' experience in preparing statements of service performance, SSP reporting by the New Zealand public-sector, as well as its accountability to the public, have been criticised as poor. The Office of the Auditor-General (OAG) (2008) expressed its disappointment in the quality of the reports and their discharge of accountability obligations to the public.

The Office of the Auditor-General (2008) pointed out that a fundamental problem of SSP reporting is the lack of comprehensive standards for their preparation and presentation. Webster (2007) contends that the authoritative requirements for service performance reporting have been based on a higher or more conceptual level than is typical for financial reporting standards. In particular, the Office of

\footnotetext{
${ }^{3}$ NZ IAS 1 sets out the basis for the presentation of general purpose financial reports, which include financial statements, SSPs and supplementary information. This standard was prepared by NZICA and approved by the Accounting Standards Review Board in November 2004; it supersedes Financial Reporting Standard No.2: Presentation of Financial Reports (FRS-2) (1994); and Financial Reporting Standard No.9: Information to be Disclosed in Financial Statements (FRS-9) (1995). New Zealand entities must apply NZ IAS 1 for annual accounting periods commencing on or after 1 January 2007 (NZICA, 2004).

${ }^{4}$ The NZ Framework provides concepts that underlie the preparation and presentation of general purpose financial reports. This standard was prepared by NZICA and approved by the Accounting Standards Review Board in June 2005; it supersedes the Statement of Concepts for General Purpose Financial Reporting (1993). New Zealand entities must apply the NZ Framework for annual accounting periods commencing on or after 1 January 2007 (NZICA, 2005).

${ }^{5}$ TPA-9 provides guidelines on the preparation of SSPs in order to promote the provision of high quality information to users. It was prepared by NZICA in November 2002. Although it is based on the Statement of Concepts for General Purpose Financial Reporting and FRS-2: Presentation of Financial Reports, which have been superseded by NZ Framework and NZ IAS 1, TPA-9 remains the best guidance in New Zealand on SSP reporting. It was re-endorsed by the Financial Reporting Standards Board and included in the 2007 Member's Handbook and the 2007 Annual Accounting Standards publication (NZICA, 2007a). TPA-9 (2002) underwent a limited revision in 2007, including the recognition of NZ IAS 1 and NZ Framework.
} 
the Auditor-General (2008) adds that New Zealand Equivalents to International Financial Reporting Standards (including NZ IAS 1, NZ Framework) are written to cater for the needs of large, profit-oriented entities in the private-sector rather than for the public-sector's specific needs for performance reporting. It is possible that the economic framework based on decision-usefulness purpose of private-sector's reports is not suitable for public-sector reporting (Mack, 2003; Parker \& Gould, 1999). It seems that the current authoritative requirements legislation and GAAP - for the New Zealand public-sector's SSP reporting provide inadequate guidance on the preparation of SSPs; however, limited empirical study has been carried out to specifically investigate the usefulness of the authoritative requirements for SSP reporting by public-sector entities in New Zealand.

The OAG seemingly responded to the call for more adequate guidance on SSP reporting. In 2010, the OAG issued the discussion paper - Local Government Examples of Better Practice in Setting Local Authorities' Performance Measures - with the stated purpose of improving 2011/2012 performance information (Office of the Auditor-General, 2010). The paper provides examples of performance measures for each of the core services (for example, wastewater services) provided by New Zealand local authorities. In addition, the International Public Sector Accounting Standards Board (IPSASB) is in the process (Exposure Draft) of issuing Conceptual Framework for General Purpose Financial Reporting by Public Sector Entities (International Public Sector Accounting Standard Board, 2010) which the New Zealand Accounting Standards Review Board intends to adopt once it becomes effective (Accounting Standards 
Review Board, 2011). This new conceptual framework includes the accountability purpose for public-sector's reporting.

Researchers have also been similarly critical of the New Zealand public-sector's SSPs and their role in the discharge of accountability to the public (Coy, Tower, \& Dixon, 1994; Thompson, 1995). Most research examining the SSPs of New Zealand public-sector entities tends to focus on the education sector (for example, Alves, Dunmore, \& Dunstan, 2005; Coy, et al., 1994; K. Dixon, Coy, \& Tower, 1991) rather than government entities. With only a few existing research studies of government entities' SSPs, the research on central government is more up-todate (Lonti \& Gregory, 2007). However, for local government, the most recent study was Smith and Coy (2000). Further, in Smith and Coy's (2000) study, while SSP disclosures were considered, they were one part of the whole annual report disclosures being studied, and thus the analysis of the SSP disclosures was scant.

Local government is the important second tier of the New Zealand government sector. ${ }^{6}$ Local authorities have coercive powers to tax, rate, or levy their local communities (including tax/rate payers) to obtain public funds. Their roles are to use the funds raised to provide the majority of community services including, wastewater services. Without opportunities to choose between alternative service providers, local communities are reliant on the services provided by their local

\footnotetext{
${ }^{6}$ New Zealand government is modelled on the British system and is referred to as Westminsterstyle government (Scott, 1996). It comprises two complementary and independent legal entities: local government and central government (McLintock, 1966). While local government's role focuses on urban and rural services, paid for from property taxes, central government's role is largely restricted to economic policy and to controlling all government spending on health, education, and welfare (Scott, 1996).
} 
authorities (Ives, 1987). Further, local communities also rely on service performance information to be able to make informed judgements about the performance of their local authorities and understand how their monies were spent (Mack \& Ryan, 2006). Service performance information is the necessary means by which local authorities attempt to discharge their accountability to the public (Barton, 1999; Boyne \& Law, 1991; R. Gray, Owen, \& Adams, 1996; Hyndman \& Anderson, 1995).

Among the wide range of community services provided by local authorities, wastewater services are one of the most crucial services. Traditionally, all city/district councils have been statutorily responsible for providing wastewater services (Bush, 1995; Local Government Act 2002, s. 130), which accounts for one of the major items of expenditure (nine percent of total expenditure) by local authorities (The Department of Internal Affairs, 2010). Wastewater contributes the largest volume of waste in New Zealand (approximately 1.5 billion litres are discharged daily) and can have a wide impact on human health and the physical environment, as well as having potential long-term consequences if not properly managed (Ministry for the Environment, 2010b). Consequently, New Zealand constituents could be expected to be concerned not only with the performance of wastewater services provided by their local authorities but also with their disclosures in SSPs about the service performance.

In view of criticisms by the OAG and researchers of SSP reporting, and the limited evidence on the usefulness of the current authoritative requirements, the first objective of this study is to examine the consistency of SSP disclosures, 
regarding wastewater services provided by New Zealand local authorities, with the existing authoritative requirements. This result will provide evidence on the correspondence of the report to the authoritative requirements and may identify the applicability (or otherwise) of the existing accounting framework for SSP reporting. This may offer suggestions for consideration to accounting standardsetters for the current improvement of SSP accounting guidance.

Some researchers have been critical about the manner in which public-sector reforms have addressed the need for accountability. Parker and Gould (1999) contend that reform models applying accountability through an economic lens and based on private-sector practice did not fully embrace the complexities of true public-sector accountability. There is vast public-sector literature addressing the multi-facets of accountability in the public-sector. This has attempted to define the possible characteristics of suitable information for public-sector entities so as to adequately discharge their accountability obligations. Among them, Stewart (1984) identifies four normative bases of accountability for public-sector entities, which provide a platform for understanding accountability expectations applicable for wastewater disclosures. They are probity, legality, process/efficiency, performance/programme/effectiveness accountability. It is possible that SSPs pertaining to these accountability expectations would ensure the adequacy of local authorities' discharging their accountability to the public. The second objective of this research is to examine the consistency of wastewater service disclosures in SSPs provided by New Zealand local authorities with these normative accountability expectations as derived from the literature. The results of this measurement will provide evidence of whether SSPs by New Zealand local 
authorities are disclosed in a manner which is suitable for evaluating the performance in accordance with the accountability framework. Hence, the result may support (or otherwise) the suitability of accountability expectations derived from the literature, as a model for the current improvement of SSP reporting guidance, which may be useful for accounting standard-setters.

The consistency of SSP disclosures with authoritative requirements and accountability expectations may vary within and/or among local authorities depending on various factors. Some prior research on public-sector reporting (Baber, 1983; Baber \& Sen, 1984; Boyne \& Law, 1991; Evan \& Patton, 1987; Giroux, 1989; Ingram, 1984; Laswad, Fisher, \& Oyelere, 2005; Zimmerman, 1997) discusses disclosure incentives and uses various influential factors of disclosures to examine their relationships with the disclosures. Such research provides some understanding of possible explanations for cross-sectional differences in disclosures. The third objective of this research is to examine the influential factors that may explain cross-sectional differences of wastewater disclosures in SSPs made by local authorities, as measured according to the authoritative requirements and accountability expectations. The findings may identify the influential factors affecting SSP disclosures and provide suggestions to regulators for the ways to improve the SSP reporting by local authorities in New Zealand.

\subsection{Research methods}

Wastewater disclosures will be extracted from SSPs presented in the 2007/2008 annual reports of all 73 local authorities in New Zealand. In order to 
quantitatively measure the consistency of SSP disclosures with the authoritative requirements and accountability expectations, two separate disclosure indices will be developed. The first index is the authoritative requirement (AR) index, measuring the consistency between wastewater disclosures and authoritative requirements; and the second index is the accountability expectation (AE) index, measuring the consistency between wastewater disclosures and accountability expectations.

Size of constituency, sophistication of constituents, staff availability, staff attributes, financial resources availability, and political visibility will be investigated as potential factors that influence the extent of consistency of the disclosures with authoritative requirements and accountability expectations. Multiple regression analysis will be used to examine the relationships.

While wastewater disclosures represent only a small sample study of a subset of the responsibilities of local government, they provide the opportunity to use a method of analysis which may be useful to future researchers in addressing similar questions. Further, the study's results may provide a base-line for any future research investigating the impact of the accounting guidance.

\subsection{Structure of the study}

Chapter 2 outlines the background to the statements of service performance requirements and wastewater services for New Zealand local authorities. In essence it identifies the current authoritative requirements for SSPs reporting, according to legislation and relevant generally accepted accounting practice. An analysis of the accountability concept as the theoretical foundation to SSP 
reporting is provided in chapter 3. Drawing from accountability literature, accountability expectations for wastewater disclosures are developed. Chapter 4 reviews the empirical work on service performance reporting, and identifies disclosure incentives as well as their influential factors applicable to wastewater disclosures by New Zealand local authorities.

The methodology used for measuring the consistency of wastewater disclosures with the authoritative requirements and accountability expectations, and for investigating the association of influential factors with SSPs is outlined in chapter 5. The independent variables of influential factors are also identified in chapter 5 . Chapter 6 discusses results from the measurement of the consistency of disclosures with authoritative requirements and accountability expectations. Chapter 7 reports on results of the multiple regression analysis undertaken to investigate the relationships between influential factors and wastewater disclosures. The thesis concludes with chapter 8 which summarises the findings, implications and limitations of the study, and future research possibilities. 


\section{Chapter 2: Service Performance Reporting Requirements for New Zealand Local Authorities}

\subsection{Introduction}

This chapter provides background to the statements of service performance requirements and wastewater services for New Zealand local authorities. Section 2.2 reviews the reforms which gave rise to the requirements. The current structure of local government and its financial management are outlined in sections 2.3 and 2.4. Section 2.5 discusses the operation of wastewater services and the related regulatory requirements for local authorities in providing the services. Section 2.6 discusses the accountability mechanisms faced by local authorities. Sections 2.7 identifies the authoritative requirements from the statutory requirements and generally accepted accounting practice (GAAP), relevant to SSP reporting; and current issues of service performance reporting are discussed in section 2.8. A summary of the chapter is provided in section 2.9.

\subsection{Reforms of the public-sector}

The requirement for local government in New Zealand to provide SSPs is a product of economic reforms carried out in the 1980s. In 1984, New Zealand faced an economic crisis of slow economic growth, high fiscal deficit, and high debt (McCulloch \& Ball, 1992; Scott, 1996). The public-sector, in particular the government sector, was seen as a major contributor to problems, with government expenditure amounting to 40 percent of gross domestic product (McCulloch \& Ball, 1992; Scott, Ball, \& Dale, 1997; Scott \& Gorringe, 1989). Such problems 
focused attention on the need to improve performance, in terms of efficiency, effectiveness, and accountability of the government sector (Coy \& Pratt, 1998; McCulloch \& Ball, 1992; Scott, et al., 1997). The programme of reforms included transferring activities producing private goods from government units to corporations owned by the government; restructuring government organisations; giving more power to chief executives; adopting accrual accounting, defining performance and performance measurement by focusing on outputs and outcomes, and introducing ex ante and ex post financial and non-financial service performance reporting (Scott, et al., 1997; Scott \& Gorringe, 1989). The extensive reforms of the New Zealand public-sector began with the central government, which set the model used for the local government reforms (Pallot, 2001c).

\subsubsection{Central government reforms}

Central government departments owned and operated many of the country's core infrastructure businesses in 1984, for example, banking, postal, telecommunications, a steel mill, a shipping company, production forests, electric power, and a large highway construction business (Bale \& Dale, 1998). The majority of these activities were nearly all run at a loss and required tax-payer support (Bale \& Dale, 1998). Departments were criticised for being too large, inefficient, and poorly managed, with a lack of transparency and accountability (Bale \& Dale, 1998; Office of the Auditor-General, 1978; Pallot, 2001b; Scott, et al., 1997; Scott \& Gorringe, 1989). Budgets were exceeded, unused balances were spent in sprees at year-end, creative accounting was used to give the 
appearance of good performance, and assets and cash were not managed systematically (Bale \& Dale, 1998). In addition, some departments were seen as unresponsive to politicians (Bale \& Dale, 1998). The accountability of government departments to Parliament had long been criticised as inadequate by the Office of the Auditor-General, as highlighted in its 1978 report Financial Management and Control in Administrative Government Departments 1978 (known as the "Shailes Report") (Office of the Auditor-General, 1978, para 2.5). ${ }^{7}$

The government adopted a model based on agency theory and public choice theory as the basis for reforms with which to tackle the accumulation of problems in central government administration (Scott \& Gorringe, 1989). The changes began by separating activities that government departments should provide from the trading activities that were to be provided by corporatised, state-owned enterprises (Bale \& Dale, 1998; Scott \& Gorringe, 1989). ${ }^{8}$ The second step was to reorganise the structure and management of the remaining departments (Bale \& Dale, 1998; Scott \& Gorringe, 1989). Chief executives (formerly known as heads of departments) are today appointed by the State Services Commission ${ }^{9}$ and negotiate their performance agreement with the minister responsible, who can allocate rewards or impose penalties for their performance, according to those

\footnotetext{
${ }^{7}$ In particular, the report criticised that the Estimates and departmental reports contained insufficient information on programme objectives, achievements, and full costs involved (Office of the Auditor-General, 1978, para 2.5). The report included recommendations for the development of quantitative measures of the achievements (para 4.1), and an emphasis in the Estimates on activities (para 9.7), and reporting to parliament on activities and achievement of objectives (para 9.8).

${ }^{8}$ Such state-owned enterprises are managed and operated similarly to firms in the private-sector, but their stock cannot be publicly traded (Bale \& Dale, 1998; Scott \& Gorringe, 1989)

${ }^{9}$ The State Services Commission is the government's principal advisor on New Zealand's public management system. It works with government entities to ensure that the New Zealand government operates efficiently and effectively. Additionally, it also recommends departmental chief executive appointments and reviews chief executive performances (State Services Commission, 2002; The Treasury, 1996).
} 
agreements (Bale \& Dale, 1998). In turn, chief executives can hire and fire department staff, set staff salaries, and negotiate conditions of their employment (Bale \& Dale, 1998; Scott, 1996; Scott \& Gorringe, 1989).

While the chief executive of a department can be seen as a service deliverer, the minister of the department can be seen as an owner of the department (similar to a shareholder of a firm) and purchaser (like a customer of that firm) of the department's services (McCulloch \& Ball, 1992). As owner of the resources of a government department, a minister would wish to ensure that capital assets are used efficiently and that the department maintains a capacity to provide services efficiently in the future (The Treasury, 1996). Hence, a minister would be interested in financial reporting (for example, expenditure, using full accrual accounting) (McCulloch \& Ball, 1992; The Treasury, 1996). As a purchaser of services, a minister would need services to be provided at specified quantities and quality for the lowest prices, whether buying them from his/her department or from other sources. Therefore, the purchase agreement was introduced, similar to a sale contract from the chief executive to the minister, who is likely to require information regarding quantity, quality, time and place of service-delivery, and price (McCulloch \& Ball, 1992). Chief executives must now provide and report on services delivered for which they are accountable (The Treasury, 1996). The reforms emphasised that chief executives are service providers contracted by their ministers through purchase agreements. Consequently, chief executives are today held accountable for their services (outputs) delivered. 
It may be seen from the above that while chief executives are responsible for producing specified outputs from their departments, ministers are responsible for the choice of outputs and, by implication, for outcomes (Bale \& Dale, 1998; McCulloch \& Ball, 1992). Outputs are goods and services produced by departments; outcomes are the impact of those outputs on the community (Scott, 1996). Arguably, outcomes cannot be controlled by the chief executive and are influenced by many different factors; therefore, the chief executive should not be held accountable for outcomes. However, outcomes are measures of governmental success and the purpose of government activities (Scott, 1996; Scott, et al., 1997). Chief executives can control outputs and thus be held accountable for them (Bale \& Dale, 1998). They set out the detail of outputs to be delivered ex ante in the purchase agreement, which are later approved by Cabinet and appropriated by Parliament (Bale \& Dale, 1998; McCulloch \& Ball, 1992; Scott, et al., 1997). Once approved and appropriated, outputs and related costs become the basis for assessing the department's performance (Scott, et al., 1997).

To facilitate changes, the new system of financial management was introduced which included the adoption of accrual accounting, development of performance measurement, focusing on outputs, and the reporting and monitoring of performance (Scott \& Gorringe, 1989). Accrual accounting now provides the fundamental basis for appropriation in budget and financial reporting. The appropriations by Parliament were changed to funding for departmental outputs (previously inputs), based on an accrual accounting of inputs, and chief executives have the freedom to choose inputs from any provider (Scott \& Gorringe, 1989). 
Information about the full costs (including cost of assets, liabilities, and returns, as well as cost of outputs) is needed for performance evaluation of the department.

At the end of the period the department must present, ex post, full financial statements, as well as statements of service performance (SSPs), which provide details of the actual delivery of outputs against the specifications agreed to and approved ex ante. These ex post financial statements and SSPs are required to be prepared so as to be consistent with generally accepted accounting practice, and to be audited (McCulloch \& Ball, 1992). These reports provide the basis for a Parliamentary committee to review the department's performance (Scott, et al., 1997) and to improve the quality of performance of departments (Scott \& Gorringe, 1989).

The reforms of central government have brought about different levels of changes: in the structure of the relationship between ministers and chief executives, to the roles of ministers and chief executives, and to reporting. To give effect to these changes in central government, the State Sector Act of 1988, and the Public Finance Act of 1989 were passed (McCulloch \& Ball, 1992).

\subsubsection{Local government reforms}

The reforms of local government closely followed central government reforms, and were equally dramatic (Pallot, 2001c). As in central government reforms the 1989 local government reforms included organisational restructuring, corporatisation, separation of policy advice and service delivery, increased powers for chief executives, adoption of accrual accounting, and the introduction of reporting, ex ante and ex post, including SSPs. 
The problems of New Zealand local government management could be traced to the late nineteenth century. After the abolition of provinces in 1876, New Zealand had a local government system which was modelled almost entirely on the British system (McLintock, 1966; Pallot, 2001b; Scott, 1979). There were two main types of local authorities: general-purpose local authorities and specialpurpose (or ad hoc) authorities. General-purpose local authorities consisted of county councils, ${ }^{10}$ cities and boroughs, ${ }^{11}$ town districts, ${ }^{12}$ and road districts. ${ }^{13}$ Special-purpose authorities were responsible for only one major function, for example, fire authorities, harbour boards, hospital boards, land drainage boards, milk boards, rabbit boards, river boards (McLintock, 1966). The number of local authorities and special purpose authorities had greatly increased over the years (McLintock, 1966); by 1974, there were 991 local authorities, comprising 357 general purpose local authorities and 634 special-purpose authorities (Scott, 1979).

This proliferation of local authorities caused much dissatisfaction, as their functions often overlapped (McLintock, 1966). In particular, there was confusion between the roles of councillors and senior management, inefficient service provision, conflict between commercial and non-commercial activities, inefficient use of resources, and poor accountability by local authorities to their

\footnotetext{
${ }^{10}$ County councils primarily administer rural areas. However, some county councils administered urban areas containing more than 200 persons, and were known as county towns (McLintock, 1966).

11 City is another name for boroughs which have population more than 20,000. Generally, boroughs would have a population of more than 1,500. Both boroughs and cities had the same powers and functions (McLintock, 1966).

12 Town districts could be independent and dependent of county control. Independent town districts were like small boroughs so far as functions and powers were concerned (McLintock, 1966).

${ }^{13}$ Road districts were responsible for district roading (McLintock, 1966).
} 
constituencies (McKinlay, 1998). Reform of the Local Government Act 1974 attempted to reduce the numerous local authorities and the problems referred to above. However, as the amalgamation of local authorities was neither mandatory nor effective, it has been argued that the problems of local authorities continued (Palmer, 1993).

In 1987, the Minister of Local Government ${ }^{14}$ announced a comprehensive programme of reforms based on three main principles: (i) local authorities should have clear, non-conflicting objectives, including a clear separation between regulatory and service delivery functions; (ii) trade-offs between objectives should be made explicit and in a transparent manner; (iii) clear and strong accountability mechanisms should be encouraged (Pallot, 2001b). The Local Government Amendment Act 1989 (a successive amendment to the Local Government Act 1974) set out changes to the fundamental system of local government in the history of local government that were significant (McKinlay, 1998).

Overnight the number of local authorities was reduced from 991 to 87 local authorities, comprising principally 13 regional councils and 74 territorial authorities (cities and districts councils) (Bush, 1995; Wallis \& Dollery, 2000). Regional councils and territorial authorities were to be regarded as separate bodies but with complementary functions, rather than as two levels of sub-national government (Pallot, 2001b). In general, the core functions of regional councils were to be in the area of environmental management, regulated by environmental law. By contrast, the functions of territorial authorities included a wide range of

\footnotetext{
${ }^{14}$ Dr Michael Bassett was the Minister of Local Government (Wallis \& Dollery, 2000).
} 
social, economic, and infrastructure development roles for their communities (Bush, 1995; Wallis \& Dollery, 2000). The core services provided by territorial authorities related to water supply, wastewater systems, stormwater, and land drainage. Local authorities were encouraged to corporatise their commercial activities (such as refuse collection and disposal, commercial forestry) with the establishment of Local Authority Trading Enterprises (LATES), similar to the establishment of state-owned enterprises of central government (Pallot, 2001b). ${ }^{15}$

Elected councillors were separated from day-to-day management (such as community service delivery) in order to focus on policy setting, and to review the chief executive's performance in implementing policy (McKinlay, 1998; Pallot, 2001b). Elected councillors appointed the chief executive (formerly known as the senior administrator with permanent tenure) to manage day-to-day operations for fixed terms of up to five years, renewable for another three years, depending on the performance agreement negotiated with councilors (Wallis \& Dollery, 2000). The chief executive could in turn appoint employees of the council and negotiate their employment contracts (McKinlay, 1998; Pallot, 2001b; Wallis \& Dollery, 2000).

In terms of financial management, each local authority was required to be financially autonomous. Apart from grants for road construction and maintenance, local authorities were to receive very little funding from central government. Their revenue was to come primarily from property taxes (rates) and user-charges (Pallot, 2001b). Consequently, local authorities were expected to be

\footnotetext{
${ }^{15}$ Local Authority Trading Enterprises are now known as council-controlled organisations
} introduced under sections 6 and 7 of the Local Government Act 2002. 
more accountable to their citizens (the electorate or ratepayers), who were viewed as consumers, while also remaining accountable to Parliament (Neale \& Anderson, 2000; Pallot, 2001b).

Consistent with the new system of financial management in central government, the 1989 Amendment Act also moved financial systems to accrual accounting and reporting by the requirement to adopt generally accepted accounting practice (GAAP) recognised by the New Zealand accounting profession (Local Government Act 1974, s. 223E; McKinlay, 1998). The Amendment Act introduced requirements for local authorities to publish ex ante and ex post document - annual plans and annual reports. Annual plans set out their intended significant policies and objectives to be achieved, significant activities to be undertaken, performance targets for each service or output, budgeted costs, and resources (Local Government Act 1974, s. 223D), providing the bases for judging performance. The annual plan focuses on the coming year (commencing 1 July) in particular terms, and for the next two in general terms; it must be audited and can only be adopted through the special consultative procedure ${ }^{16}$ (Local Government Act 1974, s. 716A; McKinlay, 1998; Pallot, 2001b).

The annual report is an assessment of the local authority's performance against the matters provided in the annual plan (McKinlay, 1998). The annual report is required to explain the performance of the local authority against the planned policies, objectives, activities, performance targets, budgeted costs, and source of funds as set out in the annual plan (Local Government Act 1974, s. 223 E).

\footnotetext{
${ }^{16}$ Special consultative procedure is introduced in the Local Government Act 1989. It ensures the availability of draft plan and the opportunity for the public to make submissions (Pallot, 2001b).
} 
Specifically, the annual report must include both financial as well as non-financial service performance information which must be audited by the Controller and Auditor- General (Local Government Act 1974, s. 223E). The (non-financial) service performance information within annual reports is the statement of service performance (SSPs) as also introduced in the central government reform. The Amendment Act requires that statement to provide a comparison between the actual performance of the local authority and the projected performance as set out in the plan (Local Government Act 1974, s. 223E).

The next wave of the reforms included the Local Government Amendment Act 1996, which built on the 1989 reforms. In essence it included new financial management and borrowing provisions for local government (Pallot, 2001b). Every three years, commencing from 1998, local authorities had to adopt (through the special consultative procedure) a long-term financial strategy (LTFS) for a period of the next ten years or more. The long-term strategy covered operating and capital expenditures, revenue, cash-flow projections, asset management, and borrowing requirements (Pallot, 2001b; Wilson, Salter, \& Grierson, 2003).

Although the Local Government Act 1974 and subsequent amendments had improved the management and accountability of local government, the Act was highly prescriptive in detailing what local authorities could do (Wilson, et al., 2003). It was criticised as being too detailed, confusing, and archaic (Wilson, et al., 2003). The Act had inherent limitations on a local government's effectiveness to meet community needs and to promote sustainable local development (The Department of Internal Affairs, 2001). In December 2002, the Local Government 
Act 2002 repealed much of the Local Government Act 1974 and subsequent amendments, and remains effective to date (Wilson, et al., 2003).

The Local Government Act 2002 removed much of the prescriptive detail and conferred a generalised power on all local authorities, giving them full control to perform their roles to promote the purpose of local government and to perform their duties, as conferred by the Local Government Act 2002 and other enactments $^{17}$ (Local Government Act 2002, ss. 11, 12). Regardless of many changes, the requirement for SSP reporting remained the same.

\subsection{Structure of local authorities}

At present, there are 85 local authorities, comprising 12 regional councils and 73 territorial authorities in New Zealand (including five unitary authorities ${ }^{18}$ ) (The Department of Internal Affairs, 2007a). Of the territorial authorities, 16 are city councils (CCs), and 57 are district councils (DCs). ${ }^{19}$

The boundaries of regional councils are mainly based on river catchments and statistical meshblock ${ }^{20}$ areas determined by Statistics New Zealand, while those of territorial authorities are based on the boundaries of regional councils and statistical meshblock areas (Local Government Act 2002, Schedule 3, s. 4). Most

17 For example, Building Act 2004, Civil Defence Act 1983, Land Transport Act 1998, Local Electoral Act 2001, Local Government (Rating) Act 2002, Health Act 1956, and Resource Management Act 1991.

${ }^{18}$ A unitary authority is a territorial authority that has the additional responsibilities, duties, and powers of a regional council (Local Government Act 2002, s. 5). The five are Gisborne DC, Nelson CC, Tasman DC, Marlborough DC and Chatham Islands Council.

${ }^{19}$ A territorial authority with a population in excess of 50,000, which is predominantly urban and a major centre of activity within the region, is designated a city council (Local Government Act 2002, Schedule 3, s. 7).

${ }^{20}$ Meshblocks are the geographic frame which identifies small units of variable geographical area. Each unit is made up of approximately 100 households (Thornley, 2007). 
territorial authorities are located within the boundaries of one regional council; however, five local councils ${ }^{21}$ fall within the boundaries of more than one regional council. Given such boundaries, regional councils or territorial authorities vary greatly from one another in terms of land area, population, and population median income. (See Appendix A for the area, population, median income of local authorities in New Zealand.)

In relation to staffing, each local authority comprises elected members and appointed employees. While territorial authority mayors and all councillors are elected by the public, regional council chairpersons are elected for a three-year term by the elected regional councillors (Local Government Act 2002, s. 41(1)(b)). Generally, mayors and chairpersons are the leaders and public voices of their local authorities. Councillors are community leaders and representatives; their primary responsibilities are to set policy, make decisions, and review the local authority's performance (The Department of Internal Affairs, 2007b). A local authority's elected members appoint the council's chief executive officer, for up to a five-year term (Local Government Act 2002, schedule 7, clause 43(1)), to manage the authority's operations. The chief executive officer, in turn, employs council staff to carry out day-to-day functions of the local authority (Local Government Act 2002, ss. 41, 42). (See Appendix A for number of staff of local authorities.) Local authorities may also establish committees to carry out primary functions, such as environmental planning, regulatory services, and resource consents (Local Government Act 2002, schedule 7, clause 30). In addition, local

\footnotetext{
${ }^{21}$ They are Waitaki District Council, Stratford District Council, Rangitikei District Council, Taupo District Council, Rotorua District Council, and Franklin District Council.
} 
authorities may contract specialist entities on their behalf, or form other entities ${ }^{22}$ to provide services to their communities (for example, wastewater services, roading, and rubbish disposal) (Local Government Act 2002, s. 6; The Department of Internal Affairs, 2007a).

\subsubsection{Functions of local authorities}

The Local Government Act 2002 and other enactments specify the functions of regional councils and territorial authorities. The primary functions of regional councils, with their relevant enactments, include:

- managing natural and physical resources - quality of water, soil, air, coastal planning (under the Resource Management Act 1991);

- controlling plant and animal pests (under Biosecurity Act 1993);

- preventing damage from soil erosion and floods (under Soil Conservation and Rivers Control Act 1945);

- providing civil defence, for example, natural disasters, and marine oil spills (under Civil Defence Emergency Management Act 2002); and

- planning and contracting land transport, such as buses and trains (under Land Transport Act 1998); and

- $\quad$ setting by-laws on, for example, matters related to forests, parks, reserves, floods, and water supply (if managed and controlled by regional councils) (under Local Government Act 2002).

\footnotetext{
${ }^{22}$ For example, council-controlled organisations in which one or more local authorities own at least 50 percent of the voting rights or have the right to appoint at least 50 percent of the directors (Local Government Act 2002, s. 6).
} 
The primary functions of territorial authorities include:

- promoting the community's economic development, for example, by providing car parks, tourism campaigns and visitor information centres (under Local Government Act 2002);

- promoting public health and safety including building control, and civil defence, (under the Health Act 1956, Building Act 2004, Civil Defence Emergency Management Act 2002);

- providing the community's services, for example, footpaths, roads, street lighting, parks, libraries, art galleries, swimming pools, waste management, water supply, stormwater, and wastewater services (under Local Government Act 2002, Land Transport Act 1998);

- administering resource management in particular to control local land-use and development (under the Resource Management Act 1991); and

- $\quad$ setting by-laws related to, for example, public health and safety, offensive behaviour, on-site wastewater disposal systems, waste management, and trade wastes (under Local Government Act 2002).

In general, the functions of regional councils and territorial authorities are distinct. Regional councils are primarily involved with environmental management and public transport, while those of territorial authorities focus on various community services relating to community well-being, development, environmental health and safety, infrastructure, recreation and culture, and land-use management.

There is also a certain degree of co-operation between regional councils and territorial authorities. The Local Government Act 2002 (s. 15) provides for 
regional and territorial authorities within each region to make an agreement to communicate and co-ordinate their activities after each triennial general election. For example, the regional council and its territorial authorities may establish a joint committee, with representatives from both the regional council and all the relevant territorial authorities, to provide for civil defence in the case of natural disaster. Some functions of territorial authorities require supervision and monitoring by the relevant regional council. For example, a territorial authority's wastewater services must be operated in compliance with the resource consent conditions and monitored by the regional council under the Resource Management Act 1991.

Both regional councils and territorial authorities are responsible for establishing a process for identifying community outcomes every six years. This process enables the community to discuss its desired outcomes, expressed in terms of present and future social, economic, environmental, and cultural well-being criteria, and the priorities for those outcomes (if this is desired); measurements to be adopted to assess progress towards achievement of outcomes are also discussed. Local authorities must also identify and collaborate with other organisations or groups ${ }^{23}$ which may help to achieve the community outcomes (Local Government Act 2002, s. 91). Once community outcomes have been identified, the local authority must decide on its contribution (through activities) towards the achievement of those outcomes. Every three years, the local authority is required to evaluate and report on progress towards achievement of the identified community outcomes (Local Government Act 2002, s. 92).

${ }^{23}$ These groups may include iwi, the police, and social welfare agencies. 
The Local Government Act 2002 and other legislation provide for local authorities to prepare policies and plans relating to the performance of their functions, and these policies and plans provide the bases for decision-making. For example, the Local Government Act 2002 requires local authorities to develop policies and plans for their community services (groups of activities), funding and financial management, asset management, ${ }^{24}$ water and sanitary services assessment, ${ }^{25}$ and waste management. In addition, each local authority has to prepare a policy on matters that are significant to its jurisdiction. ${ }^{26}$ Before deciding on these matters, local authorities are required to consult with their communities (Local Government Act 2002, ss. 76-81). For certain decisions (such as the adoption of by-laws, policies and plans), the Act requires the use of the special consultative procedure. ${ }^{27}$

\subsubsection{Relationships with other agencies}

Local authorities are also overseen by and associated with a number of central government agencies and other bodies. These include:

\footnotetext{
${ }^{24}$ An asset management plan is a typically prepared to meet the statutory requirements in Schedule 10 [Part 1, Clause 2(1)(d)]. Basically, such plans provide details of: how local authorities will maintain current and future services by the assets currently held; additional assets which may be required; and the cost of, and funding for, maintaining the current assets or investing in new ones.

${ }^{25}$ Water supply, wastewater, stormwater drainage, and sanitary works are major expenditures and significant community services provided by local authorities. The assessment provides details of: the current demand for, and capacity of, the water supply, sewerage, and wastewater treatment; assessment of the quality of drinking water and discharged water; and assessment of future demands and the authority's capacity to supply the services (Local Government Act 2002, s. 126).

${ }^{26}$ Generally, significant matters have an impact on: the current and future social, environmental, economic, and cultural well-being of a district or region; any persons who are likely to be affected by a matter; and the capacity of the local authority to perform its functions (Local Government Act 2002, s. 5).

27 A special consultative procedure involves local authorities making publicly available a statement of proposal (including description of the consultative process to be undertaken), and ensuring that any person making a submission is given an opportunity to be heard (Local Government Act 2002, s. 83).
} 
The Minister of Local Government - who is primarily responsible for legislation relating to local government and also for the performance of local government. However, the Minister cannot intervene in decisions of local authorities. In the case where a local authority fails to perform in accordance with the Local Government Act 2002 or other relevant enactment, the Minister may appoint a review authority, or a commissioner to perform the local authority's duties, or a person to act on behalf of the local authority (Local Government Act 2002, ss. 254-256).

The Department of Internal Affairs - which provides the Minister of Local Government with advice concerning local government, and information to the public about local government (The Department of Internal Affairs, 2011).

The Local Government Commission - which has primary responsibility for defining local authorities' boundaries (Local Government Act 2002, s. 26). The Commission must also review and report on the operation of Local Government Act 2002 and the Local Government Electoral Act 2001 (Local Government Act 2002, s. 32).

The Controller and Auditor-General - who is an independent Officer of Parliament. He/she primarily provides Parliament with independent assurance about the performance of, and information about, public-sector organisations (Office of the Auditor-General, 2007b). In particular, the Auditor-General provides audit reports on local authorities' compliance with the requirements of the Local Government Act 2002 (Local Government Act 2002, ss. 94, 99). 
The Ombudsmen ${ }^{28}$ - who are independent staff of Parliament. Their primary function is to investigate complaints from the public about governmental bodies (including local government) (Office of the Ombudsmen, 2011).

The Parliamentary Commissioner for the Environment - is an independent Officer of Parliament. The Commissioner's primary function is to investigate, and make recommendations to local authorities about, environmental management.

The Department of Conservation is primarily responsible for conserving New Zealand's land and all other natural and historic resources (Department of Conservation, 2004). Under the Resource Management Act 1991, the Department of Conservation jointly administers the coastal marine area with regional councils.

The Ministry for the Environment has its primary functions, as set out in the Environment Act 1986 (s. 31), to advise the government (including local government) on all aspects of environmental administration (Ministry for the Environment, 2007a). The Resource Management Amendment Act 2005 (No 5, ss. $24 \mathrm{~A}, 25 \mathrm{~A}, 27)$ further empowers the Ministry to review the performance of, and make recommendations to, local authorities; and to direct a local authority to prepare or change its regional or district/city plan in order to address resource management issues. In addition to these formal responsibilities the Ministry for the Environment provides strategic direction, ${ }^{29}$ best practice guides and

\footnotetext{
${ }^{28}$ Presently, there are two Ombudsmen: Beverley Wakem and David McGee (Office of the Ombudsmen, 2011).

${ }^{29}$ An example of a direction is the New Zealand Waste Strategy: Towards Zero Waste and a Sustainable New Zealand (Ministry for the Environment, 2007b).
} 
guidelines, ${ }^{30}$ and technical reports for specific aspects of environmental management. ${ }^{31}$

There are also other local government advocate organisations (such as Local Government New Zealand and the Society of Local Government Managers) which engage with local authorities to assist in carrying out their functions.

\subsection{Financial management of local authorities}

Local authorities are also responsible for managing their funding. Each local authority is able to decide its own funding and financial policies, providing that policies promote the current and future interests of the community. They include policies, for revenue and financing, ${ }^{32}$ borrowing, ${ }^{33}$ investment $;{ }^{34}$ development and financial contributions under the Resource Management Act $1991 ;^{35}$ partnerships with private-sector entities, and rate reductions and exemptions (Local Government Act, ss. 102-110). Adoption of the council's funding and financial policies is subject to the special consultative procedure.

\footnotetext{
30 An example of a guideline is the Wastewater Monitoring Guidelines (Ministry for the Environment, 2007b).

${ }^{31}$ An example of a technical report is the assessment of Greenhouse Gas Emissions from Waste Disposal as a Result of Implementation of the Proposed New Zealand Waste Strategy (Ministry for the Environment, 2007b).

${ }^{32}$ Revenue and financing policies set out why and how operating and capital expenditures are to be funded from different sources, such as from rates, fees and charges, interest and dividends from investments, grants and subsidies, borrowing, proceeds from sales of asset, development contributions, and financial contributions under the Resource Management Act 1991 (Local Government Act 2002, s. 103).

${ }^{33}$ Local authorities are permitted to borrow from any sources but only in New Zealand currency (Local Government Act 2002, s. 113). The borrowing policies include matters such as interest rate exposure policy, liquidity policy, and policies on security (Local Government Act 2002, s. 104).

${ }^{34}$ Investment policy includes matters such as objectives in managing investments, and how risks are managed (Local Government Act 2002, s. 105).

35 The development/financial contributions policy includes the capital expenditure (for example, network infrastructure) to be funded by the contributions, the amount of capital expenditure to be funded by the contributions and other sources, the reasons for choosing the funding from contributions, activities to be funded by contributions, and the total amount of funding required from contributions (Local Government Act 2002, s. 106).
} 
Further, each local authority is required to prepare a funding impact statement, which details the revenue and financing mechanisms to be used (including the rating system), ${ }^{36}$ the amount to be raised by each mechanism, and the activities to be funded from that revenue (Local Government Act 2002, Schedule 10, Part 1, Clause 10). The statement is an integral part of the long-term council community plan (see section 2.6.1).

In 2007/2008 and 2008/2009, local authorities in New Zealand received operating revenue amounting to $\$ 6.2$ and $\$ 6.3$ billion; their operating expenditure amounted to $\$ 5.6$ and $\$ 6.7$ billion, respectively (The Department of Internal Affairs, 2009b, 2010). Table 2.1 provides a summary of local authorities' sources of operating revenue and their operating expenditure, by percentage, for the years 2007/2008 and 2008/2009.

From Table 2.1, local authorities derive their operating revenue primarily from locally imposed rates (property taxes). Other operating revenue is obtained from sales of goods and services, central government grants and subsidies, investments, and regulatory sanctions (fees and fines). Roading and transport; culture, recreation and sport; governance; wastewater, and regulation planning account for the major share of operating expenditure.

\footnotetext{
${ }^{36}$ The rating system consists primarily of several types of rates such as general rates and targeted rates. General rates are paid by ratepayers and land owners, based on the value of individual properties and the particular formula the authority applies. Targeted rates are charged to fund a particular activity or function (for example, water supply, or wastewater treatment). The local authority may base its rates calculation on factors such as floor space or number of water connections (The Department of Internal Affairs, 2007b).
} 
Table 2.1: Sources of operating revenue and items of operating expenditure of local authorities by percentage for the years $2007 / 2008$ and $2008 / 2009$

\begin{tabular}{|c|c|c|c|c|c|}
\hline $\begin{array}{l}\text { Operating revenue } \\
\text { sources }\end{array}$ & $\begin{array}{l}2007 / 2008 \\
(\%)\end{array}$ & $\begin{array}{c}2008 / 2009 \\
(\%)\end{array}$ & $\begin{array}{l}\text { Operating } \\
\text { expenditure items }\end{array}$ & $\begin{array}{c}2007 / 2008 \\
(\%)\end{array}$ & $\begin{array}{c}2008 / 2009 \\
(\%)\end{array}$ \\
\hline Rates & 58.4 & 61.1 & $\begin{array}{l}\text { Roading and } \\
\text { transport }\end{array}$ & 27.5 & 26 \\
\hline $\begin{array}{l}\text { Sales of goods and } \\
\text { services, and all } \\
\text { other revenue }\end{array}$ & 17.1 & 16.43 & $\begin{array}{l}\text { Culture, recreation } \\
\text { and sport }\end{array}$ & 16.9 & 15 \\
\hline $\begin{array}{l}\text { Government grants } \\
\text { and subsidies }\end{array}$ & 12.9 & 10.96 & $\begin{array}{l}\text { Governance and } \\
\text { council support } \\
\text { services }\end{array}$ & 16.5 & 18 \\
\hline Regulatory & 6.1 & 7.73 & Wastewater & 9.4 & 9 \\
\hline \multirow[t]{6}{*}{ Investment } & 5.5 & 4.78 & Regulation planning & 9.1 & 7 \\
\hline & & & Water supply & 6.7 & 6 \\
\hline & & & $\begin{array}{l}\text { Environmental } \\
\text { protection }\end{array}$ & 5.1 & 4 \\
\hline & & & Solid waste & 4.8 & 4 \\
\hline & & & $\begin{array}{l}\text { Property forestry, } \\
\text { agriculture and } \\
\text { other }\end{array}$ & 3.4 & 10 \\
\hline & & & $\begin{array}{l}\text { Emergency } \\
\text { management }\end{array}$ & .6 & 1 \\
\hline
\end{tabular}

(The Department of Internal Affairs, 2009b, 2010)

As of June 2008 and 2009, the local authorities in New Zealand owned total assets of $\$ 94.9, \$ 98.75$ billion and had liabilities of $\$ 6.23, \$ 7.5$ billion, respectively. (See Appendix A for local authorities' operating revenue, operating expenditure, total assets, and liabilities.)

\subsection{Wastewater services}

Among wide-ranging community services provided by local authorities, wastewater services are one of the most crucial services provided by New Zealand local authorities. Territorial authorities have traditionally been statutorily responsible for their provision (Bush, 1995; Local Government Act 2002, s. 130). Wastewater services represent one of the major items of expenditure ( 9 percent of total expenditure) by local authorities (The Department of Internal Affairs, 2010). 
Wastewater contributes the largest volume of waste in New Zealand (with approximately 1.5 billion litres of daily discharge), and can potentially have a wide and immediate impact on human health and the physical environment as well as long-term consequences if not properly managed (Ministry for the Environment, 2010b). Any substandard treated water discharged, can cause blockages or overflowing, and can be harmful for swimming, gathering seafood, marine farming and affect the quality of drinking water (Ministry for the Environment, 2010a). The primary purpose of wastewater services provided by local authorities is to minimise health risks from wastewater, and the secondary purpose is to protect the environment (Office of the Auditor-General, 2010). The key pieces of legislation governing the local authorities' provision of wastewater services are the Resource Management Act 1991 and the Health Act 1956.

Wastewater (commonly known as sewage) services encompass sewer systems (sewerage), wastewater treatment, and wastewater disposal. Sewer systems include wastewater collection and delivery to a wastewater treatment plant through pipelines (reticulation). Wastewater treatment is a process that removes contaminants and produces a liquid effluent and sludge (solid waste) that are disposed of to an outfall (for example, a marine area, river, and wetland) or a landfill, respectively. ${ }^{37}$

\footnotetext{
${ }^{37}$ Wastewater or sewage is the liquid waste collected through pipes from the baths, showers, kitchens and toilets of homes, restaurants, office buildings, and factories. As wastewater pollutes the environment, it must be treated before being discharged into lakes, oceans, rivers or streams. The conventional wastewater treatment system in most cities involves three stages: primary treatment, secondary treatment, and tertiary treatment. In brief, primary treatment takes out the heaviest solid material from the wastewater. Secondary treatment removes the dissolved and emulsified biological content of the wastewater which can be dried for use as fertilizer. The tertiary treatment aims to produce more pure effluent that is safe to the receiving environment. Tertiary treatment methods include filtration over activated carbon to remove residual toxin,
} 
Under the Resource Management Act 1991, unless expressly permitted or prohibited by the relevant regional, district or city plan ${ }^{38}$, any activity that involves the use, development and/or protection of natural and physical resources, and has adverse environmental effects, ${ }^{39}$ requires resource consent to be granted by the relevant local authority (usually a regional council). Wastewater activities pollute primarily air (odour), land (sludge) and water (wastewater discharged). Therefore, a territorial authority must be granted resource consent from its regional council to operate a wastewater system. Due to the different environmental spheres affected by a wastewater system, different types of resource consents are required. For example, the New Plymouth Wastewater Treatment Plant ${ }^{40}$ holds five resource consents granted by the Taranaki Regional Council, as follows (Taranaki Regional Council, 2004):

1. a coastal permit for the discharge of treated water into the Tasman Sea (granted by the Department of Conservation in conjunction with Taranaki Regional Council);

2. a coastal permit for its outfall structure in the coastal marine area;

3. a discharge permit for the discharge of liquid waste from the sludge lagoon into groundwater in the vicinity of the Waiwhakaiho River;

\footnotetext{
lagooning, biological nutrient removal, nitrogen removal, phosphorus removal, and radiation treatment (WorldBook, 2003).

38 A 'plan' may be a regional plan, regional coastal plan or a district or city plan. Generally, the plans address resource management issues, objectives to be achieved, policies to achieve the objectives, methods for implementing those policies, and rules (Resource Management Act 1991, ss. 73, 75).

${ }^{39}$ Effects can be positive or negative, temporary or permanent, past, present or future, cumulative, of high probability, of low probability but high impact. (Resource Management Act 1991, s. 3) Adverse environmental effects may include increases in traffic, soil erosion, changes to the character of a street or landscape, decreases in water quality or quantity, and odour.

${ }^{40}$ The plant is situated in the Waiwhakaiho catchment (Taranaki Regional Council, 2004).
} 
4. a discharge permit for sludge disposal on to land; and

5. a discharge permit for the discharge of deodorised air from the treatment plant.

Invariably conditions are attached to resource consents; these may be in the form of terms, standards, restrictions, prohibitions and requirements with which consent-holders must comply (Resource Management Act 1991, s. 2). To ensure that resource consent conditions are met, consent-granting authorities ${ }^{41}$ are required to monitor and keep records of consent-holders' compliance with those conditions (Resource Management Act 1991, s. 35). Compliance monitoring involves evaluating the performance of consent-holders and the environmental effects of consented activities. In addition to regular self-inspection by a territorial authority consent-holder of a wastewater operation, the resourcegranting regional council undertakes site inspections, sampling, and analysis of physical and chemical parameters of discharged treated wastewater, groundwater and surface water, and reviews both its laboratory results and the self-inspection data recorded by a territorial authority (Taranaki Regional Council, 2004).

When consent-holders comply with their resource consent conditions, they are assessed as displaying good compliance by the relevant regional council and their resource consents are likely to be renewed if, and when, they are sought. However, where instances of non-compliance are encountered, the relevant consent-granting authority can apply enforcement mechanisms. These may range from informal means (for example, educational supervision or a verbal warning)

\footnotetext{
${ }^{41}$ For coastal permits granted by the Department of Conservation, the relevant regional councils monitor compliance of the consent holders on behalf of the Minister.
} 
to statutory enforcement (for example, abatement notice or prosecution). The enforcement mechanisms vary according to the severity of the non-compliance and the particular authority's judgement of the significance of the environmental impact resulting from the non-compliance.

While the Resource Management Act 1991 sets out the details applicable for wastewater management, the Health Act 1956 broadly requires territorial authorities to provide sanitary works, which include all reticulation, treatment, and disposal systems of the wastewater (Health Act 1956, s. 25). Accordingly, territorial authorities are expected to ensure that the wastewater services are reliable (no overflows or blockages) and that authorities are responsive to incidents.

Territorial authorities may subcontract their wastewater services to other entities (for example, council-controlled organisation). However, they still need to be in control over the management of the service and undertake performance monitoring of that entity (Local Government Act 2002, ss. 136, 65). Currently, two territorial authorities (Auckland CC and Manukau CC) use their councilcontrolled organisations (Metrowater Ltd and Manukau Water Ltd, respectively) and two other authorities (Papakura DC and Wellington CC) contract a company (United Water International Pty Ltd) to run their wastewater services. 


\subsection{Accountability mechanisms for local authorities}

Planning and reporting of performance are important mechanisms of accountability (Boyne, Gould-Williams, Law, \& Richard, 2002). The Local Government Act 2002 requires local authorities to prepare planning documents in the form of a long-term council community plan (LTCCP) and an annual plan. These provide the long-term and short-term focus in financial and non-financial terms respectively, as well as co-ordinating the authorities' various policies and plans. In addition, the results of local authorities' implementation of plans during a year, in terms of financial and non-financial performance, must also be reported on in an annual report. The purpose and the content of these reports are specified in the Local Government Act 2002, sections 93, 95, 98 and Schedule 10, as summarised in Table 2.2. Local authorities' LTCCP, annual plans and annual reports must be prepared in accordance with generally accepted accounting practice (GAAP) ${ }^{42}$ (Local Government Act 2002, S. 111).

\footnotetext{
${ }^{42}$ The Accounting Standards Review Board announced its decision that New Zealand entities producing general purpose financial statements would have to adopt New Zealand equivalents to International Financial Reporting Standards (NZ IFRS) for the period beginning on or after 1 January 2007 (NZICA, 2004, 2005). However, entities were given the option to adopt NZ IFRS from the period beginning on or after 1 January 2005(Office of the Auditor-General, 2007a).
} 
Table 2.2: Purpose and content of long-term council community plans, annual plans, and annual reports

\begin{tabular}{|c|c|c|}
\hline Reports & Purposes & Contents \\
\hline (i)LTCCP & $\begin{array}{l}\text { i. To describe the local authority's } \\
\text { activities; } \\
\text { ii. to describe the community } \\
\text { outcomes of the local authority's } \\
\text { district or region; } \\
\text { iii. to provide a basis for integrated } \\
\text { decision-making and co- } \\
\text { ordination of the local } \\
\text { authority's resources; } \\
\text { iv. to provide a long-term focus } \\
\text { when making decision; } \\
\text { v. to provide a basis on which the } \\
\text { community can hold the local } \\
\text { authority accountable for its } \\
\text { actions; and } \\
\text { vi. to provide an opportunity for } \\
\text { public participation in decision- } \\
\text { making. }\end{array}$ & $\begin{array}{l}\text { i. The community outcomes of the local authority's } \\
\text { district or region; } \\
\text { ii. groups of activities planned to be undertaken by } \\
\text { the local authority; } \\
\text { iii. a summary of water supply, wastewater and } \\
\text { sanitary service assessments and waste } \\
\text { management plans; } \\
\text { iv. information about council-controlled } \\
\text { organisations; } \\
\text { v. development of Maori capacity in the decision- } \\
\text { making process; } \\
\text { vi. a summary of local authorities' policy on } \\
\text { determining significance under the Local } \\
\text { Government Act } 2002 \\
\text { vii. funding and financial policies; } \\
\text { viii. forecast financial statements }{ }^{43} \text { for at least the } \\
\text { next } 10 \text { years; } \\
\text { ix. statement concerning balancing of budget } \\
\text { x. funding impact statement for at least the next } 10 \\
\text { years; } \\
\text { xi. significant forecasting assumptions. }\end{array}$ \\
\hline $\begin{array}{l}\text { (ii)Annual } \\
\text { plans }\end{array}$ & $\begin{array}{l}\text { i. To detail the annual budget and } \\
\text { funding impact statement for the } \\
\text { year; } \\
\text { ii. to identify any variation from } \\
\text { the funding and financial } \\
\text { information as stated in the } \\
\text { LTCCP for that year; } \\
\text { iii. to support the LTCCP; } \\
\text { iv. to contribute to the local } \\
\text { authority's accountability; and } \\
\text { v. to extend the opportunity for } \\
\text { public participation in decision- } \\
\text { making particularly on costs and } \\
\text { funding. }\end{array}$ & $\begin{array}{l}\text { i. forecast financial statements for the next } \\
\text { financial year; } \\
\text { ii. funding impact statement for the next financial } \\
\text { year; }\end{array}$ \\
\hline $\begin{array}{l}\text { (iii)Annual } \\
\text { reports }\end{array}$ & $\begin{array}{l}\text { i. To compare activities undertaken } \\
\text { and results achieved with } \\
\text { forecasts in the long-term } \\
\text { council community plan and } \\
\text { annual plan; } \\
\text { ii. to promote accountability to the } \\
\text { community for the local } \\
\text { authority's decisions made } \\
\text { during the previous year. }\end{array}$ & $\begin{array}{l}\text { i. Information about groups of activities taken by } \\
\text { the local authority; }{ }^{44} \\
\text { ii. annual financial statements; } \\
\text { iii. remuneration of the mayor, council } \\
\text { members, and the council's chief } \\
\text { executive; } \\
\text { iv. severance payments to employees; } \\
\text { v. council-controlled organisations; } \\
\text { vi. statement of compliance with the Local } \\
\text { Government Act } 2002\end{array}$ \\
\hline
\end{tabular}

${ }^{43}$ Financial statements usually include a statement of financial position, a statement of financial performance, a statement of cash flows and a statement of movements in equity, and those notes and other statements and explanatory material (NZICA, 2005, para 7).

${ }^{44}$ Groups of activities are one or more related activities. Activities, in the context of Local Government Act 2002, are goods or services provided by a local authority. They include the provision of facilities and amenities, the making of grants, and the performance of functions (Local Government Act 2002, s. 5). 


\subsubsection{Long-term council community plans}

A LTCCP replaces a long-term financial strategy (introduced in the Local Government Amendment 1996). All local authorities had to prepare and adopt a LTCCP from the period beginning 1 July 2006 (Local Government Act 2002, s.280). A new LTCCP must be prepared every three years - covering at least the following 10 years (Local Government Act 2002, s.93). These plans constitute the fundamental strategic planning tools of councils, and are subject to the special consultative procedure, as are any amendments to the LTCCP (Local Government Act 2002, s. 95). ${ }^{45}$

The Local Government Act 2002 requires LTCCPs to disclose the identified community outcomes, the relationship between the community outcomes and other plans (such as district plans), other agencies involved in achievement of the outcomes, and the measurements to be used to assess progress towards achievement of the outcomes.

Local authorities' LTCCPs must also include the councils' funding and financing policies, a funding impact statement, and forecast financial statements for each year covered by the LTCCP.

The core section of a LTCCP relates to groups of activities to be undertaken by the local authority. It includes the following information:

\footnotetext{
${ }^{45}$ Local authorities may amend their LTCCPs at any time. Significant changes in level of service or the other decisions described in section 97 are subject to the special consultative procedure (Local Government Act 2002, s. 88).
} 
- the activities to be carried out;

- reasons why these activities are to be undertaken;

- the contribution of activities to the achievement of identified community outcomes;

- any significant negative effects of the activities on the community's wellbeing;

- asset management plans for the service provision;

- performance measures, and performance targets ${ }^{46}$ for each activity; and

- estimated revenues and expenditures required for the performance of the activities.

Provided that wastewater services represent a significant activity of a local authority, it is most likely that wastewater services would be included in the LTCCP. Consequently, the appropriateness of their performance measures and targets would be provided.

\subsubsection{Annual plans}

Annual plans are prepared in each year that a LTCCP is not prepared (Local Government Act 2002, s. 95(4)). They consist primarily of forecast financial statements and a funding impact statement for the following year. As well, any variation between the annual plan and the LTCCP must be explained in the relevant annual plan (Local Government Act 2002, s. 85). Although not statutorily required, most local authorities detail their planned activities, service

\footnotetext{
${ }^{46}$ Performance targets are levels of service performance that should be delivered or achieved within the performance period (usually one year). Performance targets can be expressed in terms of numbers, percentages, ratios, or point estimates (NZICA, 2002).
} 
levels, performance measures, performance targets, and estimated expenses for each activity for the year the plan covers. ${ }^{47}$

Annual plans, like LTCCPs, are subject to the special consultative procedure (Local Government Act 2002, s. 95). However, they are not required to be audited.

\subsubsection{Annual reports}

In contrast to the forward-looking annual plans and LTCCPs, annual reports focus on the results of activities undertaken during the previous year. The Local Government Act 2002 (s. 98) requires that local authorities' annual reports be publicly available by 31 October, following the end of each financial year (30 June). The annual report of local authorities for the year ended 30 June 2007 was therefore the first report prepared in accordance with New Zealand Equivalents to International Financial Reporting Standards (NZ IFRS).

From Table 2.2 it may be seen that annual reports are required to include financial statements for the past year (for example, a statement of financial performance, statement of financial position, and statement of cash flows), supplementary information (that is, remuneration of the mayor, council members, and chief executive; severance payment to employees, council-controlled organisations and a statement of compliance with the Local Government Act 2002), and nonfinancial information (that is, groups of activities). 'Groups of activities' (outputs) refers to (i) the activities carried out, (ii) the community outcomes to

\footnotetext{
${ }^{47}$ Under the Local Government Act 1974, local authorities' annual plans were required to provide these details about their planned service performance. The relevant provisions have been omitted from the Local Government Act 2002.
} 
which the activities contribute, (iii) any identified effects of the activity on the community's well-being, and (iv) comparison between the actual level of service provision of the group of activities and the intended level of service provision, as specified in the LTCCP, with any reasons for significant variance (Local Government Act, Schedule 10, Part 3, s.15). Note that information about the latter is what is referred to in a Statement of Service Performance under the 1989 Amendment Act and in this study.

\subsection{Authoritative requirements for SSP reporting}

Authoritative requirements for SSP reporting by New Zealand local authorities are derived from the statutory requirements under the Local Government Act 2002, and relevant generally accepted accounting practice (GAAP).

\subsubsection{Statutory requirements for SSP reporting}

The Local Government Act 2002 addresses the requirement for SSP reporting in Schedule 10, Part 3 (15(e)), which requires audited information on:

(i) setting out a comparison between the actual levels of service provision of that group of activities and the intended levels of service provision (as set out in the long-term council community plan in respect of that year) of that group of activities; and

(ii) giving the reasons for any significant variance between the actual service provision and the expected service provision; 
Statements of service performance are not standalone reports, but are part of the reporting cycle in relation to non-financial service performance information. Performance measures and performance targets for each activity stated in the LTCCPs are reported against actual achievements in the SSPs in annual reports. In addition, explanation of significant variance, if any, must also be provided. Therefore, wastewater services performance measures and targets reported in LTCCPs are reported against actual achievements in SSPs in annual reports with explanation of significant variance, if any.

As part of annual reports, SSPs need to be prepared in accordance with the relevant GAAP (Local Government Act 2002, s. 111). Note that the Local Government Act 2002 does not require SSPs to be audited against GAAP, but rather, against Schedule 10, Part 3 (15(e)) of the Act.

\subsubsection{GAAP relevant to $S S P$ reporting}

In 1982 the New Zealand Institute of Chartered Accountants (previously the Institute of Chartered Accountants of New Zealand, and the New Zealand Society of Accountants) made a commitment to the development of an accounting standard for non-financial performance measures in external reports, for which they coined the term "statement of service performance" (Neale \& Pallot, 2001).

In spite of this commitment, when the SSP reporting requirement in 1989 was introduced, no standards existed concerning its preparation (Neale \& Pallot, 2001). In 1990, the OAG developed criteria on the audit of SSPs for internal use, which also provided guidance for SSP reporting (Neale \& Anderson, 2000; Neale \& Pallot, 2001). The guidance discussed the significant dimensions of output 
(quantity, quality, location, time and cost where applicable), and the reporting of actual against planned outputs, and evidence used to verify the data (Neale \& Pallot, 2001). Although the audit guidance for SSP reporting was followed, almost all local authorities received qualified opinions in the first year (1990/1991) of SSP reporting (Neale \& Pallot, 2001).

The first accounting guidance relating to SSPs was released in 1993. The New Zealand Institute of Chartered Accountants published Statement of Concepts for General Purpose Financial Reporting (SOC) which had application to both financial statements and non-financial information (including SSPs) of privatesector and public-sector entities, with the objective of decision usefulness and accountability (NZICA, 1993). In essence, SOC discusses the qualitative characteristics for general purpose financial reports, that is, relevance, reliability, comparability, and understandability (NZICA, 1993, para. 4.1). In 1994, the NZICA issued Financial Reporting Standard 2 (FRS-2) Presentation of Financial Reports, of which section C deals specifically with the presentation of SSPs. Those reporting entities required by legislation to prepare a SSP must report on the entity's output - if applicable, in terms of quantity, quality, time, location, and cost of the output - and present both projected and actual service performance in output terms (NZICA, 1994, paras 11.1, 11.3, 11.6).

During the 1990s, the problems of SSP reporting persisted (Neale \& Anderson, 2000; Neale \& Pallot, 2001). Performance measures which developed in response to the statutory reporting requirement and audit guidance were considered reliable 
but at the expense of appropriateness ${ }^{48}$ (Neale \& Pallot, 2001). For example, given the auditor's insistence on evidence of performance measures, the most easily quantified measures ("number of letters to the Minister") were used. In fact, performance measures were insufficient as they did not cover all significant activities (Neale \& Pallot, 2001). They were often not sufficiently relevant so as to provide clear links with the goals set (Neale \& Pallot, 2001). Further, comparisons between forecast and actual performance were inadequate (Neale \& Pallot, 2001). However, an auditor would only qualify the SSPs if those performance measures were both significantly and fundamentally misleading or not meaningful (Neale \& Pallot, 2001).

To address these reporting problems, Technical Practice Aid No. 9 (TPA-9): Service Performance Reporting, which was fundamentally based on SOC and FRS-2, was published in 2002. TPA-9 contains detailed guidelines on the preparation of SSPs, including the use of performance measures to express different dimensions of outputs (NZICA, 2002). It is considered highly relevant guidance on New Zealand SSP reporting (Office of the Auditor-General, 2008). Although not authoritative, compared to a financial reporting standard (Office of the Auditor-General, 2008), it was re-endorsed by the Financial Reporting Standards Board and included in the 2007 Member's Handbook and 2007 Annual Accounting Standards publication (NZICA, 2007a). TPA-9 (2002) underwent a limited revision in 2007.

\footnotetext{
${ }^{48}$ Appropriateness of performance measures was defined as information being relevant, complete and understandable (Anderson, 1995).
} 
In 2004, FRS-2 was superseded by the New Zealand Equivalent to International Accounting Standard 1 (NZ IAS 1): Presentation of Financial Statements, of which section 126 deals with SSP reporting (NZICA, 2004). ${ }^{49}$ As in FRS-2, a requirement was made for outputs to be reported in relation to, where applicable, the five dimensions (quantity, quality, time, location, and cost of output) presenting both projected and actual performance remains (NZICA, 2004). Similarly, SOC was superseded by the New Zealand Equivalent to the International Accounting Standards Board (IASB) Framework for the Preparation and Presentation of Financial Statements (NZ Framework), which remains the same decision usefulness objective and the qualitative characteristics (relevance, reliability, comparability, and understandability) applicable for financial and nonfinancial performance information of private-sector and public-sector entities (NZICA, 2005). All New Zealand entities (including local authorities) must apply NZ IAS 1 and NZ Framework for annual accounting periods commencing on or after 1 January 2007 (NZICA, 2004). To date, the current GAAP applicable for SSP reporting is NZ Framework, NZ IAS 1, and TPA-9 (NZICA, 2007b).

The IASB is currently in the process of replacing its framework with a revised IASB Conceptual Framework for Financial Reporting. However, New Zealand has decided to adopt the new framework for profit-oriented entities only. In the Appendix to the NZ Framework it is explained that New Zealand will retain the New Zealand Equivalent to the IASB Framework for the Preparation and Presentation of Financial Statements for public benefit entities until the IASB has finished its consideration of non-for-profit entities and the New Zealand Ministry

\footnotetext{
${ }^{49}$ This was the requirement for entities adopting NZ IFRS voluntarily from 2005 or who were required to adopt from 2007 (NZICA, 2004).
} 
of Economic Development and the Accounting Review Board has reviewed this work (NZICA, 2010).

\subsubsection{NZ IAS 1}

According to NZ IAS 1 (para 126.4), the elements of service performance comprise inputs, outputs and outcomes, ${ }^{50}$ however the standard requires entities to report only their outputs in SSPs. ${ }^{51}$ It should be noted that the outputs defined by NZ IAS 1 are similar to activities, as referred to in the Local Government Act 2002. Each output disclosed can include, but is not limited to, the quantity, quality, timeliness, location and cost of each service's outputs (NZ IAS 1, para 126.4).

\subsubsection{TPA-9}

TPA-9 (NZICA, 2002) defines further the different dimensions of outputs as follows:

- Quantity of outputs relates to how much or how many units of the output are delivered (NZICA, 2002, para 5.13); for example, the length (kilometres) of pipelines for collecting wastewater, the amount of wastewater treated, the amount of treated water discharged to the receiving environment.

\footnotetext{
50 'Outputs' in the current context refers to goods and services provided by local authorities in servicing their communities (NZICA, 2002, para 4.2). Outputs are produced using inputs, which are the resources (such as funding, staffing and equipment) used to produce these outputs (NZICA, 2002, para 4.7).

${ }^{51}$ However, NZ IAS 1 (para 126.6) does not require them, but encourages the reporting of outcome.
} 
- Quality of outputs can be related standards to be met, reliability issues, and stakeholder satisfaction issues (NZICA, 2002, para 5.22); for example, compliance with resource consent conditions, incidence of negative incidents, and complaints received or customers' satisfaction with services.

- Time of outputs relates to a date when an output is to be delivered, a particular response time for an output to be delivered, and time during which the services will be available (NZICA, 2002, para 5.33); for example, completion date for the maintenance of wastewater mains, response time to emergency calls, no loss of service for longer than 12 hours.

- Location of outputs is a place where outputs are delivered. However, it is not relevant for many outputs and often not reported (Office of the Auditor-General, 2005, para 3.51, and NZICA, 2002, para 5.35). This may reflect the fact that a location is known intuitively by users, for example, the location of a local council swimming pool. However, for some other outputs, such as health services, education, boarder control or regional development, users are likely to have an interest in the location of the delivery of the services where accessibility to the service is a priority (NZICA, 2002, para 5.35).

- Cost of outputs should be calculated on a full accrual accounting basis, which requires the allocation of all direct and indirect expenses related to the output (NZICA, 2002, para 5.38). Costing of an output (operating 
expenditure) and provision of costing information below the aggregated output level are recommended (NZICA, 2002, para 5.39).

To disclose these output dimensions, TPA-9 (para 5.1) recommends the use of performance measures and targets ${ }^{52}$ which can enable comparison with current performance achievements. Such a recommendation is consistent with the Act's 2002 requirement (discussed earlier) that each SSP presents both target and actual service performance. Given the wide range of activities or outputs of local councils (for example, water supply, wastewater treatment, public health and safety), which must be reported in the SSPs, output performance measures are most likely to vary for the different dimensions (TPA-9, 2002, para 5.10). For example, performance measures for recreation services would differ from those of wastewater services. Given this study's focus on wastewater services, Table 2.3 provides an example of performance measures and their targets for each dimension of wastewater services.

\footnotetext{
${ }^{52}$ Performance targets (or standards) are precise levels of performance to be achieved within the performance period. Performance targets can be expressed in terms of absolute numbers, percentages, ratios, and/or point estimates or as a range (TPA-9, 2002, para 5.4).
} 


\section{Table 2.3: Example of performance measures and their targets for each dimension of wastewater services}

\begin{tabular}{|c|c|c|}
\hline $\begin{array}{c}\text { Output } \\
\text { dimensions } \\
\text { (NZ IAS 1) }\end{array}$ & $\begin{array}{l}\text { Classes for output dimensions } \\
\text { (TPA-9) }\end{array}$ & $\begin{array}{l}\text { Example of the performance measures } \\
\text { and their targets for wastewater services }\end{array}$ \\
\hline Quantity & $\begin{array}{l}\text { How much or how many units of } \\
\text { the output are delivered }\end{array}$ & $\begin{array}{l}-200 \mathrm{~km}_{\text {of reticulation maintained }} \\
-2.8 \text { million } \mathrm{m}^{3} \text { of sewerage volume } \\
\text { treated } \\
-2 \text { million } \mathrm{m}^{3} \text { treated wastewater } \\
\text { discharged to an outfall. }\end{array}$ \\
\hline Quality & $\begin{array}{l}\text {-Standard met } \\
\text {-Reliability of a service } \\
\text { - Customer's focus }\end{array}$ & $\begin{array}{l}-100 \% \text { compliance with resource consent } \\
\text { conditions } \\
\text {-Zero blockages, or overflows } \\
\text {-No complaints received } \\
100 \% \text { customer satisfaction with the } \\
\text { service }\end{array}$ \\
\hline Time & $\begin{array}{l}\text {-Date by which a service is to be } \\
\text { completed/rendered } \\
\text {-Response time for a service } \\
\text {-Time availability of service }\end{array}$ & $\begin{array}{l}\text {-Completion of reticulation work at ... by } \\
30 \text { June } 2007 \\
\text {-Complaints are rectified within } 24 \text { hours; } \\
\text { and } \\
\text {-Response time to interruptions to service } \\
\text { is below } 24 \text { hours per property per year } \\
\text {-At least } 24 \text { hours' notice is provided to } \\
\text { affected parties of planned work that } \\
\text { disrupts use of property }\end{array}$ \\
\hline Location & $\begin{array}{l}\text {-A place in which a service is } \\
\text { delivered }\end{array}$ & $\begin{array}{l}\text {-Wastewater treatment plants or } \\
\text { reticulation work is located at..... }\end{array}$ \\
\hline Cost & $\begin{array}{l}\text {-Cost of an output (service) } \\
\text {-Provision of cost below the } \\
\text { aggregated output level by direct } \\
\text { and indirect cost } \\
\text {-Provision of cost below the } \\
\text { aggregated output level by plant } \\
\text { or system }\end{array}$ & $\begin{array}{l}-\$ 5,243 \text { budgeted operating expenditure } \\
-\$ 520 \text { budgeted employee salary, } \$ 2058 \\
\text { budgeted depreciation and amortisation, } \\
\$ 1321 \text { budgeted activity expense; and } \\
-\$ 14,416 \text { budgeted cost of sewage } \\
\text { collection and disposal, } \$ 19,502 \text { budgeted } \\
\text { cost of sewage treatment }\end{array}$ \\
\hline
\end{tabular}

\subsubsection{NZ Framework}

The NZ Framework (para.s 25-42) discusses four qualitative characteristics relevance, reliability, comparability, and understandability - which underpin 
general purpose financial reports (including the SSP). The Office of the AuditorGeneral (OAG) has provided supplementary guidance on the qualitative characteristics of SSP information in the Auditor-General's Observations on the Quality of Performance Reporting (2008). The qualitative characteristics, based on the NZ Framework (NZICA, 2005) and the OAG's (2008) view in the area of SSP reporting, are explained below:

- To be relevant: information should assist users in their decision-making by helping them to evaluate past, present or future events, and to confirm or correct their past evaluations (NZICA, 2005, para 26). The Office of the Auditor-General (2008, para 6.5) adds that relevant information should be presented in the context of present performance of the reporting year, show clear and logical links with an entity's objectives, and meet the information requirements of stakeholders.

- To be comparable: information needs to be presented in a manner that facilitates its comparison over time for the same entity, and with similar information for other entities (NZICA, 2005, para 39). However, the OAG (2008, para 6.56) points out that while comparison of the current year's performance with other entities may not be appropriate for publicsector entities, a comparison with targets and present years' performance is recommended. The latter is consistent with the Act's 2002 requirement (Schedule 10, Part 3, 15(e)) for a comparison between actual achievement and the target set out in LTCCP. However, the Act's 2002 requirement in Schedule 10, Part 3, 15(e) goes a little further to include explanation of any significant differences between the current year's performance and 
targets. In summary, comparable information cannot only compare a council's achieved performance for the year in question with the present period's results, but also the targets, with explanation of any significant variance.

- To be understandable: information needs to be readily understood by users, assuming those users have a reasonable knowledge and a willingness to study the information with reasonable effort (NZICA, 2005, para 25). Further, OAG (2008, para 6.55) points out that reported items should be clearly classified, presented in a way that engages the reader (for example, through the use of charts, tables, and symbols), and content should be easy to read and written in plain English (with adequate explanation of acronyms, jargon, and technical terms) (Office of the Auditor-General, 2008, para 6.55).

- To be reliable: information must be free from any material error and bias so that users can depend on the actual position being faithfully represented (NZICA, 2005, para 31).

As discussed, the authoritative requirements from the Local Government Act 2002 and relevant GAAP focus on different aspect of SSP reporting and are complementing each other in some way. Schedule 10, Part 3 (15(e)) of the Act provides broad presentation of the statement while NZ IAS 1 and TPA-9 specifically focus on the items to be presented. The NZ Framework provides the overall characteristics of the information presented. In relation to wastewater services, wastewater disclosures in terms of quantity, quality, location, time, and 
cost (according to NZ IAS 1 and TPA-9) should be provided in SSPs in such a manner that the information is relevant, comparable, understandable, and reliable (according to NZ Framework). Note that, the notion of comparability is further reinforced by Schedule 10, Part 3 (15(e)) of the Local Government Act 2002 for the provision of explanation of significant variance, if any. Figure 2.1 presents the building blocks to summarise the connection between these components of the authoritative requirements in the context of wastewater disclosures.

From Figure 2.1, the five dimensions of wastewater services (quantity, quality, location, time and cost) can be individually presented on their relevance and comparability, of which the latter includes the requirement for explanation of any significant variance. All disclosures can then be presented for their understandability and reliability. 
Figure 2.1: Connection of components of authoritative requirements in the context of wastewater disclosures

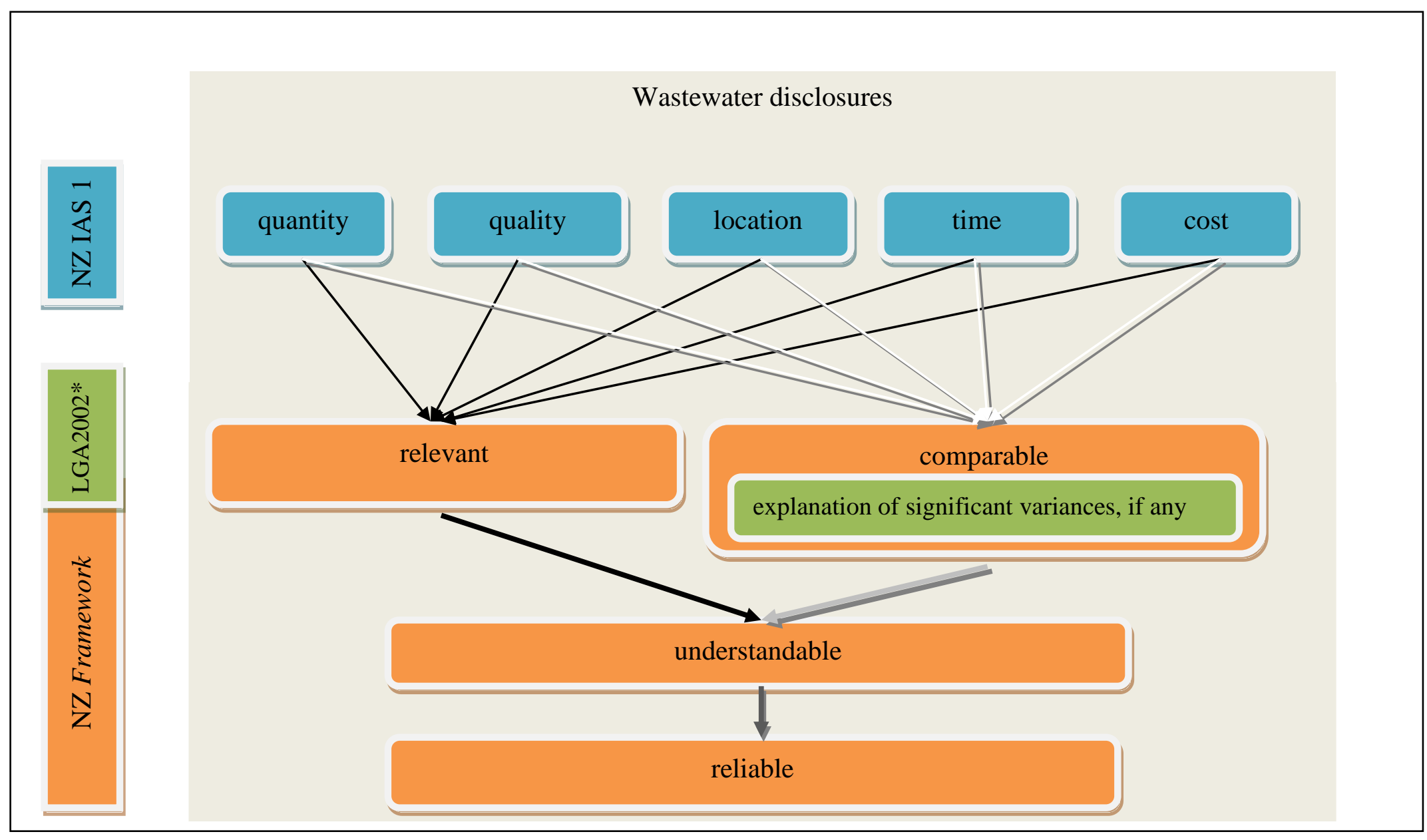

*LGA 2002 is Local Government Act 2002 
Given the authoritative requirements for SSP reporting from legislation and accounting guidance, New Zealand led the world with its requirement for all government financial statements to be reported on a full accrual basis, including the SSP requirement (Pallot, 2001a). While the UK and Australia have adopted a New Public Management focus and accrual accounting (Guthrie, 1993; Humphery, Miller, \& Smith, 1998), their emphasis has been on financial reporting aspects, moving only gradually towards all government (financial and nonfinancial) reporting. Arguably they have not made explicit achievement with the requirement for service performance reporting (Australian Accounting Standards Board, 2010).

Although mandatory requirements and accounting standards for service performance reporting in Australia and the United Kingdom have not been made concurrently, the reporting of such information is not entirely ignored. Both jurisdictions have addressed some aspects of service performance reporting. In Australia, there are varying degrees of enforcement of the service performance reporting requirements for the public-sector across the States. Not only the Australian government agencies but also in a few States (Victoria, Queensland, and Western Australia), public-sector entities are statutorily required to provide performance information, particularly in the form of performance indicators (Australian Accounting Standards Board, 2010). New South Wales, South Australia, Northern Territories and Tasmania public-sector entities were encouraged and provided with guidelines for the reporting of performance information by their State audit offices or other authoritative bodies (Australian Accounting Standards Board, 2010). 
In spite of the statutory requirement or encouragement for service performance reporting, Australian accounting standards for service performance reporting by public-sector entities have not yet been formulated (Australian Accounting Standards Board, 2010; Lee, 2006). However, there are some limited suggestions for reporting on performance indicators in AAS 27 (Financial Reporting by Governments, 1995), AAS 29 (Financial Reporting by Government Departments, 1996) and AAS 31 (Financial Reporting by Governments, 1996) (Lee, 2006). ${ }^{53}$ Similarly, in the United Kingdom, the statutory requirements and accounting standards for service performance reporting by public-sector entities have not yet been made explicit (Australian Accounting Standards Board, 2010; Rutherford, 2000). However, the Treasury has provided recommendations for performance indicators in the non-mandatory guidance, A Guide to Setting Targets and Measuring Performance (Lee, 2006). Without mandatory requirements and accounting guidelines for service performance information, it is possible that the reporting of service performance would potentially be less uniform and hence less comparable across public-sector entities in both countries.

\subsection{Current issues with SSP reporting}

The objective of SSP reporting is to strengthen public accountability for the delivery of outputs (NZICA, 2002, para 1.10). However, the SSP reporting of public-sector entities (including local authorities) has been criticised as poor, thus the accountability is also poor and needs improvement.

\footnotetext{
53 In February 2008 AASs 27, 29, and 31 were withdrawn (Australian Accounting Standards Board, 2008). However, their requirements have been incorporated into numerous other accounting standards which are broader in focus with application to all public benefit entities.
} 
The Office of the Auditor-General (2008) expressed its disappointment in the quality of reports by public-sector entities (including local authorities) in spite of nearly 20 years of public-sector experience in preparing statements of service performance, and the development of the relevant GAAP in early 2000s. The Office of the Auditor-General (2008) also sought significant improvement in the reports to allow Parliament and the public to hold public entities to be accountable for their use of taxes and rates and for the effectiveness of their service delivery.

Regardless of the OAG's disappointment at SSP reporting practice for 2007/2008, all 2007/2008 SSP disclosures by local authorities were unqualified. ${ }^{54}$ This may be because of the lesser requirement under the Local Government Act 2002 for SSPs to be audited only against Schedule 10, Part 3 (15(e)), not GAAP. In addition, the threshold for auditor to qualify the report is high. An auditor would not consider qualifying an audit report unless the disclosures were both significantly and fundamentally misleading or not meaningful (Neale \& Pallot, 2001). This raises the concern on the unqualified statements on SSPs, which are not explicit about the non-compliance with the authoritative requirements, if there is.

Given the long-standing criticism of poor SSP reporting, some reasons discussed by accounting professionals are as follows:

1. Lack of demand: It is possible that because SSPs are not well used by the public the reporter lacks incentives to produce high quality reports (Office of the

\footnotetext{
${ }^{54}$ Usually, the unqualified statement for SSPs states: "The service provision information of the council... fairly reflects the levels of service provision as measured against the intended levels of service provision adopted, as well as the reasons for any significant variances, for the year ended on that date."
} 
Auditor-General, 2008). The Office of the Auditor-General (2008) suggests that public-sector entities need to be encouraged consistently in the use of performance reports, in particular, by exploring the needs and interests of their different users, and by reporting information that better meets their different needs.

2. Lack of resources: Some public entities may not have sufficient resources (staff, and system capacity), ability (know-how), and data to prepare the reports (Neale \& Anderson, 2000).

3. Avoiding intervention: Chief executives may try to avoid generating reaction from media and politicians and therefore do not report more than is required, particularly in relation to bad news (Neale \& Anderson, 2000).

4. Lack of comprehensive standards: Guidance by the legislation and accounting profession is not helpful enough in the preparation of SSPs (Office of the AuditorGeneral, 2008; Webster, 2007). The Office of the Auditor-General (2008) argues that financial reporting standards heavily prescribe financial statements in their structure, composition, measurement, and disclosure. However, no reporting standards exist in New Zealand specifically for SSPs. TPA-9 is highly relevant but has limited authority compared to a financial reporting standard (Office of the Auditor-General, 2008). ${ }^{55}$ Webster (2007), the Assistant Auditor-General, is critical that the authoritative requirements describe the purposes, elements and qualitative characteristics of service performance reports, but they have been pitched at a higher or more conceptual level than financial reporting standards.

\footnotetext{
55 TPA-9 has recently been updated for consistency with New Zealand International Financial
} Reporting Standards and legislative requirements (Office of the Auditor-General, 2008). 
The Office of the Auditor-General (2008) adds that New Zealand Equivalents to International Financial Reporting Standards (including NZ IAS 1, NZ Framework) are written to cater the needs of large, profit-oriented entities in the private-sector rather than for the public-sector's specific needs for performance reporting. Large profit-oriented entities in the private-sector place emphasis on financial statement reporting (R. Gray, 1983). Public-sector entities on the other hand highlight their service performance reporting (Boyne \& Law, 1991; Hyndman \& Anderson, 1995). It is possible that International Financial Reporting Standards are based on economic framework highlighting decisionusefulness objective of private-sector's reporting, which is not suitable for publicsector reporting (Mack, 2003; Parker \& Gould, 1999). In short, the current authoritative requirements based on economic framework for the New Zealand public-sector's SSP reporting provides less than adequate guidance on the preparation of SSPs.

Webster (2007) and the OAG (2008) conclude that the development of standards and guidance for service performance reporting needs more attention by the accounting profession to improve the current SSP reporting by public-sector entities. The Office of the Auditor-General responded seemingly to the call for more guidance on SSP reporting. In 2010 the OAG issued the discussion paperLocal Government Examples of Better practice in Setting Local Authorities' Performance Measures - in an attempt to improve performance information in 2012-22 LTCCPs (Office of the Auditor-General, 2010). In essence, the discussion paper provides examples of appropriate performance measures specifically for local authorities' core activities - roading, water supply, 
wastewater, libraries, and building control. In particular to wastewater disclosures, the performance measures suggested are related to standard met, reliability of the service, and response time for a service (Office of the AuditorGeneral, 2010) which reflect the quality and time dimension of wastewater services. It is possible that this discussion paper could have an impact on local authorities' SSP disclosures for the 2012 forward when the performance measures are addressed in the LTCCP.

Further, in the near future, there will be the accounting standard frameworks for public-sector entities' reporting which embrace the accountability obligation of public-sector entities' reporting. Currently, the International Public Sector Accounting Standards Board (IPSASB) is in the process (Exposure Draft) of issuing Conceptual Framework for General Purpose Financial Reporting by Public Sector Entities with the objectives of the financial reporting be both for accountability and decision usefulness (International Public Sector Accounting Standard Board, 2010). New Zealand Accounting Standards Review Board, which supports the adoption of International Financial Accounting Standards, has concluded its intention to adopt the new accounting conceptual framework for public-sector entities (Accounting Standards Review Board, 2011). It is expected that the new framework would enable the public-sector entities in New Zealand to prepare their SSPs. 


\subsection{Summary}

This chapter provides the background to the statements of service performance requirements and wastewater services for New Zealand local authorities. The statement of service performance is a product of the extensive reforms of the public-sector in the late 1980s. The SSP reporting requirement for New Zealand local government was first introduced in 1989 and continues to the present under the Local Government Act 2002. Specifically, SSPs present non-financial information about the performance of entities in providing goods and services (outputs), with the stated objective of strengthening accountability to the public (Local Government Act 2002, s. 98; NZICA, 2002, para 1.10; 2004, para. 126.2).

Given two complementary levels of local authorities (regional councils and territorial authorities), regional councils' functions primarily focus on environmental management and public transport, while those of territorial authorities focus on various community services. Wastewater services are one of the most crucial services provided by territorial authorities and are disclosed in their SSPs.

The authoritative requirements of SSPs are from the Local Government Act 2002 and relevant GAAP. The Local Government Act 2002 states the SSP requirement in Schedule 10, Part 3 (15(e)); specifically requiring a comparison between actual service performances and the targets of service performance (as set out in the plan), with reasons given for any significant variances. They need to be prepared in compliance with generally accepted accounting practice (GAAP) and audited by the Auditor-General (Local Government Act 2002, s. 99). The relevant GAAP 
to SSPs is NZ IAS 1, TPA-9, and NZ Framework, which require the report to include, but not limit to, quantity, quality, location, time, and cost of the service and the disclosures to be relevant, comparable, understandable, and reliable.

In spite of twenty years' experience in preparing statements of service performance, the OAG (2008) has been critical of the reporting practice and the usefulness of the authoritative requirements. It is possible that the authoritative requirements, based on economic framework highlighting decision-usefulness model, are not suitable for public-sector's reporting (Mack, 2003; Parker \& Gould, 1999). The result of the first objective of the study is expected to provide evidence on the applicability (or otherwise) of the current authoritative requirements.

If accountability is the preferred objective of public-sector reporting as suggested by authors including Pallot (1992), then it would be important for the authoritative requirements to match the needs of those users. There is vast public-sector literature addressing the multi-facets of accountability of the public-sector entities. The next chapter will explore the literature that address the theoretical concept of accountability and different components of accountability, which underpin the SSP reporting and sets up the basis for the second objective of the study. 


\section{Chapter 3: Accountability and Statements of Service Performance as an Accountability Tool}

\subsection{Introduction}

This chapter provides an analysis of accountability concept as the theoretical foundation to statements of service performance reporting in order to understand the potential role of the statement in discharging accountability obligations, regarding wastewater services of New Zealand local authorities. The normative accountability expectations for the desirable characteristics of service performance information to be disclosed by local authorities will be derived from this literature. Section 3.2 presents the theoretical foundations of accountability theory, and section 3.3 discusses different types of accountability. Section 3.4 reviews accountability expectations that can be applied to develop a set of desired characteristics for wastewater disclosures, and section 3.5 summarises the chapter.

\subsection{Accountability theory}

"Accountability is the corner stone of all financial reporting in government" to quote from an address by the Government Accounting Standards Board of the United States (GASB, 1987, cited in Pallot, 1992, p. 40). The public-sector's accountability obligations derive from the fact that the public is required to pay taxes or rates involuntarily, while not having the freedom to choose, and that they are reliant on the service providers (Ives, 1987). They also rely on service performance information to be able to make informed judgements about the performance of their local authorities and on how their monies were spent (Mack 
\& Ryan, 2006). A number of researchers (Barton, 1999; Boyne \& Law, 1991; R.

Gray, et al., 1996; Hyndman \& Anderson, 1995) support that service performance information is a necessary means by which local authorities attempt to discharge their accountability to the public. Pallot (1992) concludes that accountability is the preferred purpose for public-sector reporting since the nature of the relationship between providers and users of government is non-voluntary. The accountability concept has been incorporated in the official purpose of a statement of service performance by the Local Government Act 2002 (s. 98) and NZICA (2002, para 1.10).

Despite the emphasis placed on accountability by the public-sector, there is no generally accepted definition or theory of what constitutes accountability. Table 3.1 provides a selection of definitions from the Oxford dictionary and the relevant literature.

Table 3.1: Prior researchers' explanations of the term 'accountability'

\begin{tabular}{|l|l|}
\hline \multicolumn{1}{|c|}{ Authors } & \multicolumn{1}{c|}{ Explanation of 'accountability' } \\
\hline $\begin{array}{l}\text { Normanton } \\
\text { (1971, p. 311) }\end{array}$ & $\begin{array}{l}\text { In its most general sense, accountability means a liability to reveal, to } \\
\text { explain and to justify what one does; how one discharges } \\
\text { responsibilities, financial or otherwise, whose several origins may be } \\
\text { political, constitutional, hierarchical or contractual. }\end{array}$ \\
\hline $\begin{array}{l}\text { Jackson } \\
\text { (1982, p. 220) }\end{array}$ & $\begin{array}{l}\text { Basically, accountability involves explaining or justifying what has } \\
\text { been done, what is currently being done and what is planned. }\end{array}$ \\
\hline $\begin{array}{l}\text { A. Gray and Jenkins } \\
\text { (1993, p. 55) }\end{array}$ & $\begin{array}{l}\text { Accountability is an obligation to present an account of, and answer } \\
\text { for, the execution of responsibilities to those who entrusted those } \\
\text { responsibilities. On this obligation depends the allocation of praise and } \\
\text { blame, reward and sanction so often seen as the hallmarks of } \\
\text { accountability in action. }\end{array}$ \\
\hline $\begin{array}{l}\text { R. Gray, Owen, and } \\
\text { Adams (1996, p. 38) }\end{array}$ & $\begin{array}{l}\text { Accountability is the duty to provide an account (by no means } \\
\text { necessarily a financial account) or reckoning of those actions for which } \\
\text { one is held responsible. }\end{array}$ \\
\hline $\begin{array}{l}\text { Coy, Fischer, and } \\
\text { Gordon (2001, p. 7) }\end{array}$ & $\begin{array}{l}\text { Accountability means the requirement for one party to account to } \\
\text { another party for its performance over a given period. }\end{array}$ \\
\hline $\begin{array}{l}\text { Oxford English } \\
\text { Dictionary (2006) }\end{array}$ & $\begin{array}{l}\text { The quality of being accountable; liability to give account of, and } \\
\text { answer for, discharge of duties or conduct }\end{array}$ \\
\hline
\end{tabular}


From Table 3.1, it appears that common to all notions of the term 'accountability' is an obligation to explain, account for, and/or justify the performance of a responsibility carried out over a given period. Other researchers have extended this basic idea and developed the concept of accountability relationships.

In simple terms, accountability arises from a relationship between two parties whereby one party (the delegator) delegates (explicitly or implicitly) a responsibility to another party (the acceptor) (R. Gray, et al., 1996; Ijiri, 1975; Jackson, 1982; Mulgan, 1997; Perks, 1993). The delegators and acceptors may be individuals, groups, or organisations (Day \& Klein, 1987; R. Gray, et al., 1996; Mulgan, 1997; Perks, 1993). When they are individuals, the relationship between the delegator and acceptor tends to be direct and straightforward. However, when groups and organisations are involved, the relationship between the parties is frequently complex and may be remote (Day \& Klein, 1987). For example, the relationship between a local authority and its various stakeholders is complex (due to the number and variety of stakeholders involved) and in some cases also remote (for example, the relationship with its local community).

The responsibility delegated to an acceptor may require the entrusting of resources (for example, funds) and/or authority to enable the responsibility to be performed. Similarly, the responsibility may have implicit and/or explicit terms and conditions attached. These may include objectives, expectations, requirements, rules, policies, and standards (A. Gray, 1984; Ijiri, 1975; Laughlin, 1990; Mulgan, 1997; Stewart, 1984). 
Acceptance of the responsibility gives the delegator the right to call on the acceptor to explain how the accepted responsibility has been performed (R. Gray, et al., 1996; Laughlin, 1990; Mulgan, 1997). Once a responsibility has been accepted, the acceptor is obliged not only to perform the responsibility in accordance with the attached terms and conditions but also to provide an explanation (an account or justification) of the performance (Coy, et al., 2001; A. Gray \& Jenkins, 1993; R. Gray, et al., 1996; Jackson, 1982; Normanton, 1971). Day and Klein (1987) referred to such explanation to the public by public-sector entities about their performance as "the life blood of accountability" (p.243).

The explanation or information provided by the acceptor about the performance of the responsibility needs to be such that it enables the delegator to evaluate the acceptor's performance (Day \& Klein, 1987; Mulgan, 1997; Stewart, 1984). The discharge of accountability is adequate or inadequate, depending on whether it enables the delegator to assess the performance of the acceptor in carrying out their responsibility (R. Gray, et al., 1996). The information can be in different languages; for example and/or financial or non-financial, quantitative or qualitative (Day \& Klein, 1987; R. Gray, et al., 1996; Normanton, 1971; Sinclair, 1995; Stewart, 1984). The information may take the form of formal or informal communications; be in written, oral or electronic form; and be delivered on a routine or ad hoc basis (Coy, et al., 2001). The information can be distributed through many channels (referred to as the means of accountability). For example, it may be through newspaper, radios or television, public consultations, plans, budget reports, special purpose reports, audited annual reports (Boyne \& Law, 1991; Coy, et al., 2001; Hyndman \& Anderson, 1995; Laswad, et al., 2005; Lee, 
2008; Milazzo, 1992; Ryan, Dunstan, \& Brown, 2002; Ryan, Stanley, et al., 2002; Sinclair, 1995; Taylor \& Rosair, 2000).

Based on the delegator's informed judgement, the delegator can allocate rewards or sanctions as appropriate (Day \& Klein, 1987; Mulgan, 1997; Stewart, 1984). The delegator's evaluation and consequent action on the acceptor is referred to as holding to account (Stewart, 1984). Holding to account is expected to have an implication for the quality of the performance offered by the acceptor (Mulgan, 1997). The awareness of possible rewards or sanctions is a constraint on all consequential acts an acceptor undertakes (Tetlock, 1985). In general, an acceptor is motivated to seek rewards from the delegator to whom he/she is accountable (Tetlock, 1985). Rewards and sanctions may be implicit or explicit, and may also be subjective or objective. Rewards may range from approval/respect or criticism, to something more tangible, such as monetary rewards (Frink \& Klimoski, 2004). In Table 3.1, A. Gray and Jenkins (1993, p. 55) note that the allocation of praise or blame (reward or sanction) is often regarded as one of the 'hallmarks' of accountability.

Jackson (1982) contends that an accountability relationship involves a set of procedures. Figure 3.1 shows the procedures - delegating responsibility, performing responsibility accepted, providing explanations, evaluating performance and allocating rewards or sanctions - involved in a simple one-toone accountability relationship. 
Figure 3.1: Procedures involved in a simple accountability relationship

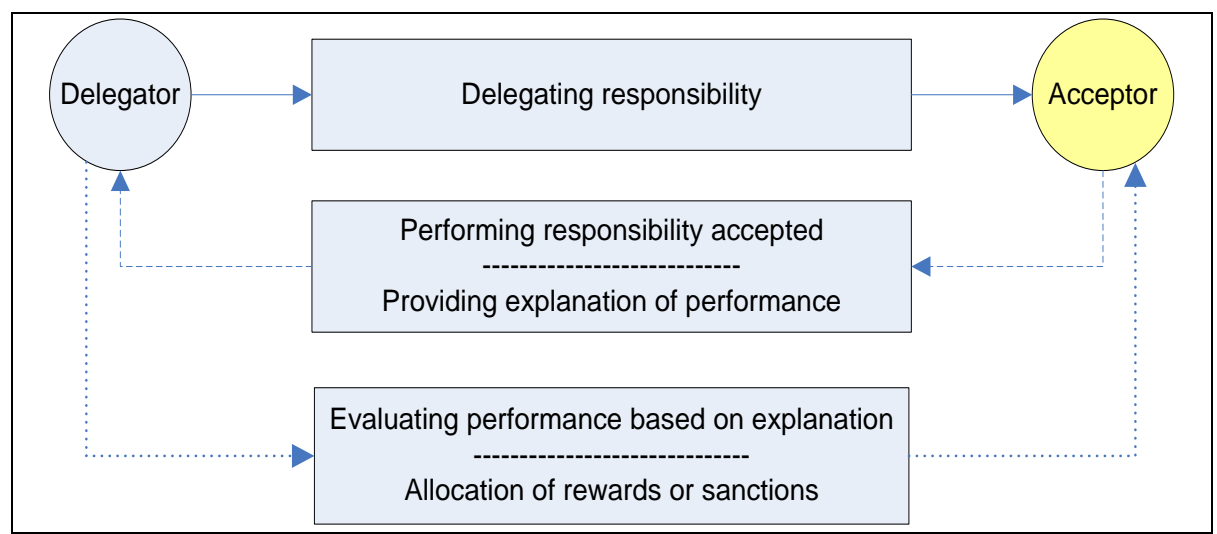

In practice, the acceptor may simultaneously have many accountability relationships and be accountable to multiple 'delegators' (Mulgan, 1997; Stewart, 1984). Accountability relationships may arise from different social arrangements; they may, for example, be created by law, contract, organisational rule, custom, or social norm (R. Gray, et al., 1996; Ijiri, 1975; Jackson, 1982; Normanton, 1971). However, irrespective of how they arise, the delegator and acceptor should agree on the terms and conditions of the performance of the responsibility and on the information to be provided about the performance (Day \& Klein, 1987; Laughlin, 1990). Nevertheless, the terms and conditions and the information to be provided may or may not be clearly defined. When they are not clearly defined, the accountability relationship is said to be communal (Laughlin, 1990). This form of accountability relationship can be expected when the accountability relationship arises through the operation of custom or social norm, and when there is no formal written agreement. An example of this type of accountability relationship is that of a local club secretary; usually neither the responsibility to be performed nor the report to be provided about the performance is explicitly specified, but is a norm of practice. 
When the terms and conditions of the responsibility to be performed and the information to be provided are clearly and formally defined (usually in writing), the accountability relationship is said to be contractual (Laughlin, 1990). This form of accountability relationship can be expected when the relationship arises through the operation of the law, a contract, or an organisational rule. For example, the responsibility of local authorities to provide goods and services to their local communities is specified in the Local Government Act 2002 and other enactments, and the annual reporting requirements concerning their performance are prescribed in the Local Government Act 2002 and generally accepted accounting practice. If a local authority outsources, for example, the collection and disposal of waste, the responsibility to be performed and the information to be provided about that performance are likely to be specified in a contract.

Nevertheless, Mulgan (1997) points out that even in a contractual accountability relationship (whether arising through law, a contract or an organisational rule), terms and conditions and/or information requirements specified by a delegator cannot identify everything that may need to be done and accounted for by the acceptor. Similarly, R. Gray, et al. (1996) observe that in some accountability relationships the terms and conditions of the responsibility to be performed may be clearly specified, but the information to be provided about the performance may not. An example of this situation is afforded by local authorities' services which affect the environment, such as wastewater treatment. Under the Resource Management Act 1991, resource consent conditions granted in respect of such services are clearly specified, with details of how the territorial authority needs to operate. However, the Local Government Act 2002 and GAAP requirements, 
relating to local authorities' reporting on their service performance, are expressed in broad, general terms (Webster, 2007). This leaves local authorities with discretion, to a greater extent, regarding the information they provide about their services in SSPs.

Where a lack of clarity exists about the terms and conditions attached to a responsibility accepted and/or the information to be provided by an acceptor, the acceptor needs to use his/her judgement, based on past experience, training and ethics, when deciding on the appropriate manner of performance and/or reporting thereon (A. Gray, 1984). However, in some circumstances, an acceptor may not act appropriately. For example, when an acceptor has discretionary authority regarding accountability information, he/she may distort or bias the information in order to avoid possible sanctions or to gain rewards (Fandt \& Ferris, 1990; Normanton, 1971; Patton, 1992; Perks, 1993). In such cases, the information may not enable the delegator to evaluate properly the performance of the acceptor and, as a consequence, the accountability of the acceptor is undermined (Perks, 1993). Jackson (1982) contends that the ability of an acceptor to control or influence the accountability information provided is a limitation of the accountability relationship.

\subsection{Types of accountability}

Various types of accountability have been identified by prior researchers, with references based on either 'to whom' or 'for what'. Each of these is developed in the next two sections. 


\subsubsection{Types of accountability based on 'to whom' an acceptor is}

accountable

In an accountability relationship, a delegator (the public) may delegate functions (seeking information, evaluating performance based on explanation, and/or allocating rewards or sanctions) to agent(s) (Ombudsmen, Officers of Parliament/OAG, and elected representatives) (Mulgan, 1997). Thus, the acceptor may be accountable not only to the delegator but also to the delegator's agents. In this study, the term 'accountability stakeholder' is used to denote both a delegator and a delegator's agent.

Prior research outlines different contexts for accountability that result in an acceptor being accountable to stakeholder(s), in various directions. Figure 3.2 summarises the four directions of accountability which have been discussed by prior researchers. Where the acceptor and accountability stakeholder(s) are in the same hierarchical structure, the acceptor may have upwards, downwards, or horizontal (lateral) accountability to the accountability stakeholders. Where the acceptor and accountability stakeholder(s) are not in the same hierarchical arrangement, the acceptor will have outwards accountability to the stakeholder(s). These directional accountabilities of an acceptor are depicted in Figure 3.2 and discussed below. 
Figure 3.2: Directional accountability of an acceptor within and outside a hierarchical structure

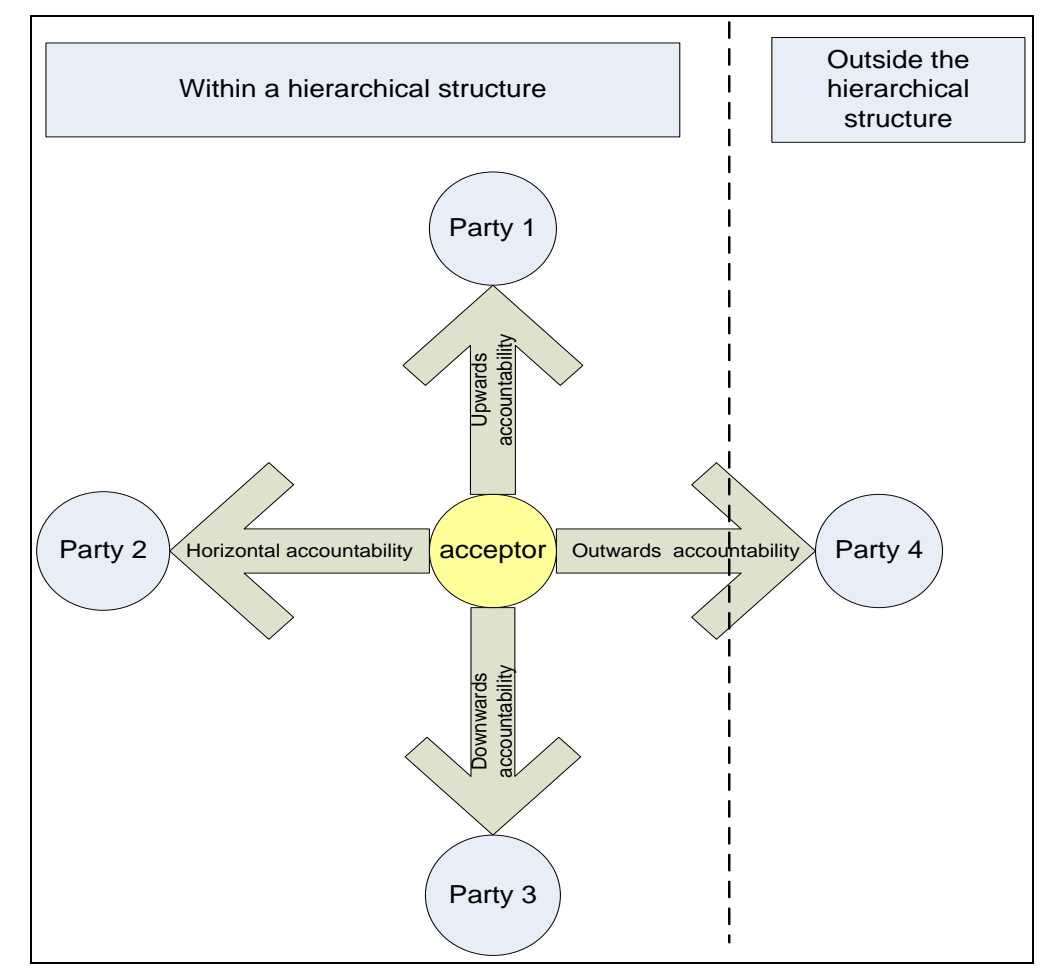

Upwards accountability is the obligation to report to the acceptor's superiors up the hierarchical structure who tend to have direct influence on the acceptor's performance and access to the information (Corbett, 1996; Mulgan, 2003; Taylor \& Rosair, 2000). In an organisational setting, Patton (1992) and Perks (1993) refer to this form of accountability as managerial accountability, such as that existing between an employee and employer. In a public-sector context, Normanton (1971), Sinclair (1995) and Mulgan (2003) refer to this form of accountability as political accountability; it includes the ministerial and parliamentary accountability of department chief executives, who are required to report, respectively, to Ministers and Parliament. In the local government context, the chief executive of a local authority has upwards accountability to his/her 
elected councillors and mayor and, for some, legal obligations to the regional council and the courts.

Downwards accountability requires a hierarchical superior to be accountable to his/her subordinate (Corbett, 1996; Mulgan, 2003). For example, the chief executive of a local authority is accountable to the council's staff for, inter alia, the equitable allocation of work and safe working conditions in conformance with the council's rules or a public-sector employees' union agreement. Nevertheless, this form of accountability may not be specified in any rule and/or may not be easily enforced by the subordinates (communal). In such cases, the accountability of the supervisor (acceptor) rests on his/her sense of moral obligation (Corbett, 1996). An example of such a circumstance is the obligation of the chief executive to inform the council's staff about any significant matter that may affect their safety and welfare (such as, heath hazards in the workplace) (Corbett, 1996).

Horizontal (or lateral) accountability arises when an acceptor is accountable to accountability stakeholders with equal status in a hierarchy (Mulgan, 2003; Munro \& Hatherly, 1993). For example, a local authority is accountable to other local authorities in the same region for the provision of civil defence services in the event of a natural disaster (such as a severe flood) under the Civil Defence Emergency Management Act 2002. The horizontal stakeholders of a local authority can also include an agent in the broader governmental setting (under constitutional bindings) who does not have an upward relationship, such as the OAG and the ombudsmen. 
Outwards accountability occurs when an acceptor is accountable to a party outside the acceptor's hierarchical structure, and no direct relational status exists (Corbett, 1996; Mulgan, 2003). Some prior researchers (for example, Coy, et al., 2001; Glenn \& Murphy, 1996; Normanton, 1971; Perks, 1993; Stewart, 1984) refer to the outwards accountability of public-sector entities to the general public as public accountability. In the context of local authorities, 'the public' comprises primarily local communities who are predominantly local authority taxpayers and ratepayers and their dependents, who are major recipients of goods and services provided by the local authority (Taylor \& Rosair, 2000).

Besides these four directions of accountability, some authors (Corbett, 1996; Mulgan, 1997; Sinclair, 1995) add inwards accountability, which requires an acceptor to be accountable to his or herself for actions to be in conformity with moral standards (Corbett, 1996; Mulgan, 2003). Arguably, morality is subjective for individuals and what appears to be moral to one may not be so for others (Corbett, 1996).

An acceptor may place different importance on different stakeholder relationships. Kloot and Martin (2001) surveyed 195 local authority managers across all States of Australia to examine perceptions of their relative accountability to their multiple stakeholder groups. Kloot and Martin (2001) found that managers accorded equal highest priority to their ratepayers and councillors (outward and upward accountability). In contrast, Steccolini (2004) found that Italian local governments perceived councillors and cabinet members (upward accountability) as the most important groups to whom they were accountable, while citizens 
(outward accountability) were the least important. Under the New Public Management, accountability of the public-sector to customers for public-sector goods and services has gained increased priority (Parker \& Gould, 1999). In this study, the outwards (public) accountability of local authorities to customers/taxpayers, who are recipients of wastewater services, are the focal stakeholders. Note that 'taxpayers' refers to anyone who pays taxes, rates, and levies to local authorities.

\subsubsection{Types of accountability based on 'for what' an acceptor is}

\section{accountable to the public}

'For what' an acceptor is accountable can be related to the type of information an acceptor owes to the delegator. A number of researchers have developed various types of accountability based on 'for what' public-sector entities are accountable to the public. Among them, Stewart (1984) proposed different bases of accountability, which provide a platform for understanding accountability expectations. Hence, the desirable characteristics of any accountability documents of public-sector entities to the public, which would enable the public to assess the performance of the public-sector entities and the pubic-sector entity to adequately discharge their public accountability. Stewart (1984) discusses six bases of accountability, which are: accountability for probity; accountability for legality; process accountability; performance accountability; programme accountability; and policy accountability. While different terminologies for the types of accountability are used by other researchers, their explanations are 
fundamentally similar to Stewart's (1984) taxonomy and can be used to augment it.

Accountability for probity concerns ensuring that funds entrusted to public-sector entities to perform delegated responsibilities are used properly, in the manner authorised, and that malfeasance is avoided (Stewart, 1984). Day and Klein (1987), Glenn and Murphy (1996), Taylor and Pincus (1999) support this notion, specifically that funds must be used in accordance with rules, and use the terms fiscal, financial, and fiduciary accountability, respectively to describe this obligation.

In the context of local government in New Zealand, funds for wastewater services must be spent in accordance with the budget specified in the LTCCP. Therefore, in order to discharge probity the local authority must disclose the actual funds expended compared to the LTCCP budget. Such disclosures would enable taxpayers to know how much of their contributions are actually spent and if they were used as planned.

Accountability for legality requires that public-sector entities exercise their delegated authority within the relevant legal and/or regulatory framework (Jackson, 1982; Stewart, 1984). Jackson (1982) terms this as legal accountability. Under the Local Government Act 2002, although local authorities are empowered with broad authority they still need to comply with many enactments.

In the case of wastewater operations, local authorities must comply with the conditions set by regional councils in their resource consents, issued under the Resource Management Act 1991. In addition, they need to ensure their 
wastewater systems (reticulation, treatment, and disposal) are provided for in full under the Health Act 1956. If local authorities expect to enable taxpayers to assess performance for legality, it could be expected that local authorities would disclose whether they had complied with the resource consents, as well as the reliability of the wastewater services, and response times to any incidents that occurred.

Process accountability addresses the appropriateness of the procedures employed to carry out delegated responsibilities to ensure there is no waste or maladministration, which in particular could lead to injustice (Stewart, 1984). Similarly, Taylor and Pincus (1999) refer to efficiency accountability, which requires the production of better outputs for any given input. While Stewart's (1984) procedures focus on the inputs (resources) usage, Taylor and Pincus's (1999) procedures focus on the outputs produced. Day and Klein (1987) embrace both ideas and use the term process/efficiency accountability that is, "about making sure that a given course of action has been carried out, and that value for money has been achieved in the use of resources ... the appropriate outputs have been produced, and that the ratio between inputs and outputs (efficiency) is the most favourable possible" (page 27). A favourable efficiency ratio can be achieved by reducing cost of inputs (including eliminating waste) and/or increasing quantity of outputs (Perks, 1993).

In the context of wastewater services provided by local authorities, to enable taxpayers to assess the efficiency of wastewater services, local authorities may disclose an efficiency ratio relating, for example, the cost of wastewater treatment with tonnes of wastewater treated. A high ratio represents the efficiency of the 
service; that is, with the amount of expenditure, a large quantity of wastewater was treated, or with the amount of wastewater treated, a reasonable cost was incurred.

Performance accountability relates to guaranteeing that the achieved performance meets the required standards of performance (Stewart, 1984). Under the Local Government Act 2002, local authorities plan their service performance targets in the LTCCP, which are 'required standards' of performance to be achieved. Comparison between the actual levels of service performance and the intended levels of service performance (as required by Local Government Act 2002) can ensure performance accountability.

Programme accountability concerns whether the work carried out meets the objectives set (Stewart, 1984). This type of accountability is similar to Taylor and Pincus' (1999) effectiveness accountability and Day and Klein's (1987) programme/effectiveness accountability.

Laughlin (1990) notes that Stewart's (1984) programme accountability is remarkably similar to performance accountability as they both relate to achieving goals. It is possible that the required standards under performance accountability mirror the objectives under programme accountability; therefore, achieving the standard can also promote the achievement of an objective. Given the similarity, for the purpose of this study, performance accountability and programmeleffectiveness accountability is combined. To assess the performance/programme/effectiveness, taxpayers need benchmarks for expected performance as well as reporting on actual achievement. 
In the case of wastewater services, local authorities discharge their performance/programme/effectiveness accountability by disclosing both actual service performance achievement (for example, 90 percent compliance with resource consent conditions) and their target set in the LTCCP (for example, 100 percent compliance with resource consent conditions). Such comparisons will enable taxpayers to assess their local authority's wastewater services, in particular their compliance with resource consents, and whether agreed targets have been met.

Policy accountability is concerned with responsibility of public-sector entities for formulating a policy that meets voters' expectations and for ensuring the policy is pursued (Stewart, 1984). This type of accountability is appropriate to superior parts of governmental agencies - both central and local - which are responsible for policy-setting and have no set standards to follow in the formulation of policy. Once policy has been set, the government is accountable to the public for both the policies it has pursued and those it has failed to pursue (Stewart, 1984). For example, under the Local Government Act 2002, local authority councillors are responsible for, inter alia, setting up revenue and financing policy for wastewater services and, in particular, may decide that the council's capital expenditure should be funded by a loan for the life of the investment. Once the policy is adopted through the special consultative procedure, councillors must ensure that the loan was raised for the appropriate purpose. The chief executive is not responsible for policy development, but rather, for day-to-day operations, such as providing community services. Policy accountability is therefore not applicable to the chief executive. 


\subsection{Accountability expectations for wastewater services}

Given the different accountability bases derived from the literature, Laughlin (1990) argues that depending on the type of accountability relationship not all the bases of accountability will be discharged in order to ensure the assessment of performance by the public and the adequacy of accountability by public-sector entities. In the case of wastewater services by local authorities, it can be argued that local authorities are expected to be accountable to the public on four bases for the services, being: probity, legality, process/efficiency, and performance/programme/effectiveness. These four bases form the accountability expectations for wastewater services, which are desirable characteristics of wastewater disclosures.

Jackson (1982) remarks that traditionally, accountability for probity and legality has been the primary focus of public accountability while efficiency and effectiveness accountability was recently added. Taylor and Rosair (2000) also note that the addition of efficiency and effectiveness accountability is pertinent to a public-sector entity discharging its accountability. The inclusion of process/efficiency, performance/programme/effectiveness accountabilities appears to be consistent with the public-sector reform principle, particularly concerning the pursuit of efficiency and effectiveness (as discussed in chapter 2).

Wastewater disclosures that are consistent with an accountability expectation are expected to enable taxpayers to evaluate a local authority's wastewater services performance. If so, a local authority's public accountability in relation to its wastewater services being adequately discharged would contradict the OAG's 
(2008) criticism, as discussed in chapter 2. The disclosures can reflect, to a limited degree, the success or otherwise of the promotion of reform themes concerning the adoption of private-sector practices.

\subsection{Summary}

The literature provides an analysis of accountability concept as theoretical foundation to SSP reporting in order to understand the potential role of SSP reporting in discharging accountability obligation, regarding wastewater services of New Zealand local authorities. Conceptually, local authorities' SSPs arise from the accountability relationship between the public and local authorities. Under the New Zealand constitution, the public delegates responsibility for management of taxes and rates for the provision of services to the chief executive responsible for the local authority. Consequently, the local authority has an obligation (accountability) to provide information about its service performance (SSPs) to the public. This obligation is reinforced by the Local Government Act 2002.

Past theoretical literature has attempted to define the possible characteristics of suitable information for public-sector entities so as to adequately discharge their accountability obligations. Among them, Stewart (1984) identifies four normative bases of accountability for public-sector entities, which provide a platform for understanding accountability expectations applicable for wastewater disclosures. They are probity, legality, process/efficiency, performance/programme/effectiveness accountability. It is expected that wastewater disclosures, corresponding to these accountability expectations, would 
enable the public to assess the performance of the local authority for its wastewater services provision. Examination of the consistency of wastewater services with the accountability expectations will provide evidence on whether New Zealand local authorities disclose information in a manner which is suitable for evaluating the performance in accordance with accountability framework. The result may then provide support on the suitability of accountability expectations as a model for SSP reporting.

The incentives of local authorities to provide wastewater disclosures that are consistent with the authoritative requirements and accountability expectations may vary, depending on their particular circumstances. The next chapter will review empirical studies regarding SSPs and possible disclosure incentives, in an endeavour to deepen understanding of cross-sectional differences in the disclosures. 


\section{Chapter 4: Review of Empirical Work on Statements of Service Performance}

\subsection{Introduction}

This chapter reviews the empirical work on statements of service performance, and identifies the disclosure incentives as well as their influential factors applicable for wastewater disclosures within SSPs by New Zealand local authorities. Section 4.2 discusses prior studies on service performance information in the United Kingdom, Australia, and New Zealand. Section 4.3 reviews prior studies on incentives of voluntary disclosures by public-sector entities. This literature presents incentives for disclosures which are developed in the context of wastewater disclosures in section 4.4. Section 4.5 provides a summary of the chapter.

\subsection{Prior research on service performance reporting}

A number of studies have examined public-sector entities' service performance information during the reform periods in various countries, for example, the United Kingdom (Banks, Fisher, \& Nelson, 1997; Boyne \& Law, 1991; Hyndman \& Anderson, 1995, 1998; Pendlebury, Jones, \& Karbhari, 1994; 2000), Australia (Herawaty \& Hoque, 2007; Kloot, 2009; Lee, 2006; Nelson, Tower, Banks, \& Fisher, 1997; Ryan, Stanley, et al., 2002), and New Zealand (Alves, et al., 2005; Coy, Dixon, Buchanan, \& Tower, 1997; Coy, et al., 1994; K. Dixon, et al., 1991; Lonti \& Gregory, 2007; Smith \& Coy, 2000; Thompson, 1995; Tooley \& Guthrie, 2001; Wei, Davy, \& Coy, 2008). Regardless of the different research criteria used 
in the examinations, public-sector entities in the United Kingdom, Australia, and New Zealand were in general seen as under-performing in their service performance reporting.

Given non-mandatory service performance reporting, studies of performance reporting in the United Kingdom public-sector focused on performance indicators/performance measures and showed that performance reporting improved after the New Public Management reforms, but remained disappointing (Banks, et al., 1997; Boyne \& Law, 1991; Hyndman \& Anderson, 1995, 1998; Pendlebury, et al., 1994). Boyne and Law (1991) investigated the performance indicators provided by 37 Welsh district councils on 13 services $^{56}$ for the years $1981 / 1982$ - 1988/1989 and found that the number of performance indicators about output, outcomes, efficiency, and effectiveness were poor, while of those about inputs were popular.

Pendlebury, Jones and Karbhari (1994) and Hyndman and Anderson (1995) analysed the performance indicators of the United Kingdom Executive Agencies (government agencies) in their 1991/1992 annual reports and found that few or no indicators were included about efficiency and effectiveness of services. Hyndman and Anderson (1998) extended their investigation of Executive Agencies' performance reporting in 1990/1991 to $1993 / 1994$ annual reports and found the numbers of performance indicators increased, and that there was a move away from simple indicators of inputs and outputs towards more sophisticated measures

\footnotetext{
56 These services included highways and transport, planning and economic development, environmental health, street cleaning, waste collection, waste disposal, housing: homelessness, housing: management and maintenance, housing: renovation grants, housing: benefits, leisure and recreation, parks and open spaces, and cemeteries.
} 
of efficiency and effectiveness. However, they contended that these changes were still inadequate. Similarly, performance indicators in United Kingdom universities were found to improve over a period (1992-1994) but were still very poor. For example, none of the universities reported information about targets (Banks, et al., 1997).

Rutherford (2000) examined the presentation and characteristics of the 1996/1997 performance indicators of the United Kingdom Executive Agencies and found that performance information was prominently disclosed. However, the understandability of many performance indicators was questioned. The United Kingdom studies showed that the merit in United Kingdom public-sector service performance reporting lay in its pursuit of accountability, in spite of its being nonmandatory and the absence of accounting standards for such reports.

Many studies in Australia have examined public-sector entities' annual report disclosures, including performance information (Herawaty \& Hoque, 2007; Kloot, 2009; Lee, 2006; Nelson, et al., 1997; Ryan, Stanley, et al., 2002). Nelson, et al. (1997) studied university annual report disclosures from 1993-1995 and concluded that performance information was not adequate and was also not improving over time. Similar results were reported by Ryan, Stanley, et al. (2002) after their study of the 1997-1999 annual report disclosures by Queensland local governments. Lee (2006) examined the 1998-2002 performance information within annual reports of Australian government trading enterprises and found there were few service quality and efficiency measures, and that their use fluctuated over the years of the study. Although most entities stated their business 
targets, they did not discuss how or whether such targets were achieved. In contrast, Herawaty and Hoque (2007) found that performance indicators were reported at a satisfactory level by government departments across Australia in the 2005/2006 annual reports. However, for the same period, Kloot (2009) found that fire-service departments did not provide adequate performance measures.

In New Zealand, Dixon, Coy and Tower (1991) examined the annual reporting practices of the seven universities in New Zealand from 1985 to 1989, which was a period of reform and initial impetus for greater accountability. Disclosure of service performance was non-existent in 1985 although increased over the study period (by three universities). However, none of the universities provided information about targets to enable comparison with actual achievements. Coy, Tower, and Dixon (1994) expanded Dixon, et al.'s (1991) study to the annual reports of tertiary education institutions (including polytechnics and colleges of education) from 1990-1992. They found that the service performance information was poor, lagging behind other disclosures, and continued to be a problem, as was found earlier in Dixon, et al. (1991). Ten years on from Coy, et al.'s (1994) study, service performance reporting by universities is still weak. Alves, Dunmore \& Dunstan (2005) studied the SSPs of eight universities in 2000, 2002, 2003 and found that some universities did not provide past performance or targets for comparison with actual achievements. They argued that some targets were vague and not quantitatively measurable.

In the second year of SSP reporting requirement for local government, Thompson (1995) examined 11 local authorities' performance indicators in SSPs, based on a 
single section analysis of public art galleries'1991/1992 annual report. Thompson (1995) found that the performance measures were not linked with stated objectives. Smith and Coy (2000) study 15 city councils' 1996/1997 and 1997/1998 annual report disclosures. In respect of service performance reporting, Smith and Coy (2000) studied 15 city councils' annual report disclosures for 1996/1997 and 1997/1998 years. In respect to service performance reporting, Smith and Coy's (2000) study covered a wide range of activities, which were divided into four separate groups of activities: roads, parking etc; water, refuse etc; arts, culture and recreation; and other. They found, overall, that performance measures were rated well (above average), however, performance measures for water and refuse activities (including wastewater services) were rated the lowest.

Lonti and Gregory (2007) conducted a longitudinal study, examining the 19922002 annual reports of five government departments. They found the average number of performance indicators per output class increased substantially between 1992 and 1997, then decreased marginally by 2002. Performance indicators about input were nil, while those about efficiency were almost absent, and outcomes and effectiveness measures (comparing actual results and targets) were very few in most departments. Performance indicators disclosed were primarily about outputs. These results seem to mirror the reform agenda, where public-sector entities are held accountable for outputs.

Most research examining the SSPs of New Zealand public-sector entities tends to focus on the education sector (for example, Alves, et al., 2005; Coy, et al., 1994; K. Dixon, et al., 1991) rather than government entities. With only a few existing 
research studies of government entities' SSPs, the research on central government is more up-to-date (Lonti \& Gregory, 2007). However, in respect of local government, the most recent study was Smith and Coy (2000). Further, in Smith and Coy's (2000) study, while SSP disclosures were considered, they were one part of the whole annual report disclosures being studied, and thus the analysis of the SSP disclosures was scant.

\subsubsection{Research using authoritative requirements}

The research studies discussed above used a number of different criteria to examine service performance reporting. Among them, authoritative requirements or recommendations (if the disclosures are voluntary) applicable for the jurisdiction studied were the most popular measure used. For United Kingdom studies, Boyne and Law (1991) used the Government's code of practice, and recommendations from the Audit Commission and the National Consumer Council. Pendlebury, Jones and Karbhari (1994) used Treasury's (1992) guideline: A Guide to Setting Targets and Measuring Performance. Rutherford (2000) used qualitative characteristics of financial reporting information developed by accounting professions. Hyndman and Anderson $(1995,1998)$ used criteria from a prior study by Brace, Elkin, Robinson, and Steinberg (1980).

Australian studies by Ryan, Stanley, and Nelson (2002) based their evaluation criteria on Coy, Tower, and Dixon's (1994) study, which originated from Dixon, et al. (1991), and guidelines (for example, from the Municipal association of Victoria). Banks, Fisher, and Nelson (1997) also used Coy, et al.'s (1994) method of evaluation. Kloot (2009) used common reporting benchmarks suggested by the 
Productivity Commission. ${ }^{57}$ Lee (2006) uses existing government documents such as from the Productivity Commission, and the International Federation of Accountants.

The New Zealand study by Dixon, Coy and Tower (1991) used primarily the accounting requirements by NZICA and a prior study of Gray and Haslam (1990) to develop evaluation criteria. Thompson (1995) used Statement of Concepts for General Purpose Financial Reporting issued by NZICA (1993). Lonti and Gregory (2007) used the Public Finance Act 1989. However, Smith and Coy (2000) used a prior research by Coy, Tower, and Dixon (1994), who modified a measure of Dixon, Coy and Tower's (1991) study.

\subsubsection{Research using accountability expectations}

Although many studies recognised some of the components of accountability expectations in some ways (Hyndman \& Anderson, 1995; Kloot, 2009; Lee, 2006; Ryan, Stanley, et al., 2002; Taylor \& Rosair, 2000), no study to date has used all of the components of accountability expectations as their basis for examining service performance disclosures by public-sector entities. The closest study was conducted by Taylor and Rosair (2000), using an exposition of the descriptive accountability literature by Davis, Weller, and Lewis (1989) and Sinclair (1995). They developed a quantitative measure for fiduciary and managerial accountability-based information within annual report disclosures, including performance indicators, of an Australian government department. Taylor and

\footnotetext{
57 The Productivity Commission is an Australian Government body which provides independent research and advisory services on a range of economic, social and environmental issues affecting the welfare of Australians (Productivity Commission, 2011).
} 
Rosair (2000) used fiduciary and managerial accountability and examined if they were reflected in annual report disclosures of Australian government departments. Arguably, fiduciary could be broken down to legality and probity accountability, and managerial accountability to efficiency and effectiveness accountability. However, their results were aggregated and could not identify whether the components of accountability expectations were reflected in the documents, and service performance information is a small part of their annual report disclosures they examined.

\subsection{Prior research on incentives for service performance reporting}

Some prior research (discussed above) goes further to discuss the incentives that may affect service performance disclosures, and it identifies influential factors to the disclosure incentives, so as to examine cross-sectional differences in the disclosures. However, the number of studies which investigate disclosure incentives for mandatory service performance information by public-sector entities is limited. The literature examined in this study extends to voluntary disclosures by public-sector entities.

The prior research's incentives can be categorised into four main possible disclosure incentives of public-sector entities. These are the public's demand for information, agent's awareness of political costs, the agent capability, and agent's awareness of funding benefits. Each of the incentives can be influenced by a number of factors. 


\subsubsection{The public's demand for information:}

Ingram (1984) argued that the extent of state government disclosure was affected by the demand for information by constituents. Zimmerman (1997) identified that the lack of incentives for voters to monitor (or demand for information from) politicians resulted directly in the current incomplete accounting disclosures of US local authorities. Specifically, he stated "we do not observe consolidated, full accrual fund statements because there is little demand for them" (page 136). Steccolini (2004) agreed that the lack of citizens' interest in reading annual reports limited the quality of government's disclosures (including service performance information). Ingram (1984) asserted that the greater the demand for information by constituents, the more accounting information that government would provide.

According to the literature, a number of factors influence the public's demand for information from public-sector entities and, hence, their disclosures. Some researchers argue that the greater the political competition, the greater the incentive for the public to demand more information to monitor incumbent politicians (Baber \& Sen, 1984; Evan \& Patton, 1987; Giroux, 1989; Ingram, 1984; Zimmerman, 1997). Baber (1983) defined political competition as the strength of opposing political parties that a politician expects to encounter in future elections. In political competition, political rivals may give ex ante promises to constituents of greater benefits at lower costs, and claim irresponsible management of incumbents (Baber \& Sen, 1984). It can be expected in scenarios of strong political competition that the opposition political party will convince 
constituents to watch the incumbent politicians. This will increase constituents' (alliance voters or opposite voters) incentives to monitor incumbent politicians for their actions and demand information to facilitate their monitoring (Baber \& Sen, 1984; Giroux, 1989). Therefore, the incumbents will attempt to satisfy voters' demands (assuming their primary objective is to win the next election and that political competition is strong) and to demonstrate their commitment to efficient management by using accepted reporting practices (Baber \& Sen, 1984; Giroux, 1989).

The studies based on the US government system most found positive, significant relationships between political competition and disclosures (Baber, 1983; Baber \& Sen, 1984; Evan \& Patton, 1987; Giroux, 1989; Ingram, 1984; Zimmerman, 1997). However, the examination of voluntary internet financial disclosures by New Zealand local authorities found no significant relationships between political competition and the disclosures (Laswad, et al., 2005).

The public's demand for information can also depend on size of the constituency. Assuming that constituents are likely to wish to maximize benefits from their share of taxes and to form shared interest groups which seek/pursue/lobby for specific service benefits (for example, the demands of Lyall Bay surfers that only clean sewage should be discharged from Moa Point wastewater treatment plants), they can demand or lobby for information to gauge resource availability and use (Ingram, 1984). The greater the size of a constituent group, the more coalitions they can form to pressure a local authority to provide a wide array of information (Ingram, 1984). This is synonymous with the private-sector, where larger firms 
with a wider range of shareholders are exposed to greater demands and pressure for information (Cooke, 1989).

Studies of government authorities found mixed results for the relationship between constituency size and governmental disclosures. Schneider \& Samkin, (2008); Ingram, (1984); Robbins \& Austin, (1986); Evan and Patton (1987) found no significant relationship between constituency size and governmental disclosures. This contrasts with Baber (1983), Ingram and DeJong, (1987), and Christiaens, (1999) who provided evidence of a significant relationship between constituency size and governmental disclosures.

In addition to political competition and size of constituency, the sophistication of constituents has been argued to influence the level of the demand for accountability information. Ingram (1984) contends that constituents who are more sophisticated (for example, higher education and/or income) are more likely to be more aggressive in demanding or lobbying the authority for more information than less sophisticated constituents. It is possible they could be active in using different means (for example, hearings, submissions, media) to lobby for more disclosures.

In the US, Ingram (1984) and Robbins and Austin (1986) examined the association between constituency sophistication and disclosures of state government and local councils, respectively. While Ingram (1984) found positive, significant associations, Robbins and Austin (1986) found no significant relationship. 


\subsubsection{The agent's awareness of political costs}

Public-sector entities that are more aware of potential political costs are likely to make more voluntary information disclosures in their annual reports, compared with those who are less aware, in order to reduce undesirable political costs (Lim \& McKinnon, 1993). 'Political costs' refers to the intervention of the government and its regulatory agencies or other interest groups of the entity which may affect redistributions of wealth (Whittred \& Zimmer, 1990). Any deficiencies of a statutory authority's management could result in intervention by a government through a reduced appropriation of a department's resources to other departments, and replacement of key senior staff, diminution of an authority's functions, removal of price subsidies, and the disallowance of price increases (Corbett, 1985; Pratt, 1982; Whittred \& Zimmer, 1990).

Employees of statutory authorities can also impose political costs, such as employee strikes, increased wages, and improved working conditions (Moore, 1985; Pratt, 1982). Employees are a workforce group dependent on the statutory authority for their income. Typically they are highly unionised, and trade unions are powerful interest groups (in Australia). They scrutinise the fairness of work and pay conditions and provide support for their members (Simms \& Singleton, 1993).

Political visibility is a factor that may give rise to political costs to an entity. Lim and McKinnon (1993) state that: "At a general level, an entity which is politically visible (or politically sensitive or exposed) may be described as one which attracts a disproportionate share of scrutiny by politicians, organized groups such as trade 
unions, and the general public, making it a potential target for the imposition of political costs" (page 192). The political visibility of local authorities may stem from, for example, the monopoly position occupied by an authority, the essential nature of its services (for example, polluting the natural environment), and/or the number of customers and employees of authorities (Lim \& McKinnon, 1993). Due to different environments and management, some authorities are more politically visible or attract more attention than others from government, trade unions, the public and the media (Pratt, 1982).

The more politically visible a local authority, the greater its awareness of political costs, and the more disclosures an authority will make in order to improve its public image and reduce any political costs (Lim \& McKinnon, 1993). Similarly, private-sector entities which are subject to greater scrutiny are more likely to disclose information than those subjected to less scrutiny, in order to reduce political costs (Watts \& Zimmerman, 1978). Consistent with this hypothesis, Lim and McKinnon (1993) found a positive correlation between the political visibility of local authorities and the level of voluntary disclosures.

\subsubsection{The agent's capability}

The agent's capability is another disclosure incentive which can be influenced by a number of factors. The main constraints on the production of service performance information by United Kingdom local authorities were the lack of staff to prepare reports, a lack of financial resources to cover the costs of producing them, and a lack of data (Boyne, et al., 2002; Boyne \& Law, 1991). The lack of data may be due to the use of new performance measures, making it 
difficult to access data, particularly when compared over time (Lee, 2008), or the diversiveness of non-financial service performance information, making it more difficult to measure and assess (Admiraal, Nivra, Turksema, \& Netherlands Court of Audit, 2009). Arguably, lack of accounting guidance may also limit the quality of the reports.

Christiaens (1999) found positive, significant associations between number of accounting employees and disclosures by Belgian municipalities. However, Boyne and Law (1991) found the relationship between size of staff (scale) and the disclosures was not significant.

Ingram (1984) and Christiaens (1999) also supported that the personal attributes or expertise of accounting officers could also influence the extent of local government reporting. Where accounting system administrators are well positioned to influence accounting practices, their personal education, business working experience and training can make a difference to accounting reporting (Christiaens, 1999; Ingram, 1984). While Ingram (1984) found a significant relationship between the extent of disclosures and personal attributes of staff, Christiaens (1999) found mixed results.

In the private-sector, the reporting capability of an entity depends on the financial resources of the firm. Wealthy firms are more likely to afford highly skilled accounting officers and efficient information systems which enable them to provide an extensive range of information (Buzby, 1975; Singhvi \& Desai, 1971). Singhvi and Desai (1971), Buzby (1975), Cooke (1989), Bozzolan, O’Regan, and 
Ricceri (2006) found a significant, positive relationship between firms' financial resources and annual report disclosures in the private-sector.

\subsubsection{The agent's awareness of funding benefits}

The greater the debt or federal funds that an authority seeks, the more incentive a local authority will have to prepare a report that is consistent with GAAP (Baber \& Sen, 1984; Christiaens, 1999; Ingram, 1984; Ingram \& DeJong, 1987). This idea appears to be based on implicit assumptions that, first, an entity relies substantially on the resource, and that secondly, the resource provider uses the report for its decision-making. Baber and Sen (1984), Ingram (1984) and Christiaens (1999) argued that public authorities seeking debt financing (for example, from bond-holders) would have increased incentives to provide compliance with a GAAP. This is because they are aware the report can signal to debt providers about the quality of management (no default on bonds) which will gain increased confidence from the resource provider (Evan \& Patton, 1987), thereby reducing the cost of debt and increasing the resources available for other public goods (Ingram \& DeJong, 1987). This idea also applies to federal fund resourcing (Ingram, 1984).

Studies in public-sector reporting give mixed results on the association between debt and disclosures. Robbins and Austin (1986), Ingram and DeJong (1987) and Evans and Patton (1987) found a positive, significant relationship between debt and disclosures. However, Baber (1983), Baber and Sen (1984), Laswad, et al. (2005), and Christiaens (1999) found no association between them. 
The agent's seeking of funds (for example, easier marketability of securities, greater ease in financing, increased investors' confidence) also motivated privatesector entities to provide information (Buzby, 1975; Singhvi \& Desai, 1971). Buzby (1975) and Singhvi and Desai (1971) argued that larger firms, which are more reliant on these benefits, tended to provide fuller or better reports, while smaller firms did not raise funds in the securities market and may not have wanted to provide fuller disclosures of their affairs, as they might endanger their competitive advantage over larger firms in their industry. Buzby (1975), Singhvi and Desai (1971), and Cooke (1989) found significant, positive relationships between the potential benefits and the extent of reporting in the private-sector.

As discussed above, the four disclosure incentives of the public-sector and their corresponding influencing factors are summarised in the Table 4.1.

Table 4.1: Disclosure incentives and their influential factors of public-sector entities

\begin{tabular}{|l|l|}
\hline \multicolumn{1}{|c|}{ Disclosure incentives } & \multicolumn{1}{c|}{ Influential factors } \\
\hline Public's demand for information & $\begin{array}{l}\text {-political competition } \\
\text {-size of constituents } \\
\text {-constituency sophistication }\end{array}$ \\
\hline Agent's awareness of political cost & -political visibility \\
\hline Agent's capability & $\begin{array}{l}\text {-staff availability } \\
\text {-personal attributes of accounting staff } \\
\text {-financial resource availability }\end{array}$ \\
\hline Agent's awareness of funding benefits & $\begin{array}{l}\text {-debt reliance } \\
\text {-government funds reliance }\end{array}$ \\
\hline
\end{tabular}

From Table 4.1, each of these four disclosure incentives can be related to the accountability concept, discussed in chapter 3. The public's demand for information is similar to the delegator call for the information from the acceptor about the performance. The agent's capability is assumed in the accountability 
relationship, whereby it is expected that an acceptor is sufficiently capable (has enough time, knowledge, and systems) to prepare the performance information. The agent's awareness of funding benefits and any political costs can be related to an acceptor's awareness of possible rewards or sanctions in the accountability relationship. Such awareness of funding benefits or rewards can motivate a public-sector entity to provide quality disclosures (Baber \& Sen, 1984; Christiaens, 1999; Ingram, 1984; Ingram \& DeJong, 1987). However, the awareness of sanctions may provide incentives for an acceptor to distort or bias the information in order to avoid possible sanctions (Fandt \& Ferris, 1990; Normanton, 1971; Patton, 1992; Perks, 1993), as discussed in chapter 3. Arguably, the awareness of political costs can motivate a public-sector entity to provide full disclosures in order to reduce political costs (Lim and McKinnon, 1993).

From another point of view, the public's demand for information and the agent's awareness of political costs are based on external pressures on the agent to be responsible to constituents (or stakeholders), while the agent's awareness of benefits comes from an internal need by the agent. These pressures can determine what public-sector entities would like to disclose. However, the agent's capability can be seen as a limitation on what they disclose.

\subsection{Incentives applicable for wastewater disclosures}

New Zealand local authorities are unique in nature and their incentives for SSP disclosure have not yet been investigated in prior research in the public-sector. In essence, New Zealand local authorities rely very little on debt and government 
funding, but rely mostly on taxes, including rates. As described in chapter 3, government grants and subsidies to local authorities, in 2009, accounted on average for only 10.96 percent of total revenue, and debt was 7.59 percent of total assets, while local taxes amounted to 61.1 percent of total revenue. Government is most likely to use its legislative report (the budget), and financial institutions are most likely to use specific reports, such as asset management plans and financial and funding policy, rather than SSP disclosures, when making decisions on funding. Hence, the awareness of funding benefits will not be a relevant incentive for SSP reporting by a New Zealand local authority, and therefore are not included in the study.

Therefore, the incentives of local authorities in New Zealand to disclose information in SSPs are: public demand for the disclosure; awareness of political costs; and the local authority's capability. Their corresponding influential factors, discussed above, will also apply. Table 4.2 summarises the disclosure incentives and influential factors applicable for wastewater disclosures in an SSP by New Zealand local authorities.

Table 4.2: SSPs wastewater disclosure incentives and influential factors of New Zealand local authorities

\begin{tabular}{|l|l|}
\hline \multicolumn{1}{|c|}{ Disclosure incentives } & \multicolumn{1}{c|}{ Influential factors } \\
\hline Public's demand for SSP disclosures & $\begin{array}{l}\text {-political competition } \\
\text {-size of constituency } \\
\text {-constituency sophistication }\end{array}$ \\
\hline Local authority's awareness of political cost & -political visibility \\
\hline Local authority's capability & $\begin{array}{l}\text {-staff availability } \\
\text {-personal attributes of accounting } \\
\text { staff } \\
\text {-financial resource availability }\end{array}$ \\
\hline
\end{tabular}


The public's demand for wastewater disclosures can be caused by heightened political competition where candidates for council persuade the public of the need to monitor incumbent councillors in relation to wastewater management. Further, the large population size of a territorial authority, in which people wish to maximise the benefits of their taxes paid, may form coalitions which lobby the territorial authority for better wastewater services. Similarly, more sophisticated constituents who are interested in wastewater performance of their territorial authority may use various means to exert pressure on the territorial authority to provide more accountable wastewater disclosures. As discussed, the effect of the public's demand for wastewater disclosures is consistent with the OAG's (2008) view that a lack of public demand may result in poor SSP reporting (Office of the Auditor-General, 2008).

Where territorial authorities operate the wastewater operation, they can expect potential intervention from the regulator as by nature wastewater operation pollutes the environment. If they do not comply with the legal requirements (for example, under the Resource Management Act 1991), they may be subject to public criticism, enforcement order from the regional council, and tighter regulations imposed by other oversight bodies. Therefore, they may choose to provide more comprehensive information on their wastewater performance in order to avoid any intervention. However, Neale and Anderson (2000) argued that public-sector entities reported less of their service performance information in order to avoid public attention that could have potential political costs. 
A local authority's capability (for example, lacking an efficient information system) may be a constraint on what can be disclosed about wastewater services. It is possible that territorial authorities with more staff, staff expertise, and the financial resources with which to compile wastewater information are more likely to provide more comprehensive disclosures. This argument is consistent with Neale and Anderson's (2002) argument that poor SSP reporting may be caused by a lack of resources to prepare the report, as mentioned in chapter 2. Although number of staff and financial resources of local authorities may be limited, staff expertise may be increased through education and comprehensive accounting guidance supported by regulators and accounting professions.

\subsection{Summary}

This chapter provides details from the empirical work on service performance information, and identifies disclosure incentives as well as their influential factors applicable to wastewater disclosures by New Zealand local authorities. As found in the United Kingdom and Australia, New Zealand public-sector entities do not satisfactorily report on their service performance information. Studies on SSP by New Zealand local authorities are very limited. Among public-sector studies, no studies have used the current authoritative requirements or all of the components of accountability expectations, derived from literature, to examine SSP reporting by New Zealand local authorities.

Given the limited prior research on service performance information, the literature reviewed in this study extends to voluntary disclosures by public-sector entities in order to identify disclosure incentives and their influential factors that are 
applicable for wastewater disclosures. According to the prior research and the particular setting of New Zealand local government, three possible incentives are identified. These are the public's demand for information, agent's awareness of political costs, and the agent capability. Each of the incentives is influenced by a number of factors as listed in Table 4.2. Provided that these incentives of SSPs by New Zealand local governments have not been empirically tested, the third objective of this study is to examine the influential factors that may explain crosssectional differences of wastewater disclosures.

Chapters 2, 3, and 4 provides basis for the study's objectives. The next chapter will discuss the methodology used for examining wastewater disclosures according to the objectives of the study. 


\section{Chapter 5: Methodology for Examining Statements of Service}

\section{Performance}

\subsection{Introduction}

This chapter describes the methodology for measuring the consistency of wastewater disclosures with authoritative requirements and accountability expectations, and for investigating the association of influential factors with SSPs. Section 5.2 outlines the appropriate methods used in this research - disclosure indices and multiple regression analysis. Section 5.3 explores the development of indices for wastewater disclosures, according to authoritative requirements and accountability expectations. The independent variables applicable for the research and used in the regression analysis are reviewed in section 5.4. Section 5.5 presents the data source, and section 5.6 summarises the chapter.

\subsection{The methods of analysis}

To address the first and second research objectives concerning the consistency of wastewater disclosures in SSPs with the authoritative requirements and accountability expectations, disclosure indices will be developed. ${ }^{58}$ The indices will enable cross sectional comparability and statistical analysis of the association of the influential factors with the SSPs.

\footnotetext{
${ }^{58}$ Beattie, McInnes, Fearnley. (2004) point out that an index is a partial form of content analysis. Content analysis makes inferences about the text examined by classifying words, phrases, sentences or other units in the text into content categories and/or items, each of which is presumed to contain units of similar meanings web(Weber, 1985). Once units of the text have been assigned to particular categories or items, analysis can be undertaken. However, there is no one right approach to the analysis (Weber, 1985); indeed, it can vary from qualitative and verbally descriptive methods to quantitative methods that permit statistical analysis (Beatie, et al., 2004). An index makes an inference about the text in a quantitative format.
} 
A disclosure index is a popular instrument used by various researchers to measure the extent of particular information in annual reports of organisations (Marston \& Shrives, 1991) (See Appendix B for examples for studies using disclosure indices to assess the different types of information within annual reports.) A number of studies use indices to examine both financial and non-financial disclosures (Buzby, 1975; Cooke, 1989; Coy, et al., 1994; Robbins \& Austin, 1986; Ryan, Stanley, et al., 2002; Smith \& Coy, 2000; Stanley, Jennings, \& Mack, 2008; Taylor \& Rosair, 2000). Some studies use disclosure indices for specific disclosures - for example, disclosures about the entity's environmental performance (Clarkson, Li, Richardson, \& Vasvari, 2008; Hughes, Anderson, \& Golden, 2001; Wiseman, 1982), intellectual capital (Bozzolan, O'Regan, \& Ricceri, 2006; Schneider \& Samkin, 2008; Williams, 2001) and service performance information (Boyne \& Law, 1991).

To investigate the relationship between the disclosures and the influential factors, as discussed in chapter 4 , multiple regression analysis will be used. Multiple regression analysis is a statistical tool that can be used to examine/determine the relationship between a single dependent variable and several independent variables (Field, 2005). Numerous accounting research studies in both private and public-sector s use multiple regression analysis to test the association between their disclosure indices and other designated variables (Baber, 1983; Baber \& Sen, 1984; Boyne \& Law, 1991; Bozzolan, et al., 2006; Buzby, 1975; Christiaens, 1999; Cooke, 1989; Evan \& Patton, 1987; Giroux, 1989; Ingram, 1984; Ingram \& DeJong, 1987; Laswad, et al., 2005; Lim \& McKinnon, 1993; Robbins \& Austin, 1986; Singhvi \& Desai, 1971). 


\subsection{Index Development}

Given the two different measures of SSPs in this study, two indices will be developed - an Authoritative Requirement (AR) index and an Accountability Expectation (AE) index. Marston and Shrives (1991) reviewed the development of an index, and found it generally involved three steps, namely: (i) selection of items to be included in the index; (ii) the allocation of weights to the items (if appropriate); and (iii) the development of a scoring system. In this study, items of the two indices will be selected from wastewater disclosures, based on two different criteria and sharing the same weight allocation and scoring system for consistency of the results.

\subsubsection{Item selection}

As the number of items disclosed in the documents studied could be very large, researchers select a certain set of items, based on various criteria (Beatie, et al., 2004). Item selection for the index may be based on statutory requirements, guidance and recommendations by authoritative bodies, best practice, an expert's suggestions, and literature. For example, Clarkson, et al. (2008) selected 95 items based on guidelines from the 'Global Reporting Initiative', published in 2002, and recommendations from an expert in environmental reporting. Buzby (1975) selected 39 items based on the US Securities and Exchange Commission requirements. Cooke (1989) based his 224 items on previous similar studies, recommendations by the International Accounting Standards Committee and Foreningen Auktoriserade Revisorere, statutory requirements, and consultation with the Swedish practising accountants for the pilot study. Stanley, Jennings and 
Mack (2008) selected 11 items based on a Local Government Finance Standard (1994), a bulletin released by the Queensland Government Department of Local Government and Planning, and research reports on 'Popular Reporting and Performance Reporting', prepared by the Government Accounting Standard Board. A number of studies (Banks \& Nelson, 1994; Coy \& Dixon, 2004; Fisher, Nelson, \& Banks, 1996; Nelson, et al., 1997; Ryan, Stanley, et al., 2002; Smith \& Coy, 2000; Tooley \& Guthrie, 2001) based their item selection on Coy, et al. (1994). Thus, the number of index items in prior studies has ranged from 11 items (Stanley, et al., 2008) to 224 (Cooke, 1989). Further, the items selected may be classified under different categories. For example, Wiseman (1982) classified the items across four categories (economic factors, environmental litigation, pollution abatement items, and other environmentally related items).

\subsubsection{Authoritative Requirement (AR) index items}

The selection of AR index items of wastewater disclosures is based on the authoritative requirements derived from statutory requirements (Local Government Act 2002, Schedule 10, Part 3 (15(e))) and relevant GAAP (NZ IAS 1, NZ Framework), as discussed in chapter 2. In short, they are:

1. contains audited information on the comparison between targets (set out in LTCC) and actual levels of service; performance; as well as explanations for any significant variance from the comparison (Local Government Act, 2002, Schedule 10, part $3(15(\mathrm{e}))$;

2. reports on quantity, quality, time, location, and cost of the output or service delivery, if relevant (NZ IAS 1, para 126.4); and 
3. be relevant, reliable, comparable, and understandable (NZ Framework, paras 25-42 and TPA-9, paras 5.10-5.39).

Figure 2.1 illustrating the connection between the components of the authoritative requirements in the context of wastewater disclosures provides a model for the selection of the AR index items which are shown in Table 5.1. From Table 5.1, the AR items selected comprise 64 items in total, which are categorised according to the qualitative characteristics of relevance, comparability, understandability and reliability. There are 15 items categorized under relevance, 45 under comparability, 3 under understandability, and 1 under reliability. Relevance and comparability categories contain the details of each of the wastewater service's dimensions (quantity, quality, location, time, and cost). 
Table 5.1: Categories and items of the AR index

\begin{tabular}{|c|c|c|c|}
\hline \multicolumn{4}{|c|}{ Categories/Items } \\
\hline Relevance & \multicolumn{3}{|c|}{ Comparability } \\
\hline Actual Quantity & Target Quantity & Explanation of sig.var. of Quantity, if any & Past Quantity \\
\hline Actual quantity of wastewater collection & Target quantity of wastewater collection & Explnt'n of sig var of quantity of collection & Past quantity of wastewater collection \\
\hline Actual quantity of wastewater treatment & Target quantity of wastewater treatment & Explnt'n of sig var of quantity of treatment & Past quantity of wastewater treatment \\
\hline Actual quantity of wastewater disposal & Target quantity of wastewater disposal & Explnt'n of sig var of quantity of disposal & Past quantity of wastewater disposal \\
\hline Actual Quality & Target Quality & Explanation of sig.var. of Quality, if any & Past Quality \\
\hline Actual standards to be met & Target standards to be met & Explnt'n of sig var of standards to be met & Past standards to be met \\
\hline Actual reliability of the service & Target reliability of the service & Explnt'n of sig var of reliability of the service & Past reliability of the service \\
\hline Actual customers' satisfaction & Target customers' satisfaction & Explnt'n of sig var of customers' satisfaction & Past customers' satisfaction \\
\hline Actual Location & Target Location & Explanation of sig.var. of Location, if any & Past Location \\
\hline Actual location of wastewater collection & Target location of wastewater collection & Explnt'n of sig var of location of collection & Past location of wastewater collection \\
\hline Actual location of wastewater disposal & Target location of wastewater disposal & Explnt'n of sig var of location of treatment & Past location of wastewater treatment \\
\hline Actual location of wastewater treatment & Target location of wastewater treatment & Explnt'n of sig var of location of disposal & Past location of wastewater disposal \\
\hline Actual Time & Target Time & Explanation of sig.var. of Time, if any & Past Time \\
\hline Actual time compliance with milestones & Target time compliance with milestones & Explnt'n of sig var of time compliance with milestones & Past time compliance with milestones \\
\hline Actual time response to incidents & Target time response to incidents & Explnt'n of sig var of time response to incidents & Past time response to incidents \\
\hline Actual time of service availability & Target time of service availability & Explnt'n of sig var of time of service availability & Past time of service availability \\
\hline Actual Cost & Target Cost & Explanation of sig.var. of Cost, if any & Past Cost \\
\hline Actual total cost of wastewater & Target/budget total cost of wastewater & Explnt'n of sig var of total cost of wastewater & Past total cost of wastewater \\
\hline Actual cost of wastewater by direct/indirect cost & Target cost of wastewater by direct/indirect cost & Explnt'n of sig var of wastewater by direct/indirect cost & $\begin{array}{l}\text { Past cost of wastewater by direct/ indirect } \\
\text { cost }\end{array}$ \\
\hline Actual cost of wastewater by system & Target cost of wastewater by system & Explnt'n of sig var of cost of wastewater by system & Past cost of wastewater by system \\
\hline \multicolumn{4}{|c|}{ Understandability } \\
\hline \multicolumn{4}{|c|}{ Separate heading for wastewater disclosures } \\
\hline \multicolumn{4}{|c|}{ Use of visual aids (tables or graphs) } \\
\hline \multicolumn{4}{|c|}{ Explanation of technical terms, if any } \\
\hline \multicolumn{4}{|c|}{ Reliability } \\
\hline \multicolumn{4}{|c|}{ Unqualified audit statement for SSP } \\
\hline
\end{tabular}


Quantity of wastewater service is based on the three main operations of the wastewater system - wastewater collection, treatment, and disposal. Its items relate to:

1. length of reticulated pipe or number of pump stations;

2. number of treatment plants or capacity, amount of wastewater that a plant can take; and

3. amount of treated wastewater discharged to an outfall.

Quality of wastewater activity concerns the activity meeting the standards or legal requirements, reliability of the service provisions, and residents' satisfaction or dissatisfaction (complaints). Its items relate to:

1. level of compliance with relevant resource consent conditions;

2. number of blockages or overflows; and

3. number of complaints relating to odours from wastewater treatment facilities, or percentage of customer satisfaction with the service.

Location of wastewater activity refers to places where their collection, treatment, and disposal occur. Its items relate to:

1. suburb of wastewater pipelines or pump stations being installed or maintained;

2. suburb of wastewater treatment plants; and

3. river where treated wastewater is disposed. 
Time of wastewater activity is about the date of completion regarding wastewater activity, response time for a service, time availability of service. Its items relate to:

1. completion date to upgrade pipelines or pump stations;

2. percentage of emergency repairs attended to within one hour; and/or hours used to clear all sewer blockages; and

3. hours of service available or unavailable.

Cost of wastewater activities can be total operating expenses of wastewater, and their details, by direct or indirect costs, for the different operations of the wastewater system. Its items relate to:

1. total expenditure for wastewater activities;

2. overheads, interest, and depreciation expenses of wastewater activities; and

3. collecting, treating, and disposing expenses of wastewater activities or wastewater expenses of plants $\mathrm{A}, \mathrm{B}$, and $\mathrm{C}$.

Using these wastewater dimensions, relevance and comparability items are formed. Understandability and reliability items will be based on all the wastewater disclosures. 
Relevance requires actual (present) performance of the reporting year. ${ }^{59}$ Therefore, the disclosure items relating to quantity, quality, location, time, and costs of wastewater activities are in their actual terms for the reporting year. Given three items in each dimension, there are 15 items in this category.

Comparability requires the presentation of target performance, explanation of significant variance, if any, between actual and target performance, and past performance. Targets of the 15 disclosure items relating to quantity, quality, location, time, and costs of wastewater activities are accounted for. Explanation is also needed of significant variance of the 15 disclosure items, relating to quantity, quality, location, time, and costs of wastewater activities. Variance arises when there are differences between the actual achievement and the target. Note that a difference above 10 percent is considered significant, for which explanation should be presented (Garrison, Noreen, \& Brewer, 2006). Past performance of the 15 disclosure items, relating to quantity, quality, location, time, and costs of wastewater activities, is also accounted for. Note that in this research, 'past' means prior year(s) beyond the year of the report. Given three aspects of comparability (targets, explanation of variance, and past) to be considered for each wastewater items, there is a maximum of 45 items in this category.

Understandability deals with the format and presentation of the information. Understandability items are a separate heading for wastewater services, and

\footnotetext{
${ }^{59}$ Actual performance information provides more objective ground for relevant information than deciding on the logical link with an entity's objective, and if the information meets the demand of stakeholders.
} 
include visual aids (such as tables or graphs) for wastewater disclosures, and an explanation of technical terms, if any. Rutherford (2000) and Stanley, Jennings and Mack (2008) support that visual aids such as tables and graphs are found to be useful for annual report disclosures by public-sector entities.

Reliability can be assured by unqualified audit statements for SSPs. The reliability item is the audit statement that 'service provision information presents fairly' in the audit report. Smith and Coy (2000), and Admiraal, Nivra and Turksema (2009) support that an audit report can provide a high level of assurance on the reliability of information. There is one item for this category.

\subsubsection{Accountability Expectation (AE) index items}

As discussed in chapter 3, the four accountability expectations (probity, legality, process/efficiency, performance/programme effectiveness) derived from literature form the bases for desired characteristics of wastewater disclosures. The AE index items are selected and categorised according to these accountability expectations. Because of the broad terms of the accountability expectations, the study's specific focus on wastewater disclosures, and absence of prior research on the disclosures, a list of AE index items were identified, based on best practice. In order to identify items for each of the categories (components of accountability expectations), the researcher looked at all the wastewater disclosures of all 73 territorial authorities. Wastewater disclosures of 10 territorial authorities that were considered to be reasonably representative as best disclosures of the category were selected. Therein, the most commonly used performance measures or information applicable for the category. Since there were four categories of AE 
index, four rounds of consideration were undertaken. Table 5.2 sets out the items selected for AE index across the categories.

Table 5.2: Categories and items of the AR index

\begin{tabular}{|c|}
\hline Categories/Items \\
\hline Probity accountability \\
\hline Actual operating expenditure for wastewater services \\
\hline Target operating expenditure for wastewater services \\
\hline Actual capital expenditure for wastewater services \\
\hline Target capital expenditure for wastewater services \\
\hline Legality accountability \\
\hline Compliance with the Resource Management Act 1991 \\
\hline Compliance with the Health Act 1956 \\
\hline Process/efficiency accountability \\
\hline Actual operating expenditure and actual quantity \\
\hline Performance/programmel effectiveness accountability \\
\hline $\begin{array}{l}\text { Performance measure (actual and target) about compliance with resource consent } \\
\text { conditions }\end{array}$ \\
\hline $\begin{array}{l}\text { Performance measure (actual and target) about compliance with resource consent } \\
\text { conditions by plants or consent types }\end{array}$ \\
\hline Performance measure (actual and target) reliability of the service \\
\hline Performance measure (actual and target) reliability of the service \\
\hline $\begin{array}{l}\text { Performance measure (actual and target) response time to } \\
\text { blockages/overflows/accidental discharges that occurred }\end{array}$ \\
\hline $\begin{array}{l}\text { Performance measure (actual and target) response time to } \\
\text { blockages/overflows/accidental discharges that occurred }\end{array}$ \\
\hline Actual and target project \\
\hline Actual project achievement by sites \\
\hline
\end{tabular}

Probity accountability items are cost disclosures relating to actual operating expenditure, target operating expenditure, actual capital expenditure, and target expenditure for wastewater services. Funds can be spent on both operating expenditures and capital expenditure. To facilitate the assessment of whether funds were spent as planned, the actual and the target expenditures of operating expenditure and capital expenditure were included. There are four items in this category. 
Legality accountability items relate to compliance with the Resource Management Act 1991 and the Health Act 1956 (the two primary pieces of legislation governing wastewater services of local authorities). The item relating to the Resource Management Act 1991 is about compliance with the resource consent conditions. The item relating to the Health Act 1991 is about reliability of the services (for example, occurrence of blockages/overflows is none) or the time response to incidents (for example, response to blockages, made within one hour). There are two items in this category - one for each Act.

Process/efficiency accountability item requires the presence of both actual operating expenditure and actual quantity. From best practice, an efficiency ratio is not provided. There is one item for this category.

Performance/programmel effectiveness accountability items are performance measures (with actual achievements and targets) relating to compliance with the resource consent conditions; reliability of wastewater service; and response time to incidents. Details by plants or consent types for compliance with the resource consent conditions, and the addition of a performance measure relating to reliability and response time are also included. Information about actual achievements and targets of the project and details of the project achievement (such as by sites) are also included. Note that targets used are required to be clear - quantitatively measurable (Alves, et al., 2005; Pendlebury, et al., 1994). There are eight items in this category. 
As discussed above, there are total of 15 items for the $\mathrm{AE}$ index across four categories: four items for probity, two for legality, one for process/efficiency, eight for performance/programme/ effectiveness accountability.

\subsubsection{Weights determination}

Some studies weigh their disclosure items and some do not. In this study, the items of both indices were not weighted. The disclosures are reported to the public at large, which comprises diverse interest groups. It is expected that different people will assign different weights to the items (Cooke, 1989). To assign weight without empirical support might impact on the validity of the results. Non-weighting is chosen as the most conservative way to avoid bias created through instrumentation.

Different disclosure items may have varying levels of importance for users of entities' annual reports and, in order to recognise these different levels of importance, the index items may be weighted appropriately (Marston \& Shrives, 1991). Typically, different levels of importance accorded to index items by users are identified by conducting an attitude survey among relevant user groups (Marston \& Shrives, 1991). For example, Schneider and Samkin (2008), Buzby (1975), Robbins and Austin (1986), Taylor and Rosair (2000) assigned weights to their index items based on the average weight score derived from survey responses. Adopting a different stance, Coy, et al. (1994) and Smith and Coy (2000) assigned weights on a 3-point scale based on their perception of the relative importance of the index items. Their weighting system was adopted by Bank and Nelson (1994); Coy, et al. (1994), Banks, et al. (1997), Fischer, et al. 
(1996), Nelson, et al. (1997), Ryan, Stanley, et al. (2002), Smith and Coy (2000), and Tooley and Guthrie (2001). However, Cooke (1989) argued that different groups in, or segments of, the wider public are likely to accord different levels of importance to different disclosure items, and their varying opinions are likely to average each other out. As a result, the index items included could be regarded as of equal importance; hence, weighting of the index items would not be necessary. Arguably, by not weighting, an item could be biased for giving equal weight to items that are not of equal importance (Wei, et al., 2008). By weighting or not weighting the index items, certain degree of subjectivity is involved. However, weighting items can run more risk of subjectivity due to the involvement of more parties.

\subsubsection{Scoring development}

The final step of index development is to decide on the scoring of items in the index. The simplest form of scoring for evaluating the index item is dichotomous scoring - to score as 1 if present; 0 if absent. Such scoring is unweighted and has been used in various studies, for example, by Clarkson, et al. (2008), Williams (2001), and Cooke (1989). Williams (2001) points out that this dichotomous method avoids "potential issues of subjectivity that tend to arise when a weighted scoring is applied" (p. 196).

Some researchers have developed a wider range of scale beyond dichotomous scoring as the scoring criteria may be more complicated and abstract. For example, quantitative information may be scored most highly (say with 4), with progressively lower scores being assigned to qualitative or descriptive information 
(for example, 3), vague/obscure information (2), the absence of relevant disclosures (1) and the absence of any information (0). Wiseman (1982), Hughes, et al. (2001), Bozzolan, et al. (2006) and Schneider and Samkin (2008) have each used such a system. However, the criteria are questionable for their subjectivity as to why quantitative information is more important than qualitative information. Bozzolan, et al. (2006) argues that this way of scoring (scaling) can be seen as another kind of weighting, based on the type of measure (qualitative vs quantitative) associated with the information disclosed.

In this research, dichotomous scoring is used to avoid any possible bias (Williams, 2001). A score of 1 is assigned to an item if it is present in the disclosure. A score of 0 is assigned if the item is absent in the disclosure. Some AR index items, relating to explanation of significant variance, if any, and the explanation of technical terms, if any, may not be relevant and are allocated as N/A (missing). In the case of explaining significant variance, if any, there may not be any variance, or the variances incurred are not significant. In the case of explanation of technical terms, if any, there may not be any technical term disclosed. Therefore, the most conservative way of treating this item is to not assign any score. For AE index items, all items can be assigned a score of 1 or 0 as there is no 'if any' item.

After scores were assigned to each item, to calculate an entity's index the scores are multiplied by weight, if any, for each item of an entity. The weighted (or unweighted) scores for all items are then aggregated to obtain a total index score for an entity (Boyne \& Law, 1991; Clarkson, et al., 2008; Coy, et al., 1994; 
Hughes, et al., 2001; Ryan, Stanley, et al., 2002; Schneider \& Samkin, 2008; Smith \& Coy, 2000; Stanley, et al., 2008; Wiseman, 1982). Alternatively, an index could be expressed in terms of a percentage of the total maximum score (Bozzolan, et al., 2006; Coy, et al., 1994; Robbins \& Austin, 1986). Buzby (1975) and Cooke (1989) took a slightly different angle by dividing the total aggregated scores with the scores expected to be earned for a given entity, rather than the maximum possible score, as some items of disclosure were not relevant to the entity and, consequently, the entity should not be penalised for its nondisclosure of an item that was not relevant.

In this study, for each local authority, the scores assigned for all the items are first aggregated. The aggregated scores were then divided by a maximum score for the council to form a percentage score (an index). For the AE index, the maximum score for each council is 15 corresponding to 15 items. However, for the AR index, the maximum score across councils varies according to the number of relevant items, for which a score (of 1 or 0 ) can be assigned. By dividing by a council's maximum possible score (AR index), an authority is not penalised for non-disclosure of those items not relevant to its situation (Buzby, 1975; Cooke, 1989). Authorities with a high percentage index score indicate a high consistency or correspondence of disclosure with the authoritative requirements (AR index) and the accountability expectation (AE index).

The AR and AE indices can be ranked cross-sectionally; however, they cannot identify the degree of difference. A disclosure index (whether weighted or nonweighted) achieves an ordinal measurement, but is unlikely to achieve an interval 
measurement (Beatie, et al., 2004; Coy, et al., 1994; Marston \& Shrives, 1991). This means that an item rated as a 4 is deemed to be better than that with 1 , but not necessarily four times better than an item rated 1 (Coy, et al., 1994; Marston \& Shrives, 1991).

\subsection{Independent variables for multiple regression analysis}

Corresponding to the incentives and their influential factors applicable for wastewater disclosures, as discussed in chapter 4 , five independent variables population, median income of constituents, number of staff, revenue and total assets - are used to test their association with the disclosure indices (AR and $\mathrm{AE}$ indices). These independent variables were chosen, based on prior research and their accessibility in the New Zealand local government context. Table 5.3 provides a summary of the empirical results of the multiple regression analysis between the disclosure index and independent variables, which derived from the same basis as the study's influential factors (political competition, size of constituents, sophistication of constituents, staff availability, staff attributes, financial resources availability, and political visibility), as discussed in chapter 4 . 
Table 5.3: Summary of empirical results of influential factors affecting disclosures

\begin{tabular}{|c|c|c|c|c|c|c|c|c|c|c|c|c|c|c|c|}
\hline $\begin{array}{l}\text { Influential factors and } \\
\text { Independent variables }\end{array}$ & $\begin{array}{l}\text { Singhvi } \\
\text { \&Desai } \\
(1971)\end{array}$ & $\begin{array}{l}\text { Buzby } \\
(1975)\end{array}$ & $\begin{array}{l}\text { Baber } \\
(1983)\end{array}$ & \begin{tabular}{|l|} 
Baber\& \\
Sen \\
$(1984)$ \\
\end{tabular} & $\begin{array}{l}\text { Ingram } \\
(1984)\end{array}$ & $\begin{array}{l}\text { Robbins\& } \\
\text { Austin } \\
(1986) \\
\end{array}$ & \begin{tabular}{|l|} 
Evan\& \\
Patton \\
$(1987)$ \\
\end{tabular} & $\begin{array}{l}\text { Ingram\& } \\
\text { DeJong } \\
(1987) \\
\end{array}$ & $\begin{array}{l}\text { Giroux } \\
(1989)\end{array}$ & $\begin{array}{l}\text { Cooke } \\
(1989)\end{array}$ & \begin{tabular}{|l|} 
Boyne \& \\
Law \\
$(1991)$ \\
\end{tabular} & $\begin{array}{l}\text { Lim\& } \\
\text { McKinnon } \\
(1993) \\
\end{array}$ & \begin{tabular}{|l|} 
Christiaens \\
$(1999)$
\end{tabular} & $\begin{array}{l}\text { Lasward } \\
\text { et al. } \\
(2005)\end{array}$ & $\begin{array}{l}\text { Bozzolan } \\
\text { et al. } \\
(2006)\end{array}$ \\
\hline \multicolumn{16}{|l|}{ Political competition } \\
\hline Percentage vote of minority party & & & + Sig & + Sig & + Sig & & & & Not Sig & & & & & & \\
\hline Ratio of candidates to position & & & & & & & & & & & & & & Not Sig & \\
\hline \multicolumn{16}{|l|}{ Size of constituents } \\
\hline Population & & & + Sig & & Not Sig & Not Sig & Not Sig & + Sig & & & & & + Sig & & \\
\hline \multicolumn{16}{|l|}{ Sophistication of constituents } \\
\hline Median income & & & & & Not Sig & Not Sig & & & & & & & & & \\
\hline \multicolumn{16}{|l|}{ Staff availability } \\
\hline No. of staff* & & & & & & & & & & & Not Sig & & + Sig & & \\
\hline \multicolumn{16}{|l|}{ Staff attributes } \\
\hline Appointed by governor & & & & & + Sig & & & & & & & & & & \\
\hline Level of education & & & & & & & & & & & & & Not Sig & & \\
\hline Having training per & & & & & & & & & & & & & + Sig & & \\
\hline Having business experience & & & & & & & & & & & & & Not Sig & & \\
\hline Revenue* & & & & & & & & & & + Sig & & & & & $+\mathrm{Sig}$ \\
\hline Total assets* & $+\mathrm{Sig}$ & $+\mathrm{Sig}$ & & & & & & & & + Sig & & & & & $+\mathrm{Sig}$ \\
\hline \multicolumn{16}{|l|}{ Political visibility } \\
\hline Revenue* & & & & & & & & & & & & + Sig & & & \\
\hline Total assets* & & & & & & & & & & & & $+\mathrm{Sig}$ & & & \\
\hline No. of staff* & & & & & & & & & & & & + Sig & & & \\
\hline $\begin{array}{l}\text { No. of pages an } \\
\text { authority is cited in the } \\
\text { Hansard Report }\end{array}$ & & & & & & & & & & & & + Sig & & & \\
\hline
\end{tabular}

*This independent variable is repeated under other influential factors.

+ Sig and Not Sig indicate positively significant relationship and insignificant relationship, respectively, based on $\mathrm{p}<.05$ 
'Percentage vote of minority party' is a popular variable used to proxy political competition and found mostly to be positively significant to the disclosure in US public-sector studies (Baber, 1983; Baber \& Sen, 1984; Giroux, 1989; Ingram, 1984). This percentage vote of minority party variable is suitable in a jurisdiction where there are only a few minority parties to which candidates can belong. However, it is not applicable in New Zealand local government elections, where candidates are independent of political parties. Further, there are a number of candidates running for various positions. Therefore, percentage vote of minority individuals may exceed the percentage vote of winning candidates. Laswad, et al. (2005) used 'number of candidates' to 'positions available' and found an insignificant relationship with the internet disclosure by a New Zealand local government study. However, this variable may not be an effective proxy for political competition and, hence, may explain the Laswad, et al. (2005) result. A local authority with a smaller number of candidates to positions available may have stronger political competition than that of a larger number of candidates to positions available. Therefore, this variable is not considered in this study. Given New Zealand's unique local government setting, a variable that is suitable for representing the level of political competition needs further development.

Population is a typical variable used to proxy size of constituents by public-sector studies. However, the relationship between population and disclosures is inconsistent across studies (Baber, 1983; Christiaens, 1999; Evan \& Patton, 1987; Ingram, 1984; Robbins \& Austin, 1986). This may be due to the fact that the population in some jurisdictions may be more aggressive in maximising its share 
of benefits from tax money and therefore forms groups of shared interests that seek/pursue/lobby for specific service benefits.

Median school years of constituents and median income of constituents are used to proxy constituency sophistication (Ingram, 1984; Robbins \& Austin, 1986). However, the information about median school years of constituents in each local authority in New Zealand is not accessible. Hence, median income of constituents is used as an independent variable for sophistication of constituents in this study.

In terms of measuring staff availability, Boyne and Law (1991) used number of staff within the authorities, while Christiaens (1999) specifically used number of 'accounting' staff who can potentially prepare reports. Although the number of 'accounting' staff is more likely to be varied proportionately with the number of an authority's staff, Boyne and Law's (1991) and Christiaens' (1999) results are contradictory. The number of 'accounting' staff seems to be more closely related to local authority's capability of preparing SSPs. However, owing to the accessibility of the information, this research uses number of staff of an authority.

Personal attributes of accounting staff can be proxied by a number of variables. Ingram (1984) uses a selection process of recruiting accounting staff (elected, appointed by legislature, jointly appointed by governor and legislature, or appointed by governor), which is thought to proxy personal attributes of the accounting staff. A governor is more able to select well-experienced staff who are more capable of providing rigorous reports (Ingram, 1984). Ingram (1984) found a significant relationship between appointed staff by a governor and the extent of disclosure. Arguably, this variable is a weak proxy to staff's personal attributes, 
as a governor can be biased in his/her selection. However, in New Zealand the selection of accounting system administrators (as well as other staff) is only through appointment by the chief executive. Therefore, this proxy is not applicable in the New Zealand local government context or this study.

Personal attributes of accounting staff can also be proxied by the level of the accounting staff's education, whether or not accounting staff have training via other accounting staff and business experience (Christiaens, 1999). Christiaens (1999) found that only having training experience is positively associated with the disclosure. In spite of the merit of Christiaens' (1999) variable to proxy staff's personal attributes, the information regarding these attributes is not accessible in New Zealand.

Revenue and/or total assets are widely used to proxy the availability of firms' financial resources and are commonly found to be significantly and positively associated with the extent of disclosures (Bozzolan, et al., 2006; Buzby, 1975; Cooke, 1989; Singhvi \& Desai, 1971). In spite of this research being based on corporate entities, the revenue and total assets offered valid comparisons for local authorities in New Zealand. It is possible that wealthier authorities will have financial resources to provide the necessary support (effective information management systems) for collecting data for SSP reporting.

A number of variables can be used to proxy political visibility. Revenue and total assets are two possible variables (Lim \& McKinnon, 1993). Each of them has different links to political visibility. The total assets give a measure of total resources that an authority controls, and mirrors the monopoly position occupied 
by an authority. Revenue provides a measure of the number of customers who may criticise the authority for its services (Lim \& McKinnon, 1993).

Lim and McKinnon (1993) also use 'number of staff' as one proxy for political visibility. They argue that the larger the number of employees or staff a local authority has, the greater the possibility that the authority will be politically visible to unions and may be subject to political costs imposed by employees. This argument can also apply in New Zealand local government.

Lim and McKinnon (1993) also use number of pages in the Hansard Report as a proxy for political visibility. The occurrence of issues about statutory authorities in parliamentary debates can reflect political visibility. However, this method is not seen as an appropriate method to measure political visibility of the New Zealand local government, as many issues are settled locally before they reach Parliament. The Ministry for the Environment (2009) surveyed resource management of local authorities 2007/2008, and found that approximately 45 percent of detected instances of non-compliance with resource consent conditions under the Resource Management Act 1991 were resolved by informal means; 54 percent were resolved by formal means (such as by abatement notices, infringement notices, prosecution, enforcement orders). Therefore, it is less likely that much evidence will be found in the Hansard Report concerning local authorities' wastewater issues in New Zealand.

The above discussion identifies the variables of influential factors used in the study - population, constituents' median income, number of staff, revenue, and total assets as independent variables in this study. Some variables can proxy for 
more than one influential factor. 'Number of staff' can proxy both staff availability and political visibility. Revenue and total assets can proxy for both financial resources availability and political visibility. Population and median income of constituents individually represents the size of constituents and constituency sophistication, respectively. Table 5.4 extends Table 4.2 with the inclusion of the variables used in this study to proxy their influential factors for wastewater disclosures.

Table 5.4: Variables used to proxy influential factors for wastewater disclosures

\begin{tabular}{|l|l|l|}
\hline \multicolumn{1}{|c|}{$\begin{array}{c}\text { Disclosure } \\
\text { incentives }\end{array}$} & \multicolumn{1}{c|}{ Influential factors } & \multicolumn{1}{c|}{ Variables } \\
\hline $\begin{array}{l}\text { Public's demand for } \\
\text { SSP disclosures }\end{array}$ & $\begin{array}{l}\text { - Political competition } \\
\text { - Size of constituency } \\
\text { - Constituency } \\
\text { sophistication }\end{array}$ & $\begin{array}{l}\text { - Not accessible } \\
\text { - Population } \\
\text { - Median income }\end{array}$ \\
\hline $\begin{array}{l}\text { Local authority's } \\
\text { awareness of political cost }\end{array}$ & - Political visibility & $\begin{array}{l}\text { - Revenue } \\
\text { - Total assets }\end{array}$ \\
\hline $\begin{array}{l}\text { Local authority's } \\
\text { capability }\end{array}$ & $\begin{array}{l}\text { - No of staff } \\
\text { - Staff availability } \\
\text { - Personal attributes of } \\
\text { accounting staff } \\
\text { - Financial resource } \\
\text { availability }\end{array}$ & $\begin{array}{l}\text { - No of staff } \\
\text { - Not accessible }\end{array}$ \\
\hline
\end{tabular}

\subsection{Data sources and collection}

The 2007/2008 annual reports have been selected for this study as they represent the first year that local authorities had to comply with the New Zealand Equivalent to International Financial Reporting Standards (NZ IFRS). Since all territorial authorities in New Zealand operate wastewater activities, all 73 city/district councils' wastewater disclosures within the annual report were 
collected. Most councils provide their annual reports on their websites, from which the wastewater disclosures of SSPs and audit reports were printed out. Those who did not provide annual reports on websites were sent email requests, and in due course they forwarded hard copies of annual reports. The audit reports in annual reports were collected for an analysis of reliability of the information as one of the AR index items.

The data of independent variables were collected from the websites by Local Government New Zealand and Statistics New Zealand, as presented in Appendix A. Table 5.5 lists the independent variables and the data sources.

Table 5.5: Independent variables and the data sources

\begin{tabular}{|l|l|}
\hline \multicolumn{1}{|c|}{ Independent variables } & \multicolumn{1}{c|}{ Data source } \\
\hline Revenues & Statistics New Zealand website \\
Total assets & Statistics New Zealand website \\
Population & Statistics New Zealand website \\
Number of staff & The Department of Internal Affairs website \\
Median income of constituents & The Department of Internal Affairs website \\
\hline
\end{tabular}

Where the data regarding total operating revenue, total assets, population were collected from the Statistics New Zealand website, the 'number of staff' and 'median income' was from the Department of Internal Affairs website. Revenues are operating revenues of local authorities, which include rates, regulatory income, all government grants and subsidies received, investment income, and sales of goods and services, and all other income for the year ended 30 June 
$2008 .^{60}$ Total assets of local authorities include cash and bank deposits, other current assets, land and buildings, other construction, other fixed assets, investment, and other non-current assets as at 30 June 2008. 'Population' is estimated resident population, as at 30 June 2008. Number of staff and median income of constituents were based on 2004 and 2006 years, as they were the latest updates by the Department of Internal Affairs at the time of data collection in early 2009. (See Appendix A for the data of these variables.)

\subsection{Summary}

This chapter has outlined the use of index for measuring the consistency of wastewater disclosures with authoritative requirements and accountability expectations, and the use of multiple regression analysis for investigating the association of influential factors with SSPs. The items for both disclosures indices - Authoritative Requirement index and Accountability Expectation index - were identified. For the AR index, there were 64 items across four categories while AE index items comprised 15 items across four categories. The items for both indices were assigned dichotomous scoring without any weighting. The total index score was then presented as a percentage of the total possible maximum score. The independent variables for multiple regression analysis used in this study are operating revenue, total assets, population, number of staff, and median income per capita. The results of indices and multiple regression analysis will be provided in the following chapters.

\footnotetext{
${ }^{60}$ Statistics NZ uses the term 'income' which, in accounting point of view, is considered to be revenue.
} 


\section{Chapter 6: Results and Discussion of the Extent of Disclosures}

\subsection{Introduction}

This chapter will discuss the results from the measurement of the consistency of wastewater disclosures with authoritative requirements and accountability expectations. Section 6.2 outlines the findings regarding the form and content of statements of service performance. Section 6.3 discusses results of the Authoritative Requirement index, while section 6.4 discusses results of the Accountability Expectation index as measures of the extent of disclosures. Section 6.5 provides a comparison of the two indices, and section 6.6 summarises the overall results.

\subsection{Form and content of wastewater disclosures}

Title of the statement: No uniform title is used for SSPs, which disclose wastewater services, across territorial authorities, while they did all present the service performance information in a separate section in their annual reports. Although the majority of authorities (17) use the heading 'statement of service performance', some authorities title it under various different headings, such as 'significant activity statement', 'group of activities', 'infrastructure,' or 'water service group.'

Presently, four territorial authorities outsource their wastewater services, as discussed in chapter 2. However, those authorities use different titles for the service performance information for disclosing their wastewater services. Two territorial authorities (Auckland CC and Manukau CC) use the titles 'council 
organisation' and 'council family', as their council controlled organisations (Metrowater Ltd and Manukau Water Ltd, respectively) operate their wastewater services. However, two other authorities (Papakura DC and Wellington CC) which contract a company (United Water International Pty Ltd) to run their wastewater services, report on their wastewater services performance under the titles 'statement of service performance' and 'environment' respectively.

Title of wastewater services: Within SSPs or other titles, wastewater services are referred to by various names but mostly: wastewater (53 authorities) and sewerage (13), sanitary (1), and sewage (1).

Wastewater section: Twelve authorities ${ }^{61}$ combine wastewater services with other services, such as stormwater, water supply, solid waste, and/or roading and use aggregated headings such as 'water wastewater stormwater and roading', 'wastewater services', 'infrastructure.' Regardless of the different headings and aggregation, wastewater service performance information typically comprises three parts: narrative introduction, performance measures, and financial information. The narrative introduction includes the service's objectives, introductory factual description, and outcomes influenced by the service. While the majority of authorities specify their objectives for the service, 22 authorities did not. Objectives given mostly concern the promotion of community health and/or the natural environment.

Performance measures are commonly used and presented with actual results, targets, and past performance information. The number of performance measures

${ }^{61}$ They are Buller DC, Central Otago DC, Far North DC, Gore DC, Kaikoura DC, Selwyn DC, South Taranaki, Wellington CC, Whakatane DC, Whangarei DC, Auckland CC, and Manukau CC. 
for the service varies from two to thirteen. Note that there is no generic term for performance measures used, which is consistent with Rutherford (2000). Some authorities use 'performance indicator,' or 'what we measure.'

Wastewater financial information is provided by almost all authorities (except Hamilton CC). It is mostly reported under the title of 'statement of cost of service', 'infrastructure service statement', or 'activity cost'. However, ten authorities $^{62}$ did not have a title for their financial information as opposed to service performance information. The financial information generally contains revenue, operating expenses (expenditure), and capital cost of the service under three periods (actual, target, and past). Many authorities (53 authorities) also report on cost of projects progressed during the year.

Most authorities use tables to disclose performance measures and financial information. However, some tables are not in normal format with a heading in each column. Two local authorities ${ }^{63}$ combine actual and target performance in one column. Two authorities ${ }^{64}$ use sideways (horizontal) tables to present their performance measures, placing headings in the first column of the table. Eight authorities ${ }^{65}$ do not provide tables for performance measures and three ${ }^{66}$ present instead their performance measures in graphs. One local council (Tasman DC)

\footnotetext{
${ }^{62}$ They are South Wairarapa DC, Buller DC, Waitaki DC, Chatham Island Council, Nelson CC, Hamilton CC, Kaipara DC, Thames-Coromandel DC, Wanganui DC, and Tasman DC.

${ }^{63}$ They are Gore DC, Stratford DC.

${ }^{64}$ They are Palmerston North CC, Taupo DC.

${ }^{65}$ They are Clutha DC, Kawerau DC, North Shore DC, Queenstown-Lakes DC, South Taranaki DC, Waimate DC, Wanganui DC, and Wellington CC.

${ }^{66}$ They areNorth Shore DC, Wanganui DC, and Wellington CC.
} 
provides a table without headings. All 73 local authorities present their financial information in tables, but two of them ${ }^{67}$ present the table horizontally.

Overall, the form and content of service performance reporting, in particular for wastewater disclosures, differ greatly across authorities. This inconsistency of the form and content of performance information has been noted by other researchers (Alves, et al., 2005; Rutherford, 2000) as well. Earlier researchers suggest that the diverse form and content may be due to the absence of specific instructions in guidance information (Rutherford, 2000). This explanation seems to provide a valid reason for the differing form and content of SSPs in New Zealand.

\subsection{Authoritative requirement index}

\subsubsection{AR index by items}

The results of AR index scores for each item and category are provided in Table 6.1 .

The mean scores of items relating to quantity of wastewater are low. Actual quantity items have the highest mean score of 23.77 percent. The mean score of target quantity is close to zero -1.37 percent. The mean score of past quantity is also near zero -0.93 percent. This result is due to the fact that quantity of wastewater is mostly disclosed in terms of its actual capacity in the descriptive introduction. Only two authorities ${ }^{68}$ express the items in terms of performance measures, comparing actual with targeted quantity. Only one authority ${ }^{69}$ of the

\footnotetext{
${ }^{67}$ They are Christchurch CC and Hurunui DC.

${ }^{68}$ They are Waipa DC and New Plymouth DC.

${ }^{69}$ It is Waipa DC.
} 
two authorities reports about the past quantity of wastewater collection and treatment. The low score of quantity items is consistent with Boyne and Law's (1991) result. Lee (2008) surveyed the perception of Australians on performance information in Australian government agencies, and found that quantity is not regarded as an important disclosure item.

The items relating to quality of wastewater have relatively high mean scores. Actual and target quality of wastewater have mean scores of 72.17 percent and 63.93 percent respectively. The mean score of explanation of significant variance of quality items is also relatively high -62.79 percent. On the contrary, past quality had the lowest mean score of 14.13 percent. The quality items are expressed in performance measures, comparing actual quality with targets. Most variances incurred were not significant but few authorities who incurred significant variances were able to provide an explanation. Performance measure on standard to be met is the most popular quality measure, followed by reliability of wastewater services and customer satisfaction. This result relates to Lee (2006), who found that the water service's quality measures were relatively highly reported by water enterprises in Australia. However, Boyne and Law (1991) found little disclosure about these items.

The items relating to location of wastewater have low mean scores. Actual location of wastewater shows a mean score of 45.3 percent, while target location has a mean score of 8.7 percent. Explanation of significant variance of location has a mean score of 100 percent as only two authorities incurred changes and provided the explanation. It is difficult to quantitatively determine if the change 
of location is significant. In this study it is assumed that any change in location is considered significant. Past location is not disclosed, so had a mean score of zero. Similar to quantity, location was mostly addressed in the descriptive introduction. Location of wastewater treatment (plant) was the most popular item compared to location of wastewater collection and disposal as the names of wastewater treatment plants indicate the locations.

The low score of location may be due to the fact that location of a wastewater system is intuitively known. TPA-9 (para 5.35) describes location in SSPs, as follows: "Frequently location is implicit and does not need to be stated explicitly.....for services such as health, education, border control or regional development, location is likely to be an important factor" (page 37). Since wastewater service is not a health service, disclosing its location is deemed to be less important.

The mean scores of items relating to time are relatively low. Actual and target time items have similar mean scores of 27.2 percent and 27.37 percent. Explanation of significant variance of time has a mean score of 62.5 percent, given few authorities who incurred significant variance. The item past time has a mean score near to zero -1.83 percent. The analysis identifies that the time items are expressed in terms of performance measures, however they fluctuate widely. Time response to incidents had most disclosures (around 60 percent for both actual and target) while the time of service availability items are few (around 13 percent) and time compliance with milestones is almost none. However, Lee (2006) found that timeliness of service (time response to incidents) was not highly 
reported by water enterprises in Australia. Boyne and Law (1991) found disclosure about timeliness of service was almost non-existent by Welsh district authorities in the United Kingdom.

The mean scores of items relating to cost are consistently high. The cost of wastewater is mostly disclosed - 94.5 percent for actual cost, 93.2 percent for target cost, and 91.8 percent for past cost, followed by cost by direct/indirect cost (around 40 percent) and cost by wastewater system (approximately 20 percent). ${ }^{70}$ The mean score of explanation of significant variance is relatively low -31.58 percent, given a number of authorities incurred significant variance.

Cost appears to be the most popular dimension of output. This result is consistent with Herawaty and Hoque (2007), and Kloot (2009) who found that cost information was well reported as part of the performance reporting by Australian public-sector entities. Similarly, Boyne and Law (1991) found that cost information was highly reported by Welsh district authorities in the United Kingdom. Lee (2008) found that Australian government entities perceived cost information as highly important and reported on it. This may be due to the fact that local authorities must provide financial information (Lee, 2008). However, while cost items are often reported, explanation for significant variance is scant. This contradicts Lee $(2006,2008)$, who found that narrative analysis of financial performance was perceived as relatively important and was well reported. The absence of explanation for significant variance, as there is, indicates non-

\footnotetext{
${ }^{70}$ Although some authorities aggregate wastewater cost with other activities (such as stormwater and water supply), the score of ' 1 ' is assigned to the aggregated cost item. It appears that by some means wastewater costs are provided for.
} 
compliance with the Schedule 10, Part $3(15(\mathrm{e}))$ of the Local Government Act 2002.

From the results discussed above, it can be seen that relevance items (disclosures about actual dimensions) fluctuate across the dimensions - high on quality and cost, and low for other dimensions (quantity, location, time). Similarly, comparability items relating to target quality and cost dimensions are disclosed more than other dimensions. However, past items are only popular for cost dimension while those of other dimensions are almost none. Explanation of significant variance of cost is far less mature than are other items.

The item understandability has a moderately high mean score of 62.4 percent. Both separate headings and visual aids have the same score ( 83.6 percent). The aggregation of wastewater services with other services necessitates extra effort to identify the disclosure for wastewater services. Such aggregation also raises a concern about the reduced decision-usefulness of the disclosures by Smith and Coy (2000). Thus, a score of ' 0 'is assigned for a separate heading item for those authorities which aggregate wastewater disclosures with others. Most of the authorities are able to provide visual aids (tables or graphs) regardless of the format. The score for explanation of technical terms is reasonably low (20 percent). Most authorities (68) do not use technical terms; however, of those (5) which used them, only one provided explanations. ${ }^{71}$ These results are slightly higher than those of Stanley, Jennings and Mack (2008) who looked at the format

\footnotetext{
${ }^{71}$ New Plymouth DC, Rangitikei DC, Upper Hutt CC, Waimakariri DC, Waitakere CC are the authorities which used technical terms, but Upper Hutt CC is the only one which provided an explanation of the technical terms used.
} 
and the provision of technical jargon in community financial reports by Queensland local authorities, and found the score slightly above half.

Reliability has a score of 100 percent. All authorities were issued an unqualified audit opinion for 2007/2008 service performance information - "service provision information presents fairly". Thus, wastewater disclosures are regarded as unqualified, and would be awarded a full score (1) for the reliability item.

In short, given the varying fluctuation of item sores, the results seem to indicate that local authorities may have some difficulty expressing (non-financial) dimensions to meet comparability characteristics. This supports the OAG (2008) and Webster's (2007) criticism on the authoritative requirements being focused on financial reports of private-sector entities and pitched at higher or more conceptual level. This may be due to the fact that the authoritative requirements were developed based on the economic framework highlighting the decisionusefulness purpose of private-sector reporting, which is not suitable for publicsector reporting (Mack, 2003; Parker \& Gould, 1999).

While cost is well reported, however the explanation of significant variance of cost is not. This indicates the non-compliance with the statutory requirement, and which was not addressed in the audit report. This raises the concern not only on the local authorities' reporting but also the audit report in providing insightful understanding whether the statutory reporting requirements is being followed. 
Table 6.1: AR index scores by categories and items

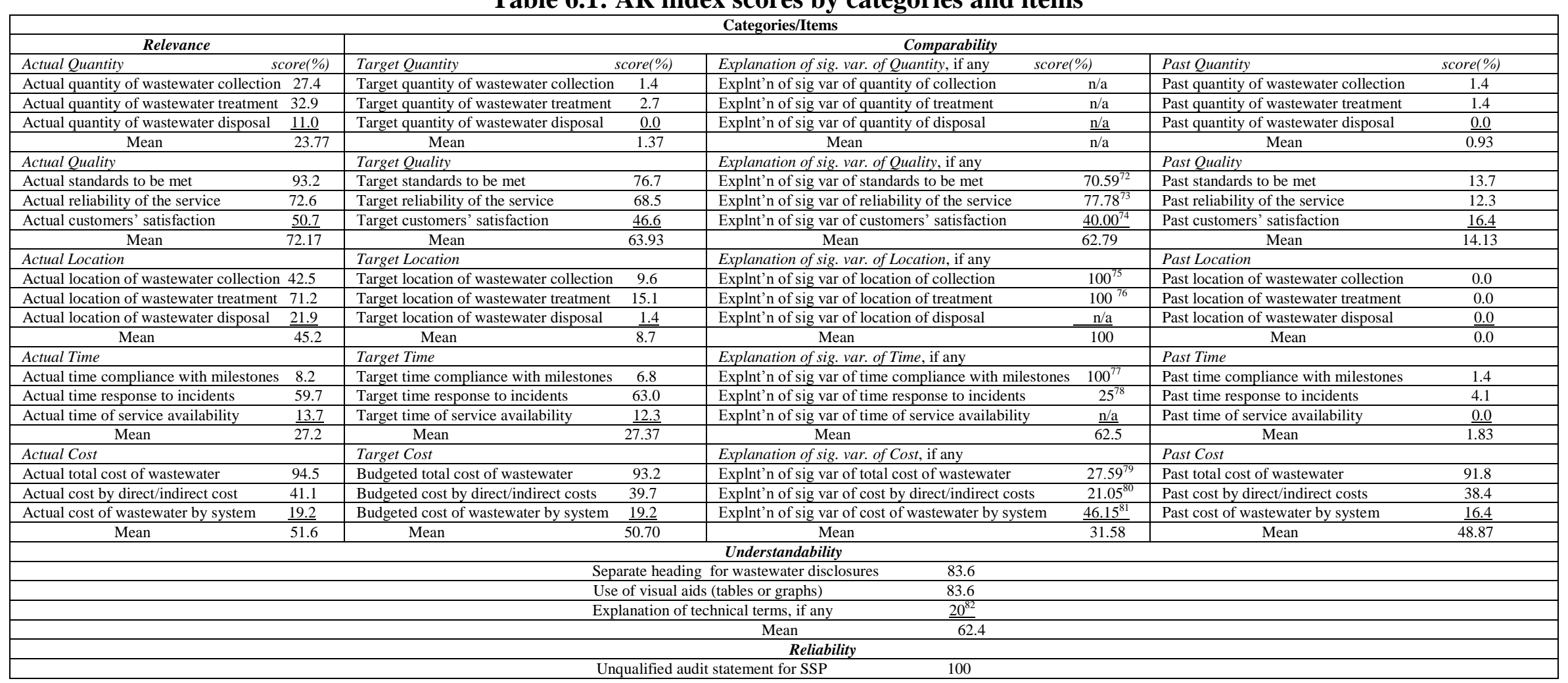

${ }^{72}$ This item is applicable for 17 authorities who incur significant variances. ${ }^{74} \mathrm{This}$ item is applicable for 5 authorities who incur significicant variances. ${ }^{75}$ This item is applicable for 2 authorities who incur significant variances. ${ }^{77}$ This item is applicable for 2 authorities who incur significant variances. ${ }^{78}$ This item is applicable for 5 authorities who incur significant variances. 79 This item is applicable for 29 authorities who incur significant variances ${ }^{30}$ This item is applicable for 19 authorities who incur significant variances. ${ }_{81}^{81}$ This item is applicable for 13 authorities who incur significant variance.

This item is applicable for five authorities which used technical terms. 


\subsubsection{AR Index by local authorities}

This section discusses the AR index scores of the local authorities. Table 6.2 presents the index score by local authorities in descending order, from highest to lowest.

Table 6.2: AR index scores by local authorities

\begin{tabular}{|r|l|c|}
\hline & \multicolumn{1}{|c|}{ Local Authorities } & $\begin{array}{c}\text { AR } \\
\text { index }\end{array}$ \\
\hline 1 & Waipa DC & $55 \%$ \\
\hline 2 & Tauranga CC & $50 \%$ \\
\hline 3 & Grey DC & $47 \%$ \\
\hline 4 & New Plymouth DC & $44 \%$ \\
\hline 5 & South Wairarapa DC & $44 \%$ \\
\hline 6 & Hamilton CC & $43 \%$ \\
\hline 7 & Masterton DC & $43 \%$ \\
\hline 8 & Southland DC & $43 \%$ \\
\hline 9 & Kapiti Coast DC & $42 \%$ \\
\hline 10 & Thames-Coromandel DC & $41 \%$ \\
\hline 11 & Hutt CC & $40 \%$ \\
\hline 12 & Nelson CC & $40 \%$ \\
\hline 13 & Christchurch CC & $39 \%$ \\
\hline 14 & Western Bay of Plenty DC & $39 \%$ \\
\hline 15 & Tararua DC & $38 \%$ \\
\hline 16 & North Shore CC & $38 \%$ \\
\hline 17 & Rotorua DC & $38 \%$ \\
\hline 18 & Marlborough DC & $37 \%$ \\
\hline 19 & Porirua CC & $37 \%$ \\
\hline 20 & Timaru DC & $37 \%$ \\
\hline 21 & Ashburton DC & $36 \%$ \\
\hline 22 & Franklin DC & $36 \%$ \\
\hline 23 & Hauraki DC & $36 \%$ \\
\hline 24 & Ruapehu DC & $36 \%$ \\
\hline 25 & Stratford DC & $36 \%$ \\
\hline 26 & Clutha DC & $36 \%$ \\
\hline 27 & Far North DC & $35 \%$ \\
\hline 28 & Selwyn DC & $35 \%$ \\
\hline 29 & Napier CC & $35 \%$ \\
\hline 30 & Upper Hutt CC & $35 \%$ \\
\hline 31 & Gisborne DC & $35 \%$ \\
\hline 32 & Central Hawke's Bay DC & $34 \%$ \\
\hline 33 & Dunedin CC & $34 \%$ \\
\hline 34 & Waikato DC & $34 \%$ \\
\hline 35 & South Taranaki DC & $33 \%$ \\
\hline 36 & Waitakere CC & $33 \%$ \\
\hline 37 & Whakatane DC & \\
\hline & & \\
\hline
\end{tabular}

\begin{tabular}{|c|c|c|}
\hline & Local Authorities & $\begin{array}{c}\text { AR } \\
\text { index }\end{array}$ \\
\hline 38 & Buller DC & $33 \%$ \\
\hline 39 & Hastings DC & $33 \%$ \\
\hline 40 & Invercargill CC & $33 \%$ \\
\hline 41 & Mackenzie DC & $33 \%$ \\
\hline 42 & Manawatu DC & $33 \%$ \\
\hline 43 & Otorohanga DC & $33 \%$ \\
\hline 44 & Palmerston North CC & $33 \%$ \\
\hline 45 & Carterton DC & $32 \%$ \\
\hline 46 & Kaipara DC & $32 \%$ \\
\hline 47 & Matamata-Piako DC & $32 \%$ \\
\hline 48 & Westland DC & $32 \%$ \\
\hline 49 & Opotiki DC & $31 \%$ \\
\hline 50 & Queenstown-Lakes DC & $31 \%$ \\
\hline 51 & Rodney DC & $31 \%$ \\
\hline 52 & Waitaki DC & $31 \%$ \\
\hline 53 & Horowhenua DC & $31 \%$ \\
\hline 54 & South Waikato DC & $31 \%$ \\
\hline 55 & Tasman DC & $31 \%$ \\
\hline 56 & Wellington CC & $31 \%$ \\
\hline 57 & Rangitikei DC & $30 \%$ \\
\hline 58 & Waimakariri DC & $29 \%$ \\
\hline 59 & Chatham Island DC & $28 \%$ \\
\hline 60 & Wairoa DC & $28 \%$ \\
\hline 61 & Kaikoura DC & $27 \%$ \\
\hline 62 & Taupo DC (west) & $26 \%$ \\
\hline 63 & Wanganui DC & $26 \%$ \\
\hline 64 & Whangarei DC & $26 \%$ \\
\hline 65 & Gore DC & $26 \%$ \\
\hline 66 & Kawerau DC & $24 \%$ \\
\hline 67 & Waimate DC & $24 \%$ \\
\hline 68 & Waitomo DC & $24 \%$ \\
\hline 69 & Central Otago DC & $23 \%$ \\
\hline 70 & Hurunui DC & $18 \%$ \\
\hline 71 & Auckland CC & $16 \%$ \\
\hline 72 & Manukau CC & $12 \%$ \\
\hline \multirow[t]{2}{*}{73} & Papakura DC & $12 \%$ \\
\hline & Average & $33.33 \%$ \\
\hline
\end{tabular}

From Table 6.2, the average AR index score is relatively low -33.33 percent.

The highest score is 55 percent (Waipa DC), which is slightly over half the total 
score. Only two local authorities are scored above or equal to 50 percent. The lowest score is 12 percent (Manukau CC, and Papakura DC). A frequency distribution of the AR index is displayed in a Histogram, in Figure 6.1.

Figure 6.1: Histogram of the AR index

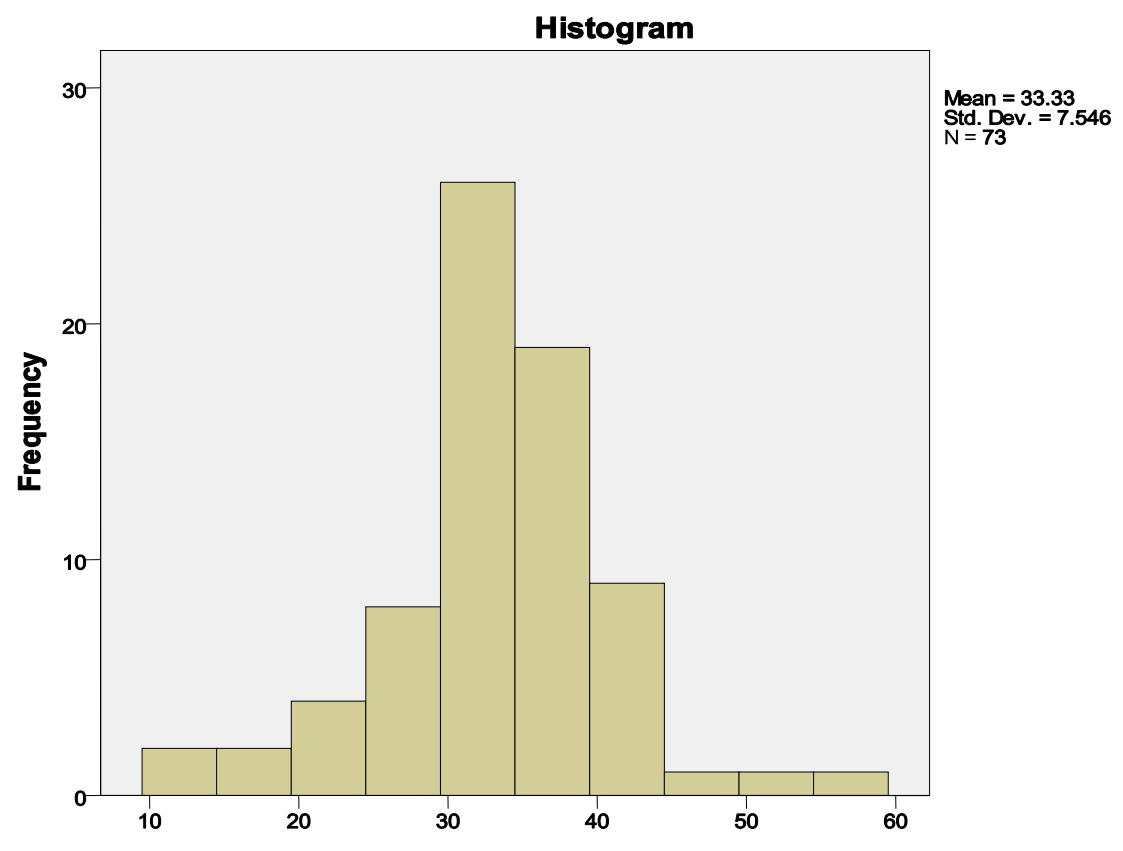

AR index scores

From Figure 6.1, it can be seen that very few (three) authorities scored above 45 percent. Most scores are clustered between 30-40 percent. The number of local authorities whose score below 30 drops sharply. The bottom (four) authorities' scores, which are the lowest group, range between 10-20 percent. Note that three authorities (Manukau CC, and Papakura DC, Auckland CC) of the lowest group outsourced their wastewater services. The distribution of the AR index is not normal. The Shapiro-Wilk normality test shows statistic of .961 $(\mathrm{p}=.023)$, which supports the conclusion that the AR index is not normally distributed. 
The scores by local authorities indicate a low level of correspondence of SSP disclosures with the authoritative requirements. This may be because of the unsuitability of authoritative requirements to evaluate SSPs, as discussed earlier.

\subsection{Accountability expectation index}

\subsubsection{AE index by items}

Table 6.3 provides index scores based on accountability expectations by items.

Table 6.3: AE index scores by categories and items

\begin{tabular}{|l|c|}
\hline \multicolumn{1}{|c|}{ Categories/Items } & $\begin{array}{c}\text { Scores } \\
(\%)\end{array}$ \\
\hline Probity accountability & \\
\hline Actual operating expenditure for wastewater services & 98.6 \\
\hline Target operating expenditure for wastewater services & 97.3 \\
\hline Actual capital expenditure for wastewater services & 84.9 \\
\hline Target capital expenditure for wastewater services & $\underline{84.9}$ \\
\hline \multicolumn{1}{|c|}{ Mean } & 91.4 \\
\hline Legality accountability & 93.2 \\
\hline Compliance with the Resource Management Act 1991 & $\underline{89.0}$ \\
\hline Compliance with the Health Act 1956 & 91.1 \\
\hline \multicolumn{1}{|c|}{ Mean } & 50.7 \\
\hline Process/efficiency accountability & \\
\hline Actual operating expenditure and actual quantity & 75.3 \\
\hline Performance/programme/effectiveness accountability & 12.3 \\
\hline $\begin{array}{l}\text { Performance measure (actual and target) about compliance with resource consent } \\
\text { conditions }\end{array}$ & 64.4 \\
\hline $\begin{array}{l}\text { Performance measure (actual and target) about compliance with resource consent } \\
\text { conditions by plants or consent types }\end{array}$ & 31.5 \\
\hline Performance measure (actual and target) reliability of the service & 57.5 \\
\hline Performance measure (actual and target) reliability of the service & 28.8 \\
\hline $\begin{array}{l}\text { Performance measure (actual and target) response time to } \\
\text { blockages/overflows/accidental discharges that occurred }\end{array}$ & 72.6 \\
\hline $\begin{array}{l}\text { Performance measure (actual and target) response time to } \\
\text { blockages/overflows/accidental discharges that occurred }\end{array}$ & 27.4 \\
\hline Actual and target project & 46.2 \\
\hline Actual project achievement by sites & \\
\hline & \\
\hline
\end{tabular}

The items relating to probity accountability have a relatively high mean score of

91.4 percent. Almost all authorities were able to provide actual operating expenditure for wastewater services (with the score of 98.6 percent) and target 
operating expenditure (97.3 percent). ${ }^{83}$ Actual and target capital expenditures (84.9 percent) are provided for equally, slightly less than those for operating expenditure. ${ }^{84}$ Overall, the score for this category is very high. This result is consistent with Herawaty and Hoque (2007), Kloot (2009), who found that cost information is well reported as part of the performance reporting by Australian public-sector entities. Similarly, Boyne and Law (1991) found that cost information was highly reported by Welsh district authorities in the United Kingdom. Lee (2008) found that government agencies perceived cost information as highly important and chose to disclose more information. This may be due to the fact that cost information is mandated as traditional information and complemented with specific accounting guidance, and local authorities are thoroughly familiar with reporting on it.

The items relating to legality accountability have a high mean score of 91.1 percent. Most authorities ${ }^{85}$ provide information about their compliance with the Resource Management Act 1991 (with the mean score of 93.2 percent). Items relating to the Heath Act 1956 are slightly less reported on than that relating to the Resource Management Act 1991 (89 percent). ${ }^{86}$

\footnotetext{
${ }^{83}$ This result is consistent with Taylor and Rosair (2000), who found items relating to compliance with legislation were highly reported. One council (Auckland CC) did not disclose operating expenditure, and two authorities (Auckland CC, Manukau, CC) did not report on target operating expenditure.

${ }^{84}$ Eleven authorities did not provide disclosure items about actual capital expenditure and target capital expenditure.

${ }^{85}$ All local authorities except Nelson CC, North Shore CC, Papakura DC, Rangitikei DC, Upper Hutt CC provide information about their compliance with the Resource Management Act 1991.

${ }^{86}$ All local authorities except Carterton DC, Central Otago DC, Chatham Island DC, Grey DC, Manukau CC, Papakura DC, Selwyn DC, South Taranaki DC do not provide items relating to Health Act 1956.
} 
Items relating to process/efficiency accountability have a mean score of 50.7 percent, which is slightly above half the maximum score. No council provided an efficiency ratio. Almost all of the authorities (72) provided actual operating expenditure, but half of those authorities (36) failed to provide quantity information. The absence of quantity prevents the efficiency ratio from being assessed. Lee (2008) notes that government agencies perceived the quantity item as not sufficiently important information to be disclosed. The poor disclosures of efficiency measures in service performance disclosures were also evident in studies by Boyne and Law (1991), Hyndman and Anderson (1995), Lonti and Gregory (2007) and Steccolini (2004). Lee (2006) found Australian government trading enterprises in water industries provided no efficiency measures over the four years (1998-2002) of study.

The items relating to performance/programme/effectiveness accountability have a mean score of 46.2 percent, which is slightly less than half the maximum score. The disclosure of the performance/programmeleffectiveness category is ranked lowest among the accountability expectation categories. Performance measures in relation to compliance with resource consent conditions are the most popular items (75.3 percent). However, their performance measures about the compliance by plants or consent types are few (12.3 percent). Performance measures about reliability of the service are moderately high (64.4 percent), while half the authorities report a similar type of the item again (31.5 percent). This result is in contrast to Boyne and Law (1991), who found the reliability performance measures were low, but consistent with Lee (2006) who found that the reliability measures of water agencies were highly reported (71 percent). Performance 
measures about response time to incidents were the least disclosed, but the score was slightly above half (57.5 percent). The result contradicts Boyne and Law (1991), who found that timeliness measures were poorly reported. Slightly more than half the authorities reporting on response time, disclosed the same type of measures again (28.8 percent). The result contradicts Pendlebury, Jones and Karbhari (1994), who found that about three-quarters (75 percent) of agencies reported on the timeliness performance measures more than once. In short, the results of performance/programme/effectiveness measures reporting is not so far behind Herawaty and Hoque (2007), who found effectiveness performance measures are moderately reported by Australian government departments, with a mean of 64 percent. In contrast, Lonti and Gregory (2007) found five New Zealand government departments provided very little reporting on effectiveness measures, mostly 9 percent. Actual and target project item was highly reported (72.6 percent), following compliance performance measures. However a few authorities (20) provided details of the actual project achievement by site (27.4 percent). As discussed, it can be seen that the mean score of performance/programmeleffectiveness has been weighted down by the second measures, or the mean score would otherwise have been much higher approximately 65 percent.

Overall, probity accountability and legality accountability received the highest score, which is nearly 100 percent, while process/efficiency accountability and performance/programme/effectiveness accountability scores were about half as high. This suggests that the traditional focus relating to disclosures still prevails. Given that all four accountability expectations are important for public-sector 
entities to discharge their accountability to the public (Jackson, 1982; Taylor \& Rosair, 2000), the failure to communicate any of them would be seen as their accountability being undermined. This provides an indication that local authorities' accountability to the public has not yet been adequately discharged.

\subsubsection{AE index by local authorities}

The index scores based on accountability expectations by local authorities, in descending order from highest to lowest, are shown in Table 6.4.

Table 6.4: AE index scores by local authorities

\begin{tabular}{|r|l|c|}
\hline & \multicolumn{1}{|c|}{ Local Authorities } & $\begin{array}{c}\text { AE } \\
\text { Index }\end{array}$ \\
\hline 1 & Southland DC & $93 \%$ \\
\hline 2 & Hamilton CC & $87 \%$ \\
\hline 3 & Kapiti Coast DC & $87 \%$ \\
\hline 4 & Stratford DC & $87 \%$ \\
\hline 5 & Taupo DC & $87 \%$ \\
\hline 6 & Waikato DC & $87 \%$ \\
\hline 7 & Waitakere CC & $87 \%$ \\
\hline 8 & Buller DC & $80 \%$ \\
\hline 9 & Christchurch CC & $80 \%$ \\
\hline 10 & Clutha DC & $80 \%$ \\
\hline 11 & Far North DC & $80 \%$ \\
\hline 12 & Mackenzie DC & $80 \%$ \\
\hline 13 & North Shore CC & $80 \%$ \\
\hline 14 & Otorohanga DC & $80 \%$ \\
\hline 15 & Rodney DC & $80 \%$ \\
\hline 16 & Whakatane DC & $80 \%$ \\
\hline 17 & Ashburton DC & $73 \%$ \\
\hline 18 & Franklin DC & $73 \%$ \\
\hline 19 & Hastings DC & $73 \%$ \\
\hline 20 & Hutt CC & $73 \%$ \\
\hline 21 & Invercargill CC & $73 \%$ \\
\hline 22 & Manawatu DC & $73 \%$ \\
\hline 23 & Nelson CC & $73 \%$ \\
\hline 24 & Rangitikei DC & $73 \%$ \\
\hline 25 & South Wairarapa DC & $73 \%$ \\
\hline 26 & Tauranga CC & $73 \%$ \\
\hline 27 & Thames-Coromandel DC & $73 \%$ \\
\hline 28 & Waimate DC & $73 \%$ \\
\hline 29 & Waipa DC & $73 \%$ \\
\hline 30 & Central Hawke's Bay DC & $67 \%$ \\
\hline 31 & Marlborough DC & $67 \%$ \\
\hline 32 & Napier CC & $67 \%$ \\
\hline 33 & Palmerston North CC & $67 \%$ \\
\hline 34 & Queenstown-Lakes DC & $67 \%$ \\
\hline 35 & Ruapehu DC & $67 \%$ \\
\hline 36 & South Waikato DC & $67 \%$ \\
\hline 37 & Timaru DC & \\
\hline & & \\
\hline
\end{tabular}

\begin{tabular}{|c|c|c|}
\hline & Local Authorities & $\begin{array}{c}\text { AE } \\
\text { Index }\end{array}$ \\
\hline 38 & Waitaki DC & $67 \%$ \\
\hline 39 & Wanganui DC & $67 \%$ \\
\hline 40 & Western Bay of Plenty DC & $67 \%$ \\
\hline 41 & Westland DC & $67 \%$ \\
\hline 42 & Dunedin CC & $60 \%$ \\
\hline 43 & Grey DC & $60 \%$ \\
\hline 44 & Hauraki DC & $60 \%$ \\
\hline 45 & Kawerau DC & $60 \%$ \\
\hline 46 & Matamata-Piako DC & $60 \%$ \\
\hline 47 & Opotiki DC & $60 \%$ \\
\hline 48 & South Taranaki DC & $60 \%$ \\
\hline 49 & Tasman DC & $60 \%$ \\
\hline 50 & Wairoa DC & $60 \%$ \\
\hline 51 & Waitomo DC & $60 \%$ \\
\hline 52 & Whangarei DC & $60 \%$ \\
\hline 53 & Gisborne DC & $53 \%$ \\
\hline 54 & Gore DC & $53 \%$ \\
\hline 55 & Horowhenua DC & $53 \%$ \\
\hline 56 & Kaikoura DC & $53 \%$ \\
\hline 57 & Masterton DC & $53 \%$ \\
\hline 58 & New Plymouth DC & $53 \%$ \\
\hline 59 & Porirua CC & $53 \%$ \\
\hline 60 & Rotorua DC & $53 \%$ \\
\hline 61 & Tararua DC & $53 \%$ \\
\hline 62 & Waimakariri DC & $53 \%$ \\
\hline 63 & Wellington CC & $53 \%$ \\
\hline 64 & Carterton DC & $47 \%$ \\
\hline 65 & Central Otago DC & $47 \%$ \\
\hline 66 & Kaipara DC & $47 \%$ \\
\hline 67 & Selwyn DC & $47 \%$ \\
\hline 68 & Upper Hutt CC & $47 \%$ \\
\hline 69 & Chatham Island DC & $40 \%$ \\
\hline 70 & Hurunui DC & $33 \%$ \\
\hline 71 & Auckland CC & $33 \%$ \\
\hline 72 & Manukau CC & $27 \%$ \\
\hline \multirow[t]{2}{*}{73} & Papakura DC & $13 \%$ \\
\hline & Average & $64.55 \%$ \\
\hline
\end{tabular}


From Table 6.4, the average AE index score is relatively high - 64.55 percent. The highest scoring council scored 93 percent while the lowest scoring council scored 13 percent. Almost all authorities (63) have an index score above 50 percent. Note that the three lowest scoring authorities (Papakura DC, Manukau $\mathrm{CC}$, and Auckland $\mathrm{CC}$ ) outsourced wastewater services. Figure 6.2 provides a histogram of the AE index.

\section{Figure 6.2: Histogram of the AE index}

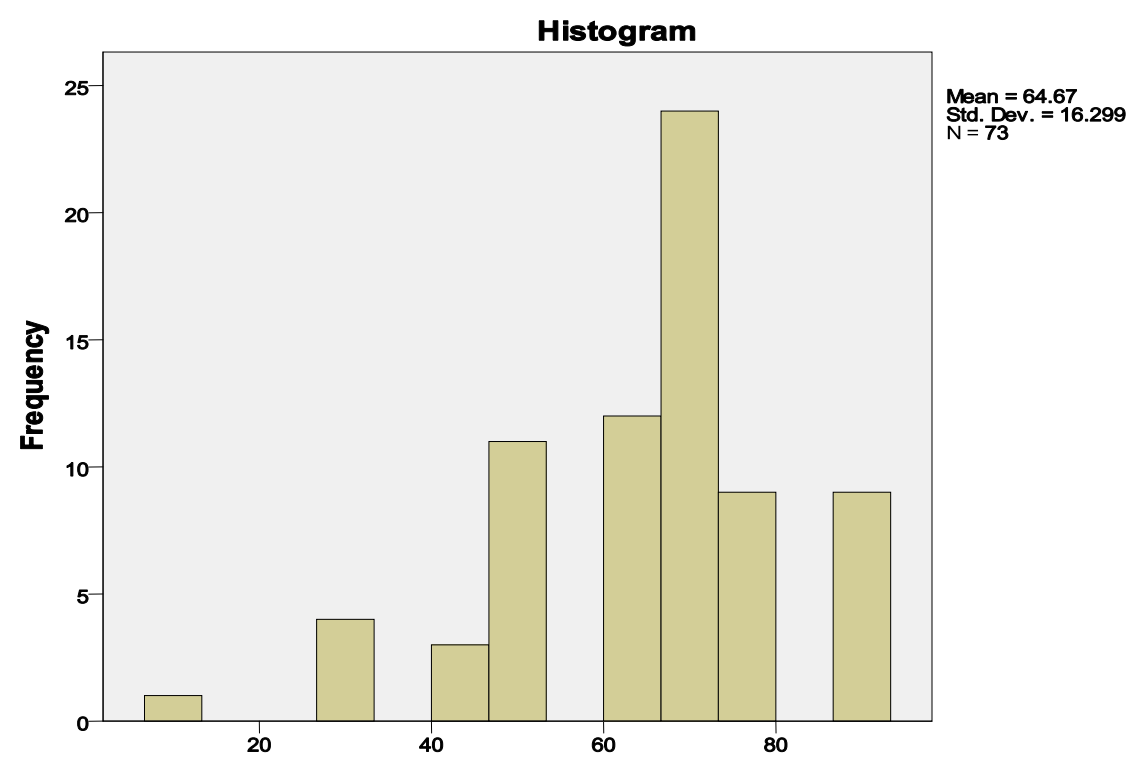

AE index scores

From Figure 6.2, it can be seen that the range of index scores spread widely and skewed to the left. The Shapiro-Wilk normality test statistic of $.953(\mathrm{p}=.008)$ confirms that the AE index is not normally distributed. There are some gaps between bars, which have distinctive reporting characteristics. The bar on the far left represents the lowest scoring local council (Papakura DC), which only reported on some items of probity. The following group (27-33 percent) basically added on some of the legality items. The next group (40-53 percent) largely reported fully on probity and legality items, introducing a few process/efficiency 
and performance/programme/effectiveness items. The next group (60-80 percent), which most scores are clustered, provided more on process/efficiency and performance/programmeleffectiveness items. The highest group on the far right, whose AE index score is above 80 percent, reported most of the items, missing some measures of performance/programmeleffectiveness accountability. This pattern supports the result of the AE index by categories and items that traditional probity and legality accountability items are more popular than the latter process/efficiency and performance/programmeleffectiveness accountability items.

From the AE index scores, it seems to appear that local authorities in New Zealand disclose information about wastewater services in a manner which is suitable for evaluating the performance in accordance with accountability expectations. It suggests that the accountability expectations provide a suitable framework for evaluating SSPs by New Zealand local authorities.

\subsection{Comparing $A R$ and $A E$ indices}

Tables 6.2 and 6.4 show that the two indices have similar results in terms of the four lowest scored authorities (Papakura DC, Manukau CC, Auckland CC, and Hurunui DC). The lowest score for the AR index is 12 percent, and for the AE index, 13 percent, which is the Papakura DC - providing very few disclosures. The remaining three authorities have slightly higher scores, ranging between 15 17 percent for both indices. Papakura DC, Manukau CC, and Auckland CC were 
found to outsource their wastewater services to other organisations. ${ }^{87}$ It is possible that such outsourcing may reduce the ability of those authorities to obtain information from the outsourced authorities for reporting on their wastewater performances. This raises the question of whether the authorities retain sufficient control over the operations of outsourced entities in order to provide adequate disclosures. More interestingly, Auckland CC and Manukau CC are the largest and the third-largest authorities respectively in terms of population. Ironically, they are among the lowest-reporting authorities, and they will probably be faced with increased expectations and demands for more information by their larger populations. Table 6.5 provides a statistical descriptive of the AR and AE indices for 73 local authorities.

Table 6.5: Statistical descriptives of the AR and AE indices of 73 local authorities

\begin{tabular}{|l|c|c|c|c|c|c|c|c|}
\hline & $\begin{array}{c}\text { Mean } \\
(\boldsymbol{\%})\end{array}$ & $\begin{array}{c}\text { Median } \\
(\boldsymbol{\%})\end{array}$ & $\begin{array}{c}\text { Max } \\
(\boldsymbol{\%})\end{array}$ & $\begin{array}{c}\text { Min } \\
(\boldsymbol{\%})\end{array}$ & $\begin{array}{c}\text { Std. } \\
\text { Dev }\end{array}$ & $\begin{array}{c}\text { Interquar } \\
\text { tile range }\end{array}$ & Skewness & Kurtosis \\
\hline $\begin{array}{l}\text { AR } \\
\text { index }\end{array}$ & 33.33 & 33 & 55 & 12 & 7.546 & 6 & -.297 & 1.578 \\
\hline $\begin{array}{l}\text { AE } \\
\text { index }\end{array}$ & 64.55 & 67 & 93 & 13 & 15.31 & 20 & -.717 & .944 \\
\hline
\end{tabular}

From Table 6.5, it can be seen that the mean and median of the AR index (33.33, 33 percent) are twice as low than those of the $\mathrm{AE}$ index $(64.55,67$ percent). Further, the $\mathrm{AE}$ index has a much higher maximum (93 percent) than the $\mathrm{AR}$ index. However, the minimum of the AE index (13 percent) is almost as low as that of $\mathrm{AR}$ index (12 percent). With a wider spread in the AE index, its standard

\footnotetext{
${ }^{87}$ Papakura DC and Wellington CC contracted United Water International Pty Ltd., Manukau CC and Auckland CC use council-controlled organisations (Manukau Water Ltd and Metro Water Ltd, respectively).
} 
deviation (15.31), interquartile range (20), absolute skewness (.717) are higher than those of the AR index, which in turn has a higher kurtosis. Consequently, the AR index is more tightly clustered than the AE index (see their histograms in Figures 6.1 and 6.2). Figure 6.3 presents a box plot of AR and AE indices, which shows the difference in spread of the indices.

Figure 6.3: Box plot for the AR and AE indices

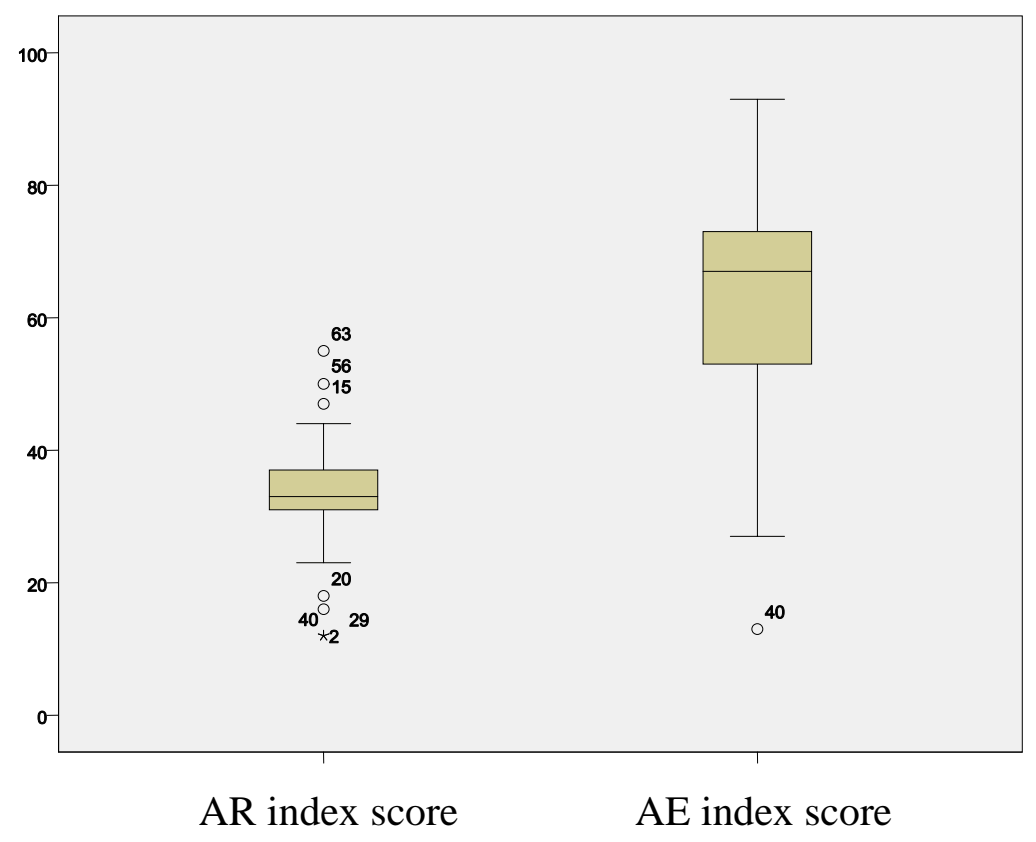

Though the indices are different in many ways, Kendall's tau_b correlation indicates that they are positively significantly correlated with the correlation coefficient at $.304(\mathrm{p}=.000)$. Both indices move in the same direction, as they measure the same phenomena. However, a degree of variation in each index exists, which is not explained by the other index.

The distinctive differences between the two index items are that the AR index includes items relating to past performance, explanation of significant variance (if any), and location of wastewater services, while the AE index includes capital 
expenditure and project items. While the AR index does poorly on those different items, the AE index does well on these different items. As a result, the AR index is lower than the AE index (see Tables 6.1 and 6.3).

Comparing the two indices, the results support the conclusion that local authorities disclose information about wastewater services in a manner which is suitable for evaluating the performance according with accountability expectations rather than authoritative requirements. This may be due to the fact that the authoritative requirements are based on economic framework of reporting which focuses on financial information and may not be specific to SSP disclosures. However, the accountability expectations, derived from the literature, are based on criteria which have been tailored more specifically to public-sector reporting, which local authorities seem to correspond to.

\subsection{Summary}

This chapter provides results and discussion from the measurement of the consistency of disclosures with authoritative requirements and accountability expectations, using the $\mathrm{AR}$ and $\mathrm{AE}$ indices. The $\mathrm{AR}$ index has a relatively low correspondence with the mean score of 33.33 percent. Most authorities are able to report well on relevant, comparable information in relation to quality and cost of wastewater, rather than quantity, location and time. Past information on nonfinancial dimensions (quantity, quality, location, time) scores the lowest. This may indicate that the comparability requirement may not be applicable for the non-financial dimensions and, hence, support the OAG's (2008) and Webster's (2007) criticisms of the vague and financially focused authoritative requirements. 
Further, while cost is an important information item (Lee, 2008) and well reported, the explanation significant variance of cost disclosed seems cryptic. The AE index has a relatively high correspondence with the mean score of 64.55 percent, approximately twice higher than the AR index. This result suggests that local authorities appear to disclose information about wastewater services in a manner which they are trying to address the accountability expectations. This result also show that items about probity and legality accountability are appropriately disclosed (slightly more than 91 percent of local authorities) while process/efficiency and performance/programme/effectiveness accountability is relatively low (about 50 percent of local authorities). The lower score may be associated with it being a new addition to the dimension of accountability expectations. However, the deficiency of process/efficiency and performance/programme/effectiveness suggests that accountability of local councils to the public is not yet adequately discharged. This may raise the concern on the success of the reform principle for greater accountability.

Comparing the two indices, results show that local authorities disclose information about wastewater services in a manner which is suitable for evaluation according to the AE index, rather than the AR index. Further, given the unsuitability of authoritative requirement for evaluating SSPs as opposed to accountability expectations framework, this suggests that the accountability framework provides an appropriate model for SSP reporting rather than economic framework. 
Both indices showed the same four lowest-scored authorities, of which three local authorities outsourced their wastewater services to other organisations. This may raise the question of whether the authorities retain sufficient control over the operations of outsourced entities to be able to provide adequate information for disclosures.

The variation of both indices may be affected by a number of factors, as discussed in chapter 4. The next chapter will provide the results and discussion of the relationship between factors and the extent of disclosures, according to the AR and $\mathrm{AE}$ indices, using regression analysis. 


\section{Chapter 7: Results and Analysis of the Factors Influencing}

\section{Disclosures}

\subsection{Introduction}

This chapter discusses the results of multiple regression analysis carried out to investigate the relationship between the indices and influential factors. Section 7.2 summarises the descriptive statistics of the variables. Section 7.3 explores linear regression analysis, for which the results are discussed in section 7.4, and section 7.5 summarises the chapter.

\subsection{Descriptive statistics}

As previously discussed in chapter 6 , the $\mathrm{AR}$ index and $\mathrm{AE}$ index are the dependent variables used in this study's multiple regression analysis. Independent variables are: number of staff, revenue, total assets, population, and medium income per capita. Table 7.1 presents the descriptive statistics for all variables of the 73 local authorities.

Table 7.1: Statistical descriptives of dependent and independent variables of 73 local authorities

\begin{tabular}{|l|r|r|r|r|}
\hline \multicolumn{1}{|c|}{ Variables } & \multicolumn{1}{c|}{ Min } & \multicolumn{1}{c|}{ Max } & \multicolumn{1}{c|}{ Mean } & $\begin{array}{c}\text { Standard } \\
\text { Deviation }\end{array}$ \\
\hline AR index & $12 \%$ & $55 \%$ & $33.33 \%$ & 7.546 \\
\hline AE index & $13 \%$ & $93 \%$ & $64.55 \%$ & 15.311 \\
\hline Revenue $(\$ 000)$ & $\$ 4,509$ & $\$ 571,493$ & $\$ 71,088.77$ & $\$ 93,695.192$ \\
\hline Total assets $(\$ 000)$ & $\$ 41,779$ & $\$ 9,633,020$ & $\$ 1,229,917.73$ & $\$ 1.655 \mathrm{E} 6$ \\
\hline Population & 640 & 438,100 & $58,465.34$ & $82,368.551$ \\
\hline Number of staff & 4 & 1666 & 242.07 & 337.963 \\
\hline Medium income per capita(\$) & $\$ 17,100$ & $\$ 32,500$ & $\$ 23,206.85$ & $\$ 2,982.790$ \\
\hline
\end{tabular}




\subsection{Multiple regression analysis}

For the purposes of the third research objective, the standard multiple linear regression model was developed and analysed, using SPSS to run statistical tests of the relationship to test the assumptions of linear regression. The standard form of this study's regression is:

$$
I N D E X_{i}=\alpha+\beta_{1} \text { REV }_{i}+\beta_{2} \text { ASSET }_{i}+\beta_{3} \text { POP }_{i}+\beta_{4} \text { STAFF }_{i}+\beta_{5} \text { MEDINC }_{i}+\varepsilon_{i}
$$

Where

\begin{tabular}{|c|c|}
\hline INDEX & $=\mathrm{AR}$ index or $\mathrm{AE}$ index \\
\hline$R E V$ & $=$ revenue \\
\hline ASSET & $=$ total assets \\
\hline$P O P$ & $=$ population \\
\hline STAFF & $=$ number of staff \\
\hline MEDINC & $=$ medium income per capita \\
\hline & $=$ local authority \\
\hline$\alpha, \beta$ & $=$ constants or parameters \\
\hline$\varepsilon$ & $=$ errors \\
\hline
\end{tabular}

Given the two dependent variables, each requiring a multiple linear regression analysis, two regression routines were run: one for the AR index and another for the $\mathrm{AE}$ index. The basic assumptions underlying the multiple linear regression models needed to be tested. If any assumptions were violated, then the estimates yielded by the regression model were possibly biased or misleading (Field, 2005). A number of ways could be used if necessary to alleviate violation. The following section discusses the test for possible violations of the assumptions and modification of the multiple linear regression model used in this study. 


\subsubsection{Outliers}

Outliers (influential observations) are cases with extreme values or large residuals which could distort statistics, such as the mean and standard deviation (Field, 2005; Garson, 2010; Tabachnick \& Fidell, 2007). Outliers for a regression model with multiple variables (multivariate outliers) can be detected from the absolute value of standardised residuals above certain cut-off points (for example, 2, 2.5, 3) and/or a Cook's Distance of more than 1 , or $4 /(n-k-1)$, where $n$ is the number of cases and $\mathrm{k}$ is the number of independent variables (Field, 2005; Garson, 2010). In this study's data, evidence of outliers were found in both regression models for $\mathrm{AR}$ and $\mathrm{AE}$ indices, for which the standardised residuals were above 2 and the Cook's Distance above $0.06(4 /(73-5-1))$. (Appendices C and D show the standardised residual and Cook's Distance values for the AR and AE indices.)

To correct outliers, the researcher may remove and analyse extreme cases or outliers separately from the sample and/or transform the data to pull in outlier/extreme values (Field, 2005; Garson, 2010; Tabachnick \& Fidell, 2007).

\subsubsection{Non-linearity}

Linear regression analysis tests a linear relationship only between dependent and independent variables. A linear model cannot explain or predict data which are non-linear (Field, 2005; Nau, 2005). Linearity between two variables can be roughly assessed by inspection of bivariate scatterplots (Tabachnick \& Fidell, 2007). A plot of standardised residuals against standardised predicted values, which are regression outputs, can be used to detect the non-linearity relationship 
involving more than one independent variable (Field, 2005; Tabachnick \& Fidell, 2007). The points should be symmetrically distributed around a horizontal zero line. If it shows a bowed or curved pattern, then non-linearity is likely to exist (Field, 2005). In this study, the relationship between the dependent and independent variables is not linear. The plots (in both models) of standardised residuals against standardised predicted values show an unusual distribution pattern - a cluster in one area. (Appendices $\mathrm{E}$ and $\mathrm{F}$ show the plot of standardised residuals against standardised predicted values for $\mathrm{AR}$ and $\mathrm{AE}$ indices.)

To correct the problem of a non-linearity relationship, transformation of dependent and/or independent variables may be used (Nau, 2005).

\subsubsection{Heteroscedasticity}

The assumption of homoscedasticity requires that the standard deviations of errors of prediction are approximately equal at each level of the predictor(s) (Tabachnick \& Fidell, 2007). In contrast, heteroscedasticity occurs when the standard deviations of errors are not constant and can bias standard deviations of the residuals and the confidence interval of the regression (Garson, 2010; Nau, 2005; Tabachnick \& Fidell, 2007). A scatterplot of the standardised predicted dependent variable by the standardised residuals is one option to detect heteroscedasticity. To meet the assumption of homoscedasticity, the graph should form a symmetrical distribution around a horizontal zero line. When the points form the shape of a funnel (close together at one end and widely spread at the other end) or a bowed or curved pattern, this shape indicates typical heteroscedasticity (Field, 2005). In this study, the plots show an unusual 
distribution pattern and heteroscedasticity may be a problem. (See Appendices E and F.)

One way to alleviate the problem of heteroscedasticity is to transform the data (both independent and dependent variables) (Nau, 2005).

\subsubsection{Non-normally distributed errors}

The assumption of normality of errors requires that errors of prediction are normally distributed for all predicted dependent variables (Tabachnick \& Fidell, 2007). In many cases, the violation of a normal distribution of errors arises due to the presence of a few large outliers, significantly non-normally distributed dependent and/or independent variables, and a non-linear relationship between dependent and independent variables. The non-normally distributed errors can be detected from the histogram of standardised residuals and also the KomogorovShirnov and Shapiro-Wilks normality tests of standardised residuals. ${ }^{88}$ If the distribution of residuals were normal, the histogram should show a rough normal curve (Garson, 2010) and the results of the normality test should be nonsignificant for residual (Field, 2005). In this study, the histogram of the standardised residuals (for both indices' regression models) does not show that the distribution of residuals differed markedly from a normal distribution. (Appendices $\mathrm{G}$ and $\mathrm{H}$ show a histogram of standardised residuals for $\mathrm{AR}$ and $\mathrm{AE}$ indices) Further, statistics of the Shapiro-Wilk normality test is 0.195 for the AR index regression model and 0.27 for the $\mathrm{AE}$ index regression model, which support the conclusion that the residuals are normally distributed for both models.

${ }^{88}$ Shapiro-Wilk normality test is recommended for smaller samples (less than 2000), while Kolmogorov-Shirnov for larger samples (Garson, 2010). 


\subsubsection{Non-independence of errors}

Errors of prediction should be uncorrelated (or independent) with each independent variable (Field, 2005; Tabachnick \& Fidell, 2007). The assumption can be tested by the Durbin-Watson test. The test statistic can vary between 0 and 4. The Durbin-Watson statistic should be 2, or closer to 2 for independent errors. When the Durbin-Watson statistic is less than 1 or greater than 3 , nonindependence of errors is a definite concern (Field, 2005). In this study, the Durbin-Watson value is 2.102 and 2.054, which is close to 2, which supports that the errors are independent.

\subsubsection{Multicollinearity}

Multicollinearity exists when there is a linear relationship between two or more predictors (independent variables) in a regression or when the predictors are highly correlated (Field, 2005). Common methods to detect multicollinearity in a regression are when the correlation coefficient between each pair of predictors is above 0.8, and the Variance Inflation Factor (VIF) ${ }^{89}$ is more than 10 (Field, 2005). ${ }^{90}$ Table 7.2 presents a correlation matrix for dependent and independent variables, as well as for VIF values.

\footnotetext{
${ }^{89}$ VIF indicate whether a predictor has a strong linear relationship with other predictors (Field, 2005).

${ }^{90}$ Alternatively, tolerance value, which is the reciprocal of VIF, is less than 0.1 (Field, 2005).
} 
Table 7.2: Kendall's tau_b correlation coefficient among independent variables

\begin{tabular}{|l|l|l|l|l|l|l|l|l|}
\hline & $\begin{array}{l}\text { AR } \\
\text { Index }\end{array}$ & $\begin{array}{l}\text { AE } \\
\text { Index }\end{array}$ & Staff & Revenue & Asset & Population & $\begin{array}{l}\text { Med. } \\
\text { income }\end{array}$ & VIF \\
\hline AR Index & 1.000 & & & & & & & \\
\hline AE Index & $.304^{* *}$ & 1.000 & & & & & & \\
\hline Staff & $.168^{*}$ & .097 & 1.000 & & & & & 15.846 \\
\hline Revenue & $.176^{*}$ & .137 & $.779^{* *}$ & 1.000 & & & & 41.450 \\
\hline Asset & $.222^{* *}$ & .141 & $.712^{* *}$ & $.817^{* *}$ & 1.000 & & & 29.066 \\
\hline Population & $.179^{*}$ & .093 & $.775^{* *}$ & $.840^{* *}$ & $.768^{* *}$ & 1.000 & & 16.916 \\
\hline Med.income &. .087 & .042 & $.225^{*}$ & $.253^{* *}$ & $.277^{* *}$ & $.279^{* *}$ & 1.000 & 1.204 \\
\hline
\end{tabular}

** Correlation is significant at the level 0.01 (2-tailed)

* Correlation is significant at the level 0.05 (2-tailed)

From Table 7.2, it is evident that multicollinearity exists between the independent variables in the standard regression model. Variables for staff, revenue, assets, and population are highly intercorrelated, with the Kendall's tau_b correlation coefficients having values close to or higher than 0.8 . Further, VIF values of staff, revenue, assets, and population are beyond the thresholds of 10 (15.846, $41.450,29.066$, and 16.916) which confirms the problem of multicollinearity.

In order to control the problem of multicollinearity, and as there is no overriding reason to choose one variable over another, a separate regression analysis including one of the highly correlated variables could be run alternately (Cooke, 1989), or factor analysis ${ }^{91}$ could be used to derive factor score(s) as independent variable(s), replacing the highly correlated variables (Craig \& Diga, 1998; Ingram, 1984).

As discussed earlier in this study, outliers, non-linearity relationships, heteroscedasticity, and multicollinearity are the principal problems of the standard

\footnotetext{
${ }^{91}$ Factor analysis combines variables with similar characteristics into a group or a single factor. As a result, it reduces a large number of independent variables to a subset of uncorrelated factors (Field, 2005).
} 
regression analysis that need to be solved. In order to tackle the first three violations, transformation and removal of outliers were considered. Factor analysis and running regression models with an alternate correlated variable could be used to control multicollinearity.

Numerous combinations of different types of transformation were regressed, and natural logarithms of both the $\mathrm{AR}$ and $\mathrm{AE}$ indices and of independent variables were found to provide the lower residual mean square error (RMSE). In using logarithmic transformation, the problems of heteroscedasicity and non-linearity were alleviated; however, outliers persisted. The statistics of both regression models for the $\mathrm{AR}$ and $\mathrm{AE}$ indices show evidence of the outliers, with standardised residuals and Cook's Distance values of more than 2 and .06 respectively. (Appendices I and J show the standardised residual and Cook's Distance values for the logarithmic transformed $\mathrm{AR}$ and $\mathrm{AE}$ indices.) These outliers were the four lowest-scored authorities (Papakura DC, Manukau CC, Auckland CC, and Hurunui DC). Given the problem of outliers, removal of the four authorities was made for both models. Consequently, the sample size reduced to 69 local authorities.

When running a factor analysis to extract the explanatory contribution of highly correlated variables (revenue, total asset, population, and staff), one principal component was found (eigenvalue $=3.785$ ) which accounted for 94 percent of total variance. Factor loadings of the components show $.984, .965, .984$, and .957 , for revenue, total assets, population, and number of staff respectively. The equation to derive a factor score for these variables, collectively called size, is: 


$$
\mathrm{SIZE}=.984 * \mathrm{REV}+.965 * \mathrm{ASSET}+.984 * \mathrm{POP}+.957 * \mathrm{STAFF}
$$

The size variable embraces, to certain degree, explanatory contribution of, the highly correlated variable, and the problem of an omitted variable is therefore avoided. This size variable is another independent variable suitable for alleviating multicollinearity problems. Since no theoretical reason exists on which of these independent variables (size derived from factor analysis, revenue, total assets, population, and number of staff) is best at capturing the effect on the disclosures and any multicollinearity problem, five regression models were developed, using each of the five variables alternately. The models are:

Model A : INDEX $i=\alpha+\beta_{2} \operatorname{SIZE}_{i}+\beta_{2} \operatorname{MEDINC}_{i}+\varepsilon_{i}$

Model B : INDEX $X_{i}=\alpha+\beta_{1} R E V_{i}+\beta_{2} \operatorname{MEDINC}_{i}+\varepsilon_{i}$

Model C : INDEX $X_{i}=\alpha+\beta_{1} A_{S S E T_{i}}+\beta_{2} \operatorname{MEDINC}_{i}+\varepsilon_{i}$

Model D : INDEX $_{i}=\alpha+\beta_{1}$ POP $_{i}+\beta_{2}$ MEDINC $_{i}+\varepsilon_{i}$

Model E : INDEX $X_{i}=\alpha+\beta_{1} \operatorname{STAFF}_{i}+\beta_{2} \operatorname{MEDINC}_{i}+\varepsilon_{i}$

Where

INDEX $\quad=\log$ of AR index scores and log of AE index

SIZE $\quad=$ size factor score derived from factor analysis

STAFF $\quad=\log$ of number of staff

REV = log of revenue

ASSET $\quad=\log$ of total assets

$P O P \quad=\log$ of population

MEDINC $\quad=\log$ of medium income per capita

$i \quad=$ local authority

$\alpha, \beta \quad=$ constants or parameters

$\varepsilon=$ errors

Note that each of these models applies for both indices. As a result, ten models are run. Commonly, all models include median income per capita. Model A 
includes the size variable derived from factor analysis, while Models B - E include one of the highly correlated variables.

\subsection{Multiple regression results}

Tables 7.3 and 7.4 report results (including the coefficients and t-statistics of intercept, and the independent variables, as well as adjusted $\mathrm{R}^{2}, \mathrm{~F}$-statistics, and significance of each model) for the AR index and AE index, respectively. In addition, each regression model was tested for any violations of regression assumptions. If any evidence of violation occurs, a remark will be provided.

Table 7.3: Multiple regression results for the AR index

\begin{tabular}{|c|c|c|c|c|c|c|}
\hline & & Model A & Model B & Model C & Model D & Model E \\
\hline & $\begin{array}{l}\text { Predicted } \\
\text { sign }\end{array}$ & \multicolumn{5}{|c|}{$\begin{array}{l}\text { Coefficients } \\
\text { (t-statistics) }\end{array}$} \\
\hline \multicolumn{2}{|l|}{ Intercept } & $\begin{array}{c}2.014 \\
(1.176)\end{array}$ & $\begin{array}{l}1.295 \\
(.781)\end{array}$ & $\begin{array}{l}1.529 \\
(.949)\end{array}$ & $\begin{array}{l}1.350 \\
(.826)\end{array}$ & $\begin{array}{l}1.312 \\
(.790)\end{array}$ \\
\hline \multicolumn{7}{|c|}{ Independent variables } \\
\hline Size & + & $\begin{array}{c}.057 \\
(2.622)^{*}\end{array}$ & & & & \\
\hline Revenue & + & & $\begin{array}{c}.054 \\
(2.284)^{*}\end{array}$ & & & \\
\hline Assets & + & & & $\begin{array}{c}.068 \\
(3.010)^{* *}\end{array}$ & & \\
\hline Population & + & & & & $\begin{array}{c}.052 \\
(2.601)^{*}\end{array}$ & \\
\hline $\begin{array}{l}\text { Number of } \\
\text { Staff }\end{array}$ & + & & & & & $\begin{array}{c}.043 \\
(2.272)^{*}\end{array}$ \\
\hline $\begin{array}{l}\text { Medium } \\
\text { Income }\end{array}$ & + & $\begin{array}{c}.150 \\
(.882) \\
\end{array}$ & $\begin{array}{l}.165 \\
(.951)\end{array}$ & $\begin{array}{c}.108 \\
(.632) \\
\end{array}$ & $\begin{array}{c}.164 \\
(.968) \\
\end{array}$ & $\begin{array}{c}.200 \\
(1.188) \\
\end{array}$ \\
\hline \multicolumn{7}{|c|}{ Regression Model } \\
\hline Adjusted $\mathrm{R}^{2}$ & & .117 & .097 & .143 & .116 & .096 \\
\hline F-Statistics & & 5.525 & 4.648 & 6.679 & 5.465 & 4.617 \\
\hline Significance & & .006 & .013 & .002 & .006 & .013 \\
\hline
\end{tabular}

** Significant at $\mathrm{p}<0.01$, two-tailed

* Significant at $\mathrm{p}<0.05$, two-tailed 
Table 7.3 shows that all models report statistically significant explanatory powers of adjusted $\mathrm{R}^{2}$ ( $\mathrm{p}<.01$ for Model $\mathrm{A}$ and Model $\mathrm{C}$, and Model $\mathrm{D}$, and $\mathrm{p}<.05$ for Model B and Model E). Model C reports the highest explanatory power (adjusted $\mathrm{R}^{2}=14.3$ percent $)$ and $\mathrm{F}$-statistics $(\mathrm{F}=6.679)$. Models $\mathrm{A}$ and $\mathrm{D}$ report close explanatory powers (11.7 and 11.6 percent, respectively), and similarly, Models B and E report close explanatory powers (9.7 and 9.6 percent, respectively).

Coefficients of all size variables in all models are also positively significant ( $\mathrm{p}<.01$ for Model $\mathrm{C}$, and $\mathrm{p}<.05$ for the remaining models) while that of median income per capita is not significant for any model. Model $\mathrm{C}$ has the highest coefficient (.068), followed by Model A (.057), Model B (.054), Model D (.052), and Model E (.043). This suggests that total assets is best at explaining the variability in the AR indices, followed by size factor score, population, revenue and number of staff, respectively, while median income per capita is not. Note that all the models showed one outlier (standardised residual $>2$ and Cook's Distance $>.06$ ), while other regression assumptions were satisfied.

Similar to the results of multiple regression models for the AR index, Table 7.4 below provides statistical details of the multiple regression models for the $\mathrm{AE}$ index. 
Table 7.4: Multiple regression results for the $\mathrm{AE}$ index

\begin{tabular}{|c|c|c|c|c|c|c|}
\hline & & Model A & Model B & Model C & Model D & Model E \\
\hline & $\begin{array}{l}\text { Predicted } \\
\text { sign }\end{array}$ & \multicolumn{5}{|c|}{$\begin{array}{l}\text { Coefficients } \\
\text { (t-statistics) }\end{array}$} \\
\hline Intercept & & $\begin{array}{c}4.976 \\
(2.586)^{*}\end{array}$ & $\begin{array}{c}4.331 \\
(2.345)^{*}\end{array}$ & $\begin{array}{c}4.360 \\
(2.382)^{*}\end{array}$ & $\begin{array}{c}4.241 \\
(2.304)^{*}\end{array}$ & $\begin{array}{c}4.247 \\
(2.279)^{*}\end{array}$ \\
\hline \multicolumn{7}{|c|}{ Independent variables } \\
\hline Size & + & $\begin{array}{c}.060 \\
(2.477)^{*}\end{array}$ & & & & \\
\hline Revenue & + & & $\begin{array}{c}.064 \\
(2.421)^{*}\end{array}$ & & & \\
\hline Assets & + & & & $\begin{array}{c}.067 \\
(2.598) *\end{array}$ & & \\
\hline Population & + & & & & $\begin{array}{c}.053 \\
(2.385)^{*}\end{array}$ & \\
\hline $\begin{array}{l}\text { Number of } \\
\text { Staff }\end{array}$ & + & & & & & $\begin{array}{c}.046 \\
(2.183)^{*} \\
\end{array}$ \\
\hline $\begin{array}{l}\text { Medium } \\
\text { Income }\end{array}$ & + & $\begin{array}{c}-.079 \\
(-.412) \\
\end{array}$ & $\begin{array}{c}-.082 \\
(-.424) \\
\end{array}$ & $\begin{array}{c}-.107 \\
(-.550) \\
\end{array}$ & $\begin{array}{c}-.060 \\
(-.317) \\
\end{array}$ & $\begin{array}{c}-.028 \\
(-.150) \\
\end{array}$ \\
\hline \multicolumn{7}{|c|}{ Regression Model } \\
\hline Adjusted $\mathrm{R}^{2}$ & & .062 & .058 & .070 & .056 & .044 \\
\hline F-Statistics & & 3.237 & 3.099 & 3.544 & 3.012 & 2.550 \\
\hline Significance & & .046 & .052 & .035 & .056 & .086 \\
\hline
\end{tabular}

** Significant at $\mathrm{p}<0.01$, two-tailed

* Significant at $\mathrm{p}<0.05$, two-tailed

From Table 7.4, only Models C and A report a significant explanatory power of adjusted $\mathrm{R}^{2}(\mathrm{p}<.05)$. Model $\mathrm{C}$ reports the highest explanatory power (adjusted $\mathrm{R}^{2}$ $=7$ percent $)$ and F-statistics $(\mathrm{F}=3.544, \mathrm{p}=.035)$, followed by those of Model $\mathrm{A}$ (adjusted $\mathrm{R}^{2}=6.2$ percent, $\left.\mathrm{F}=3.237, \mathrm{p}=.046\right)$. The adjusted $\mathrm{R}^{2}$ scores of the remaining models are slightly lower (ranging from $4.4-5.8$ percent) and insignificant $(\mathrm{p}>.05)$.

As in the regression analysis for the AR index, coefficients of size variables in all the models are positively significant $(\mathrm{p}<.05)$ while that of median income per capita is not significant. Model $\mathrm{C}$ also has the highest coefficient (.067), followed by Model B (.064), Model A (.060), Model D (.053), and Model E (.046). This suggests that total assets is best at explaining the variation of the $\mathrm{AE}$ indices, 
followed by, revenue, size factor score, population, and number of staff, respectively, while median income per capital does not. This order is similar to that for the models of the AR index - except that revenue has a higher coefficient than size factor score in AE index models. However, median income per capita is not significant to all the models or cannot explain any association with the disclosures. $^{92}$ Note that Model $\mathrm{C}$ and Model E incur violation of a non-normal distribution of errors, as its Shapiro-Wilk test of normality reports a significant level at .032 and $.047(\mathrm{p}<.05)$.

When comparing the results of Table 7.3 and Table 7.4, the adjusted $\mathrm{R}^{2}$ for all models of the AE index are about half those for models of the AR index. This suggests that the independent variables cannot explain as much about the $\mathrm{AE}$ index as for the AR index. In particular, size variables (number of staff, revenue, total assets, population) can explain the disclosures to a certain degree for the AR index but to a lesser degree for the AE index. No particular proxy for size stands out.

The significant positive relationship between population and the extent of wastewater disclosures indicates that a larger size of constituents can have an impact on more wastewater disclosures. It is possible that a larger population can form coalitions of stronger interest groups to demand more wastewater disclosures from the local authority. The result is similar to Baber (1983), Ingram and DeJong (1987), and Christiaens (1999). However, it contradicts findings of Ingram (1984), Robins and Austin (1986), and Evan and Patton, (1987).

\footnotetext{
${ }^{92}$ Although not statistically significant, the coefficients of median income have negative signs, indicating that a possible inverse relationship exists between the extent of SSPs and constituency sophistication.
} 
Because number of staff proxies both staff availability and political visibility, the positive relationship between number of staff and the extent of wastewater disclosures indicates that the more staff and political visibility an authority has, the more wastewater disclosures an authority would make. It is possible that more staff increases the capability of local authorities to report on their wastewater services. It can also reflect that a local authority is subject to more political costs from external oversight bodies and would therefore provide more comprehensive explanation about wastewater services to signal a fair performance. While this result contradicts Boyne and Law (1991), who did not find a significant relationship between staff availability and the extent of disclosures, it is consistent with Christiaens (1999). Lim and McKinnon (1993) found a significant positive relationship between political visibility (proxied by number of staff) and disclosures.

The positive relationships between revenue and total assets with the extent of wastewater disclosures indicate that the greater the financial resources and political visibility, the more wastewater disclosures local authorities will make. Similar to number of staff, the more financial resources an authority has, the more capability the authority has to provide comprehensive disclosures about wastewater services. It may also mean the local authority is subject to more political costs, from pollution to the wider environment, and would therefore tend to report wastewater disclosure to a greater extent, so as to signal a fair performance. These results are consistent with Lim and McKinnon (1993) who found that the public-sector entity with greater revenue and assets is more politically visible and reports more quality information. These results are also 
consistent with Bozzolan, et al. (2006), Buzby (1975), Cooke (1989) and Singhvi and Desai (1971), who found that companies in the private-sector with larger financial resources would provide more disclosures.

The insignificant relationship found between median income and wastewater disclosures could imply that the sophistication of constituents does not influence the disclosures. It is possible that greater sophistication of constituents may not be associated with the necessary aggression to demand more wastewater information. However, this may be due to the small sample size and/or there might be a better measure of constituency sophistication. The result contradicts Ingram (1984) and Robbins and Austin (1986).

It can be seen that the results of multiple regression found in this study and other studies are not consistent. Laswad, et al. (2005) argued that the nature of the public-sector is very diverse across countries. In other words, different jurisdictions have different local government objectives, structures, and regulatory environments, and the results of one jurisdiction may not be applicable to others.

\subsection{Summary}

Both indices (authoritative requirements and accountability expectations) employed to measure the extent of performance disclosures were found to be consistently associated with the size variables (number of staff, revenue, total assets, and population). The size variables (number of staff, revenue, total assets, population) are significantly and positively associated to a limited degree with the $\mathrm{AR}$ index, but to a lesser degree with the AE index. 
Overall, the results imply that larger local authorities tend to provide more extensive disclosures regarding wastewater services, and thus constituents in larger authorities are more likely to have more confidence in the disclosures than those based in smaller authorities. This suggests that demand from the public for wastewater disclosures, local authorities' capability to gather wastewater information, and local authorities' awareness of political costs arising from the operation of wastewater services can provide incentives for local authorities to disclose comprehensive information. 


\section{Chapter 8: Conclusions}

\subsection{Introduction}

This chapter provides conclusions of the study. Section 8.2 provides an overview of the objectives of the study. The major findings are summarised in section 8.3. The implications of the study are discussed in section 8.4. Sections 8.5 and 8.6 discuss limitations of the study and some opportunities for future research.

\subsection{Objectives of the study}

The provision of statements of service performance (SSPs) by local government in New Zealand is a product of the economic reforms carried out in the late 1980s. A statement of service performance is regarded as an important document of New Zealand local government reporting. It is statutorily required by the Local Government Act 2002 and complemented by accounting guidance provided by the New Zealand Institute of Chartered Accountants (NZICA), with the objective of strengthening accountability obligations (Local Government Act 2002, s. 98; NZICA, 2002).

In spite of twenty years' experience in preparing statements of service performance, the Office of the Auditor-General (OAG) (2008) criticised that the quality of SSPs prepared by local authorities (and other public-sector entities) was poor. A fundamental problem of statements of service performance reporting is the lack of comprehensive authoritative requirements on their preparation and presentation (Office of the Auditor-General, 2008). Arguably, the present authoritative requirements have been written to cater for the needs of large, profit- 
oriented entities in the private-sector rather for the public-sector's specific needs for performance reporting and pitched at a higher or more conceptual level than is typically required for financial reporting standards (Office of the Auditor-General, 2008, Webster, 2007). This may be due to the fact that the current authoritative requirements, developed in early 1990s, have been influenced by the economic framework highlighting the decision-usefulness purpose of private-sector reporting, which is not suitable for public-sector reporting (Mack, 2003; Parker \& Gould, 1999).

Pallot (1992) points out that accountability is the preferred purpose for publicsector reporting since the nature of the relationship between providers and users of government is non-voluntary. Past theoretical literature has attempted to define the possible components of accountability that would be suitable for public-sector entities to adequately discharge their accountability. Among them, Stewart (1984) has developed accountability bases, which provide a platform for understanding accountability expectations and, hence desirable characteristics of any accountability documents provided by public-sector entities for the public. It is possible that accountability documents pertaining to these accountability expectations will enable the public-sector entities to adequately discharge their accountability.

New Zealand local government is the important second tier of the New Zealand government sector. Among a wide range of community services provided by New Zealand local authorities, wastewater services represent one of the most crucial services. New Zealand constituents could be expected to be concerned not 
only about the performance of wastewater services provided by their local authorities, but also with the disclosures about that performance. However, the research on SSP wastewater disclosures by New Zealand local authorities is limited (Smith \& Coy, 2000). Given the criticism on the usefulness of authoritative requirements for SSP reporting and the recognition of accountability expectations in the literature, the first two objectives of this study are to examine the consistency of SSP disclosures, regarding wastewater services provided by New Zealand local authorities, with the existing authoritative requirements, and the accountability expectations, using the disclosure index as a measurement tool. To understand possible explanations for the cross-sectional differences on the extent of disclosures, according to the authoritative requirements and accountability expectations, the third objective of this study is to examine the influential factors of the disclosures, using multiple regression analysis.

\subsection{Summary of findings}

In addressing the first objective, the study applied a disclosure index based on the authoritative requirements (AR). The AR index score is relatively low with the mean score of 33.33 percent. The highest score is 55 percent while the lowest score is 12 percent. The distribution of the scores is not normally distributed. Most scores are clustered between 30 - 40 percent and unevenly distributed to both ends.

This finding indicates that local authority disclose information about wastewater services in a manner which does not correspond very well with the authoritative requirements. In other words, the authoritative requirements may not provide a 
suitable framework for evaluating the wastewater disclosures. This therefore raises a concern whether the authoritative requirements are a suitable framework for public-sector SSP reporting.

In particular, comparability items for non-financial information are very poorly reported. Past quantity, quality, location, and time were scored 0.93, 14.13, 0.0, 1.83 percent respectively. Target quantity, location, and time - scoring 1.37, 8.7, 27.37 percent respectively. On the contrary, comparability items of financial dimensions (costs) are well reported on both their past and target terms.

This finding supports Office of the Auditor-General's (2008) criticisms of the New Zealand Equivalents to International Financial Reporting Standards particularly NZ Framework - for being focused on private-sector reporting and the private-sector reporting emphasises on financial statements. This also supports the view that accounting guidance highlighting the decision-usefulness purpose is not suitable for public-sector reporting (Mack, 2003; Parker \& Gould, 1999). It suggests that the current authoritative requirements are not suitable for the preparation of SSP reporting.

The results also show that item scores for each dimension of wastewater vary widely. Items relating to cost and quality are highly reported while of those to location, time, and quantity are not. The total cost of wastewater is the most disclosed items at 94.5 percent, followed by the disclosure item of standard to be met at 93.2 percent. Location of wastewater treatment is disclosed at 71.2 percent, time response to incidents at 59.7 percent, and quantity of wastewater treatment at 32.9 percent. 
This indicates that the traditional focus of financial information still prevails in spite of the requirement for output's dimension reporting in NZ IAS 1 and TPA-9. Further, local authorities may have some difficulty expressing some non-financial output's dimensions to be reported than financial dimension (cost). It is possible that the NZ IAS 1 and TPA-9 do not provide enough specific guidance to report about these non-financial output dimensions. This seems to support Webster's (2007) conclusion that the authoritative requirements for SSPs are pitched at a higher or more conceptual level than financial reporting standards. In other words, the current NZ IAS 1 and TPA-9 are not yet helpful enough in guiding local authorities to report on non-financial output's dimensions. The OAG (2010) has provided some guidance through their discussion paper - Local Government Examples of Better practice in Setting Local Authorities' Performance Measures - which specifically identifies performance measures for different services.

While cost items are often reported, the explanation for its significant variance is scant. In spite of the fact that some authorities incur significant variances for cost of wastewater services, only about 30 percent of them provide explanation of significant variance of cost. The majority of local authorities are not providing an explanation for the significant variance although it is required in Schedule 10, Part 3, (15(e)) of the Local Government Act 2002.

This finding identifies the existence of non-compliance with the statutory requirement for SSP reporting, which was not addressed in the audit report. This raises the concern not only on the local authorities' reporting but also the audit 
report in providing insightful understanding on the local authority's reporting compliance with all statutory reporting requirements.

In addressing the second objective, the study created an index based on the accountability literature. This index was found to provide a useful means of comparing the extent of disclosures made by local authorities. Using AE index, the average score of the index is moderately high -64.55 percent. The highest is 93 percent while the lowest is 13 percent. The dispersion of the scores are not normally distributed - clustered between $63-67$ and skewed to the left percent. Although there is a wide range from the lowest to the highest, the majority of disclosures have a relatively high level of correspondence with the accountability expectations.

The finding identifies that local authorities seem to be able to disclose performance information in a manner which is suitable for evaluating the performance in accordance with accountability expectations. This provides an indication that accountability expectations derived from the accountability literature, can afford a suitable framework for SSP reporting.

The finding supports the work in progress of the International Public Sector Accounting Standards Board (IPSASB) in issuing Conceptual Framework for General Purpose Financial Reporting by Public Sector Entities (which the Accounting Standards Review Board intends to adopt). Given the framework's focus on public-sector entities and the inclusion of an accountability objective, the new framework might be expected to recognise the complexities of public-sector environment and accountability needs. 
This study finds that that the four accountability expectations are not equally addressed. Probity and legality accountability were more concentrated than process/efficiency, performance/programmeleffectiveness accountability. The average scores of probity and legality accountability are 91.4 percent and 91.1 percent while those of process/efficiency, performance/programme/effectiveness accountability are 50.7 percent and 46.2 percent.

The result indicates that traditional types of accountability (probity and legality) is better reported than the newly added types of accountability (process/efficiency, performance/programme/effectiveness). Given that all four accountability expectations are important for public-sector entities to adequately discharge their accountability to the public (Jackson, 1982; Taylor \& Rosair, 2000), the failure to communicate any of them would be seen to undermine accountability. Although on average local authorities provided disclosures consistent with the accountability expectations, the components of process/efficiency, performance/programme/effectiveness accountability were not well applied. This implies that accountability of local councils to the public is not yet adequately discharged, and hence the reform principle for greater accountability has not yet been widely applied.

In essence, the four lowest-scored authorities for both indices are the same. They are Papakura DC, Manukau CC, Auckland CC, and Hurunui DC of which their $\mathrm{AR}$ and $\mathrm{AE}$ index scores range between $12-18$ percent, and $13-33$ percent.

These four authorities all outsource their wastewater services. It might be expected that disclosures for theses authorities are especially important to enable 
constituents to assess the performance of the agent. It is also possible that such outsourcing reduces the capacity of those authorities to control, and access the necessary information in order to report on their wastewater performance although it is required by the Local Government Act 2002 (s. 36) for outsourcing councils to remain in control of the outsourced water related operation. This highlights the weakness of the outsourcing local authorities and, hence their reporting on the outsourced operations.

In addressing the third objective, the regression analysis shows that size variables (number of staff, revenue, total assets, and population) are significantly and positively associated with the $\mathrm{AR}$ index and, to a lesser degree, with the $\mathrm{AE}$ index. No particular proxy for size dominates. The coefficients of size variables of AR index models varies between $0.043-0.068$ while those of $\mathrm{AE}$ index models fluctuate between $0.06-0.067$. However, there is no evidence that the median income per capita is significantly associated with the indices.

This result indicates that larger local authorities tend to provide more comprehensive disclosures on wastewater services, and thus their constituents are likely to have more confidence in the disclosures than those in smaller authorities. The results support the conclusion that size of constituents, staff availability, financial resource availability, and political visibility of a local authority can influence the manner in which the local authority chooses to disclose information in their SSPs. Although sophistication of the constituency, proxied by median income, does not provide any significant relationship with the disclosures, this may be due to the inappropriate proxy (median income per capita) used or the 
small sample size. In essence the association supports three possible incentives the demand from the public, local authorities' awareness of political costs, and local authorities' capability to prepare the report.

Overall the findings of the study's objectives indicate that the authoritative requirements are not a suitable framework for SSP reporting but the accountability expectations are. The study supports the current development of more specific accounting guidance by the OAG (2010) and the International Public Sector Accounting Standards Board (2010) which seems to move towards direction addressing the property of accountability expectations. Additionally, the study highlights the local authorities' non-compliance with the statutory requirement and the absence of audit report comments on such non-compliance. There are also concerns raised on the control of the outsourcing local authorities over their outsourced operations, and the reporting of smaller local authorities to provide more comprehensive disclosures on their service performance.

\subsection{Implications of the study}

The findings of this study provide three immediate implications for the improvement of the SSPs provided by local authorities in New Zealand. The first implication deals with the development of accounting guidance for SSP reporting, the second implication concerns the detail of the audit report on SSP reporting, and the third implication challenges the reporting improvement of some special local authorities.

The current development of accounting guidance by the OAG (2010) and the International Public Sector Accounting Standards Board (2010) is moving 
forward in a positive direction where there has been virtually no development for 20 years. The authoritative requirements relating to SSP reporting within the Local Government Act 2002, NZ Framework, NZ IAS 1, and TPA-9 have not been significantly changed since their first development. From the study, it has been identified that, authoritative requirements remain at a high conceptual level with financial-focus and are not helpful for local authorities to report on their SSPs. The study supports the current improvement of SSP reporting guidance and suggests that accountability expectations provide a model suitable for the SSP guidance which standard-setters may consider.

According to the study results, local authorities could improve on their reporting about process/efficiency and performance/grogramme/effectiveness accountability, of which the latter is reflected in wastewater performance measure examples addressed in the OAG's (2010) discussion paper - Local Government Examples of Better practice in Setting Local Authorities' Performance Measures. As this paper focus on 2012-22 LTCCP, it is possible that it could have an impact on local authorities' SSP disclosures for the 2012 forward. However, process/efficiency accountability should also be emphasised. It is suggestive that the office of the Auditor-General would consider including performance measures relating to process/efficiency (for example, efficiency ratio) in their discussion paper.

Given its specific accountability objective of financial reporting for public-sector entities, the Conceptual Framework for General Purpose Financial Reporting by Public Sector Entities (International Public Sector Accounting Standards Board, 
2010), it is expected this will encourage the public-sector entities to pay more attention on their reporting particularly on their non-financial reports which are an important tool for their discharge of accountability. However, in order to ensure that all of the components of the accountability expectations are incorporated in the accountability information, it is suggested that the standard setter may consider including further details of different components of accountability expectations in the objective. It is possible that accounting guidance of SSPs that is more specific at practical level would provide better direction for public-sector entities in their preparation of the statements.

The lack of any comment in any of the audit report of the local authority regarding non-compliance with Schedule 10, Part 3 (15(e) of the Local Government Act 2002 suggests that the OAG needs to pay greater attention in this area. The increased attention by the OAG may increase incentives for local authorities to report more comprehensively on their SSP reporting.

The relatively low extent of performance disclosures made in the SSPs of outsourcing local authorities might suggest to regulators (the Minister of Local Government and the Minister for the Environment) that they should ensure that disclosures are adequate to report comprehensively about the operation. Further, given the tendency of smaller authorities to provide less comprehensive SSPs, this provides suggestions to a regulator (the Ministry of Local Government) to consider ways to encourage the authorities to provide more comprehensive SSPs. The regulator may consider (i) the imposition of tighter regulation to smaller authorities so as to increase their awareness of political cost, and/or (ii) the 
provision of education for smaller authorities in preparing SSP reporting. However, without comprehensive accounting guidance for SSP reporting to facilitate the education provided, the local authorities' capability to prepare the reports may not yet be as effective.

In sum, the whole environment of SSP reporting of New Zealand local authorities has potentially moved to a positive direction from its first introduction to the time of the study. However, it appears that there is still a need for improvement of SSP by local authorities, which requires collaboration from several parties. This study provides suggestions useful to standard-setters about the ways to improve SSP reporting guidance, to the OAG for their comments in the audit report regarding non-compliance with the Schedule 10, Part 3 (15(e)) of the Local Government Act 2002, and to a regulator for increased attention on the SSP reporting of outsourcing and smaller local authorities. By doing so, it is expected that New Zealand local authorities may lead the world in providing comprehensive SSPs, which enable them to adequately discharge their accountability and, hence in reaching a reform principle for greater accountability.

\subsection{Limitations of the study}

This study has provided an empirical understanding of SSP reporting by New Zealand local authorities as well as the factors that might influence the reports. Moreover, it has identified the inappropriateness of current authoritative requirements for SSP reporting and the usefulness of accountability expectations that have been derived from literature. However, in any research study some limitations are always involved. This study has two limitations. 
The first limitation concerns the study's focus on wastewater disclosures, which limits the ability to generalise from the results to disclosures of other services. However, wastewater services are considered a critical service of local authorities on which disclosures are commonly reported by all 73 New Zealand local authorities. Therefore, focusing on wastewater disclosures has enabled the sample size to be maximised.

The second limitation lies in the inevitable subjectivity of index construction (Marston \& Shrives, 1991). However, this study uses unweighted items and dichotomous scoring which possibly minimises the subjectivity of the index.

\subsection{Future research}

The study reports on local authorities' disclosures in the period that little guidance was provided, which can provide a base for future study on the impact of the new accounting guidance. The Office of the Auditor-General's (2010) discussion paper and the International Public Sector Accounting Standards Board's (2010) exposure draft could have an impact on local authorities' SSP disclosures in the future. Future research could investigate its impact on the future SSPs by comparing findings with this study. Results may provide more understanding of a way in which SSPs can be improved.

The AE index, developed from literature, proved a useful tool for evaluating accountability documents. Future research may use this method to investigate SSP disclosures of other core activities (such as roading, water supply, libraries, and building control) of New Zealand local authorities. This would enable an extension of the database and generalisability of the results of the study. 
Given the relatively low adjusted $\mathrm{R}^{2}$, it is possible that other independent variables have not been included in the regression model. This provides an opportunity for future research to investigate other variables that are appropriate to proxy the influential factors (for example, sophistication of constituents, and political competition). This may provide more understanding of the factors that influence the disclosures.

While this study has provided insights into the extent of performance disclosures made by local authorities, it has not directly measured the quality of those disclosures. Future research might directly address the usefulness of disclosures for the discharge of accountability by making reference to the needs of the constituency. 


\section{References:}

Accounting Standards Review Board. (2011). Retrieved May, 2011, from http://www.asrb.co.nz/Site/Standards_Approval/Default.aspx

Admiraal, M., Nivra, R., Turksema, R., \& Netherlands Court of Audit. (2009). Reporting on nonfinancial information. International Journal of Government Auditing, 15-20.

Alves, J., Dunmore, P., \& Dunstan, K. (2005) Measuring service performance reporting quality by New Zealand universities using an information accessibility index. Working paper no. 29 (pp. 1-23). Wellington: Centre for Accounting, Governance and Taxation Research, School of Accounting and Commercial Law, Victoria University of Wellington.

Australian Accounting Standards Board. (2008). AASB Public Sector Policy Paper (as at February 2008). www.aasb.govt.au/Archive/Publications.aspx

Australian Accounting Standards Board. (2010). Report on staff research into domestic and international requirements and practices relating to service performance reporting. Retrieved September, 2010: http://www.aasb.gov.au/admin/file/content102/c3/Paper_2_(as_at_Mar_20 $\underline{10) . p d f}$

Baber, W. R. (1983). Towards understanding the role of auditing in thepublic sector. Journal of Accounting and Economics, 5(3), 213-227.

Baber, W. R., \& Sen, P. K. (1984). The role of generally accepted reporting methods in the public sector: An empirical test. Journal of Accounting and Public Policy, 3(2), 91-106.

Bale, M., \& Dale, T. (1998). Public sector reform in New Zealand and its relevance to developing countries. The World Bank Research Observer, 13(1), 103-121.

Banks, W., Fisher, J., \& Nelson, M. (1997). University accountability in England, Wales, and Northern Ireland: 1992-1994. Journal of International Accounting Auditing \& Taxation, 6(2), 211-226.

Banks, W., \& Nelson, M. (1994). Financial disclosures by Ontario universities: 1988-1993. Journal of International Accounting Auditing \& Taxation, 3(2), 287-305.

Barton, A. (1999). Public and private sector accounting - The non-identical twins. Australian Accounting Review, 9(2), 22-31.

Beatie, V., McInnes, B., \& Fearnley, S. (2004). A methodology for analysing and evaluating narratives in annual reports: a comprehensive descriptive profile and metrics for disclosure quality attributes. Accounting forum, 28(3), 205-236.

Boyne, G., Gould-Williams, J., Law, J., \& Richard, W. (2002). Plans, performance information and accountability: The case of best value. Public Administration, 80(4), 691-710. 
Boyne, G., \& Law, J. (1991). Accountability and local authority annual reports: The case of Welsh District Councils. Financial Accountability \& Management, 7(3), 179-195.

Bozzolan, S., O'Regan, P., \& Ricceri, F. (2006). Intellectual capital disclosure (ICD); A comparison of Italy and the UK. Journal of Human Resource Costing \& Accounting, 10(2), 92-113.

Bush, G. (1995). Local government \& politics in New Zealand. Auckland: Auckland University Press.

Buzby, S. (1975). Company size, listed versus unlisted stocks, and the extent of financial disclosure. Journal of Accounting Research, 13(1), p. 16-37.

Christiaens, J. (1999). Financial accounting reform in Flemish municipalities: An empirical investigation. Financial Accountability and Management 15(1), 21-40.

Clarkson, P., Li, Y., Richardson, G., \& Vasvari, F. (2008). Revisiting the relation between environmental performance and environmental disclosure: An empirical analysis. Accounting, Organizations and Society, 33(4/5), 303327.

Cooke, T. E. (1989). Disclosure in the corporate annual reports of Swedish companies. Accounting and Business Research, 19(74), 113-124.

Corbett, D. (1985). The administrative organization and performance of the states. Melbourne: Longman Cheshire.

Corbett, D. (1996). Australian public sector management. Sydney: Allen \& Unwin.

Coy, D., \& Dixon, K. (2004). The public accountability index: Crafting a parametric disclosure index for annual reports. The British Accounting Review, 36(1), 79-106.

Coy, D., Dixon, K., Buchanan, J., \& Tower, G. (1997). Recipients of public sector annual reports: Theory and an empirical study compared. The British Accounting Review, 29(2), 103-127.

Coy, D., Fischer, M., \& Gordon, T. (2001). Public accountability: A new paradigm for college and university annual reports. Critical Perspectives on Accounting, 12, 1-31.

Coy, D., \& Pratt, M. (1998). An insight into accountability and politics in universities: A case study. Accounting, Auditing \& Accountability, 11(5), 540-561.

Coy, D., Tower, G., \& Dixon, K. (1994). Public sector reform in New Zealand: The progress of tertiary education annual reports, 1990-1992. Financial Accountability \& Management, 10(3), 253-261.

Craig, R., \& Diga, J. (1998). Corporate accounting disclosure in ASEAN. Journal of International Financial Management \& Accounting, 9(3), 246-274.

Day, P., \& Klein, R. (1987). Accountabilities: Five public services. London: Tavistock. 
Department of Conservation. (2004). About Department of Conservation. Retrieved August, 2004, from http://www.doc.govt.nz/AboutDOC/index.asp.

Dixon, J., Kouzmin, A., \& Korac-Kakabadse, N. (1998). Managerialism something old, something borrowed, little new economic prescription versus effective organizational change in public agencies. The International Journal of Public Sector Management, 11(2/3), 164-187.

Dixon, K., Coy, D., \& Tower, G. (1991). External reporting by New Zealand universities 1985 -1989: Improving accountability. Financial Accountability \& Management, 7(3), 159 -178.

Evan, J. H., \& Patton, J. M. (1987). Signaling and monitoring in public-sector accounting. Journal of Accounting Research, 25(suppl), 130-158.

Fandt, P., \& Ferris, G. (1990). The management of information and impressions: When employees behave opportunistically. Organisational behavior and human decision processes, 45, 140-158.

Field, A. (2005). Discovering statistics using SPSS (2 nd ed.). London: Sage Publications.

Fisher, J., Nelson, M., \& Banks, W. (1996). Accountability in Scottish universities. Certified Accountant May.

Frink, D., \& Klimoski, R. (2004). Advancing accountability theory and practice: Introduction to the human resource management review special edition. Human Resource Management Review, 14, 1-17.

Garrison, R., Noreen, E., \& Brewer, P. (2006). Managerial Accounting (11 ed.). New York: McGraw-Hill Irwin.

Garson, D. (2010). Testing of assumptions. Retrieved February, 2010, from http://faculty.chass.ncsu.edu/garson/PA765/assumpt.htm

Giroux, G. (1989). Political interests and governmental accounting disclosure. Journal of Accounting and Public Policy, 8(3), 199-217.

Glenn, J., \& Murphy, M. (1996). Public management failing accountabilities and failing performance review. International Journal of Public Sector Management, 9(5/6), 125-137.

Glynn, J., \& Perkins, D. (1997). Control and accountability in the NHS market: a practical proposition of logical impossibility? International Journal of Public Sector Management, 10(1/2), 62-75.

Gray, A. (1984). Codes of accountability and the presentation of an account: Towards a micro-administrative theory of public accountability. Public administration bulletin, 46, 2-14.

Gray, A., \& Jenkins, B. (1993). Codes of accountability in the new public sector. Accounting , Auditing \& Accountability Journal, 6(3), 52-67.

Gray, R. (1983). Accounting, financial reporting and not-for-profit organisations. AUTA Review, 15(1), 2-23. 
Gray, R., Owen, D., \& Adams, C. (1996). Accounting and accountability. London: Prentice Hall.

Guthrie, J. (1993). Australian public business enterprises: Analysis of changing accounting, auditing and accountability regimes. Financial Accountability \& Management, 9(2), 101-114.

Guthrie, J., \& Parker, L. (1998). 'Managerialism' and 'Marketisation' in financial management change in Australia. In O. Olson, J. Guthrie \& C. Humphery (Eds.), Global Warning: Debating International Developments in New Public Financial Management. Oslo: Cappelen Akademisk Forlag.

Health Act 1956.

Herawaty, M., \& Hoque, Z. (2007). Disclosure in the annual reports of Australian government departments. Journal of Accounting \& Organizational change, 3(2), 147-168.

Hughes, S. B., Anderson, A., \& Golden, S. (2001). Corporate environmental disclosures: are they useful in determining environmental performance? Journal of Accounting and Public Policy, 20, 217-240.

Humphery, C., Miller, P., \& Smith, H. (1998). Financial management in the UK public sector: Ambiguities, paradoxes and limits. In O. Olson, Guthrie, J., and Humphery, C. (Ed.), Global Warning: Debating International Developments in New Public Financial Management. Oslo: Cappelen Akademisk Forlag.

Hyndman, N., \& Anderson, R. (1995). The use of performance information in external reporting: An empirical study of UK executive agencies. Financial Accountability \& Management, 11(1), 1-17.

Hyndman, N., \& Anderson, R. (1998). Performance information, accountability and executive agencies. Public Money \& Management, 18(3), 23-30.

Ijiri, Y. (1975). Theory of accounting measurement. Sarasota, Florida: American Accounting Association.

Ingram, R. W. (1984). Economic incentives and the choice of state government accounting practices. Journal of Accounting Research, 22(1), 126-144.

Ingram, R. W., \& DeJong, D. V. (1987). The effect of regulation on local government disclosure practices. Journal of Accounting and Public Policy, 6(4), 245-270.

International Public Sector Accounting Standard Board. (2010). Conceptual Framework Exposure Draft 1. Toronto.

Ives, M. (1987). Accountability and government financial reporting. Journal of Accountancy, October 164(4), 130-134.

Jackson, P. M. (1982). Accountability, and control of bureaucracy. In P. M. Jackson (Ed.), The political economy of bureaucracy (pp. 212-229). Southampton: Philip Allan. 
Kloot, L. (2009). Performance measurement and accountability in an Australian fire service. International Journal of Public Sector Management, 22(2), 128-145.

Kloot, L., \& Martin, J. (2001). Local government accountability: Explaining differences. Accounting, Accountability \& Performance, 7(1), 51-72.

Laswad, F., Fisher, R., \& Oyelere, P. (2005). Determinants of voluntary internet financial reporting by local government authorities. Journal of Accounting and Public Policy, 24(2), 101-121.

Laughlin, R. (1990). A model of financial accountability and the Church of England. Financial Accountability \& Management, 6(2), 93-114.

Lee, J. (2006). Performance reporting by Australian government trading enterprises: An empirical study 1998-2002. Australian Accounting Review, 16(2), 34-48.

Lee, J. (2008). Preparing performance information in the public sector: An Australian perspective. Financial Accountability \& Management, 24(2), 117-149.

Lim, S., \& McKinnon, J. (1993). Voluntary disclosure by NZW statutory authorities: The influence of political visibility. Journal of Accounting and Public policy, 12(3), 189-215.

Local Government Act 1974.

Local Government Act 2002.

Lonti, Z., \& Gregory, R. (2007). Accountability or countability? Performance measurement in the New Zealand public service, 1992-2002. Australian Journal of Public Administration, 66(4), 468-484.

Mack, J. (2003). An investigation of the information requirements of users of Australian public sector financial reports. Queensland University of Technology.

Mack, J., \& Ryan, C. (2006). Reflection of the theoretical underpinnings of the general-purpose financial reports of Australian government departments. Accounting, Auditing \& Accountability Journal, 19(4), 592-612.

Marston, C., \& Shrives, P. (1991). The use of disclosure indices in accounting research: A review article. British Accounting Review, 23, 195-210.

McCulloch, B., \& Ball, I. (1992). Accounting in the context of public sector management reform. Financial Accountability \& Management, 8(1), 7-12.

McKinlay, P. (1998). Local government reform : What was ordered and what has been delivered.

McLintock, A. H. (1966). An encyclopedia of New Zealand (Vol. 1.). Wellington: R E Owen: Government Printer.

Milazzo, C. (1992). Annual reports: Impediments to their effective use as instruments of accountability. Australian Journal of Public Administration, 51(1), 35-41. 
Ministry for the Environment. (2007a). Laws and treaties. Retrieved April, 2007, from http://www.mfe.govt.nz/laws/

Ministry for the Environment. (2007b). Waste publications. Retrieved May, 2007, from http://www.mfe.govt.nz/publications/waste/\#consult

Ministry for the Environment. (2009). Resource Management Act: Two yearly survey of local authorities 2004/2008. from http://www.mfe.govt.nz/publications/rma/annual-survey/2007-2008/rmaresource-consents.pdf

Ministry for the Environment. (2010a). Proposed national environmental standard for on-site wastewater systems. Retrieved September, 2010, from http://www.mfe.govt.nz/laws/standards/wastewater-systemsstandards.html

Ministry for the Environment. (2010b). Wastewater. Retrieved September, 2010, from http://www.mfe.govt.nz/issues/waste/wastewater/

Moore, B. (1985). Administrative chronicle: New South Wales. Australian Journal of Public Administration, 44(2), 137-145.

Mulgan, R. (1997). The processes of public accountability. Australian Journal of Public Administration, 51(1), 35-41.

Mulgan, R. (2003). Holding Power to Account: Accountability in Modern Democracies (1 ed.). United Kingdom: Palgrave Macmillan.

Munro, R. J. B., \& Hatherly, D. J. (1993). Accountability and the new commercial agenda. Critical perspectives on Accounting, 4, 369-395.

Nau, B. (2005). Testing the assumptions of linear regression. Decision 411 forecasting Retrieved May, 2010, from http://www.duke.edu/ rnau/testing.htm

Neale, A., \& Anderson, B. (2000). Performance reporting for accountability purposes - Lessons, issues, future. Paper presented at the International Public Management Workshop.

Neale, A., \& Pallot, J. (2001). Frontiers of non-financial performance reporting in New Zealand. Australian Accounting Review, 11(3), 27-34.

Nelson, M., Tower, G., Banks, W., \& Fisher, J. (1997). University accountability in Australia 1993-1995. Accountability and Performance, 3(2), 1-19.

Normanton, L. (1971). Public accountability and audit: a reconnaissance. In B. S. a. D. Hague (Ed.), The dilemma of accountability in modern government: Independence versus control. London: St. Martin's Press.

NZICA. (1993). Statement of Concepts for General Purpose Financial Reporting. Wellington: New Zealand Institute of Chartered Accountants.

NZICA. (1994). Financial Reporting Standard No. 2: Presentation of Financial Reports Wellington: New Zealand Institute of Chartered Accountants.

NZICA. (2002). Technical Practice Aid No.9 Service Performance Reporting. Wellington: New Zealand Institute of Chartered Accountants. 
NZICA. (2004). New Zealand Equivalent to International Accounting Standard 1: Presentation of Financial Statements. Wellington: New Zealand Institute of Chartered Accountants.

NZICA. (2005). New Zealand Equivalent to the IASB Framework for the Preparation and Presentation of Financial Statements. Wellington: New Zealand Institute of Chartered Accountants.

NZICA. (2007a). Financial reporting standards board developments summary as at 19 December 2005. Wellington: New Zealand Institute of Chartered Accountants.

NZICA. (2007b). Technical Practice Aid No.9 Service Performance Reporting. Wellington: New Zealand Institute of Chartered Accountants.

NZICA. (2010). New Zealand Equivalent to the IASB Conceptual Framework for Financial Reporting 2010. Wellington: New Zealand Institute of Chartered Accountants.

Office of the Auditor-General. (1978). Financial management and control in administrative government departments. Wellington.

Office of the Auditor-General. (2007a). Local government: Results of the 2005/2006 audits. Wellington: Office of the Auditor-General.

Office of the Auditor-General. (2007b). Role and functions of the AuditorGeneral. $\quad$ Retrieved 11 September, 2007, from http://www.oag.govt.nz/about-us/the-controller-and-auditor-general

Office of the Auditor-General. (2008). The Auditor-General's observations on the quality of performance reporting. Wellington: Office of the AuditorGeneral.

Office of the Auditor-General. (2010). Local government: Examples of better practice in setting local authorities' performance measures. Wellington.

Office of the Ombudsmen. (2011). Retrieved April, 2011, from http://www.ombudsmen.parliament.nz/

Olson, O., Guthrie, J., \& Humphery, C. (1998). Global warning: Debating internaitonal developments in new public financial management. Oslo: Cappelen Akademisk Forlag.

Oxford English Dictionary. (2006). Oxford English Dictionary Online. Retrieved March, 2006, from http://helicon.vuw.ac.nz:2126/

Pallot, J. (1992). Elements of theoretical framework for public sector accounting. Accounting Auditing \& Accountability Journal, 5(1), 38-59.

Pallot, J. (1998). The New Zealand revolution. In O. Olson, J. Guthrie \& C. Humphery (Eds.), Global warning: Debating international developments in new public financial management. Oslo: Cappelen Akademisk Forlag.

Pallot, J. (2001a). A decade in review: New Zealand's experience with resource accounting and budgeting. Financial Accountability \& Management, 17(4), 383-400. 
Pallot, J. (2001b). Local government reform in New Zealand: Options for public management as governance: University of Canterbury.

Pallot, J. (2001c). Transparency in local government: Antipodean initiatives. The European Accounting Review, 10(3), 645-660.

Palmer, K. (1993). Local government law in New Zealand (2nd ed.). Sydney: The Law Book Company Limited.

Parker, L., \& Gould, G. (1999). Changing public sector accountability: Critiquing new directions. Accounting Forum, 23(2), 109-136.

Patton, J. (1992). Accountability and governmental financial reporting. Financial Accountability \& Management, 8(3), 165-180.

Pendlebury, M., Jones, R., \& Karbhari, Y. (1994). Developments in the accountability and financial reporting practices of executive agencies. Financial Accountability \& Management, 10(1), 33-46.

Perks, R. W. (1993). Accounting and society. London Chapman \& Hall.

Pratt, G. (1982). Administrative chronicle: New South Wales. Australian Journal of Public Administration 41(3), 259-269.

Productivity Commission. (2011). Retrieved April, 2011, from http://www.pc.gov.au/

Public Finance Act 1989.

Resource Management Act 1991.

Robbins, W., \& Austin, K. (1986). Disclosure quality in governmental financial reports: An assessment of the appropriateness of a compound measure. Journal of Accounting Research, 24(2), 412-421.

Rutherford, B. (2000). The construction and presentation of performance indicators in executive agency external reports. Financial Accountability \& Management, 16(3), 225-249.

Ryan, C., Dunstan, K., \& Brown, J. (2002). The value of public sector annual reports and annual reporting awards in organisational legitimacy. Accounting, Accountability \& Performance, 8(1), 61-76.

Ryan, C., Stanley, T., \& Nelson, M. (2002). Accountability disclosures by Queensland local government councils:1997-1999. Financial Accountability \& Management, 18(3), 261-289.

Schneider, A., \& Samkin, G. (2008). Intellectual capital reporting by the New Zealand local government sector. Journal of Intellectual Capital, 9(3), 456-486.

Scott, G. (1979). Local and regional government in New Zealand: Function and finance. Sydney: George Allen and Unwin.

Scott, G. (1996). Government reform in New Zealand. Washington DC: International Monetary Fund. 
Scott, G., Ball, I., \& Dale, T. (1997). New Zealand's public sector management reform: Implications for the United States. Journal of Policy Analysis and Management, 16(3), 357-381.

Scott, G., \& Gorringe, P. (1989). Reform of the core public sector: the New Zealand experience. Australian Journal of Public Administration, 48(1), 81-91.

Simms, M., \& Singleton, G. (1993). Trade unions. In R. Smith (Ed.), Politics in Australia (2 nd. ed., pp. 285-300). Sydney: Allen \& Unwin Pty Ltd.

Sinclair, A. (1995). The chameleon of accountability: forms and discourses. Accounting Organizations and Society, 20(2/3), 219-237.

Singhvi, S., \& Desai, H. (1971). An empirical analysis of the quality of corporate disclosure. The Accounting Review, January, 129-138.

Smith, S., \& Coy, D. (2000) The quality of city council annual reports, 1996-97 \& 1997-98. Working paper no. 64 (pp. 1-41). Waikato: The University of Waikato.

Stanley, T., Jennings, N., \& Mack, J. (2008). An examination of the content of community financial reports in Queensland local government authorities. Financial Accountability \& Management, 24(4), 411-138.

State Services Commission. (2002). State services commission. Retrieved September 13, 2010, from http://www.ssc.govt.nz/display/home.asp

Statistics New Zealand. (2009a). Estimated resident population Retrieved September, 2009, from http://www.stats.govt.nz/browse_for_stats/population/estimates_and_proje ctions/subnational-pop-estimates-tables.aspx

Statistics New Zealand. (2009b). Local authority financial statistics by council. Retrieved September, 2009, from http://www.stats.govt.nz/browse_for_stats/government_finance/local_gov ernment/local-authority-financial-statistics-by-council-june-2008.aspx

Steccolini, I. (2004). Is the annual report an accountability medium? An empirical investigation into Italian local governments. Financial Accountability \& Management, 20(3), 327-351.

Stewart, J. D. (1984). The role of information in public accountability. In A. Hopwood \& C. Tomkins (Eds.), Issues in Public Sector Accounting (pp. 13-34). Oxford: Philip Allen.

Tabachnick, B., \& Fidell, L. (2007). Using multivariate statistics (5 ed.). Boston: Pearson Education, Inc.

Taranaki Regional Council. (2004). New Plymouth wastewater treatment plant, marine outfall, and sludge lagoon monitoring programme annual report 2002/2003. New Plymouth: Taranaki Regional Council.

Taylor, D., \& Pincus, K. (1999). Core concepts of accounting information. Sydney: McGraw Hill Companies, Inc 
Taylor, D., \& Rosair, M. (2000). The effects of participating parties, the public and size on government departments' accountability disclosures in annual reports. Accounting, Accountability \& Performance, 6, 77-97.

Tetlock, P. E. (1985). Accountability: The neglected social context of judgement and choice. Research in Organizational Behavior, 7, 297-332.

The Department of Internal Affairs. (2001). Reviewing the Local Government Act 1974. Wellington: Department of Internal Affairs.

The Department of Internal Affairs. (2007a). Local Government - What does it do? Retrieved August, 2007, from http://www.dia.govt.nz/pubforms.nsf/URL/LocalGovtWhatitdoes.pdf/\$file LocalGovtWhatitdoes.pdf

The Department of Internal Affairs. (2007b). Your local council: Shaping our communities together, How does local government work? Wellington.

The Department of Internal Affairs. (2009a). Councils A-Z. Retrieved September, 2009, from http://www.localcouncils.govt.nz/lgip.nsf/wpg_url/ProfilesIndex?OpenDocument

The Department of Internal Affairs. (2009b). Local government finance. Retrieved November, 2009, from http://www.localcouncils.govt.nz/lgip.nsf/wpg_url/About-LocalGovernment-Local-Government-Statistical-OverviewIndex\#LocalGovernmentIncome

The Department of Internal Affairs. (2010). Local government finance. Retrieved February, 2011, from http://www.localcouncils.govt.nz/lgip.nsf/wpg_url/About-LocalGovernment-Local-Government-Statistical-Overview$\underline{\text { Index\#LocalGovernmentIncome }}$

The Department of Internal Affairs. (2011). The department's role in local government. $\quad$ Retrieved April, 2011, from http://www.dia.govt.nz/diawebsite.nsf/wpg_URL/About-us-OurOrganisation-The-Departments-role-in-LocalGovernment?OpenDocument

The Treasury. (1996). Putting it together: An explanatory guide to the New Zealand public sector financial management system: The Treasury.

Thompson, G. (1995). Problems with service performance reporting: The case of public art galleries. Financial Accountability \& Management, 14(4), 337350 .

Thornley, A. (2007). Development indicators for local communities: The New Zealand experience. Paper presented at the Paper for the Istanbul World ForumMeasuring and Fostering the Progress of Societies. 
Tooley, S., \& Guthrie, J. (2001). Performance accountability disclosures in annual reports: An application in the New Zealand compulsory school sector. Paper presented at the Third Asian Pacific Interdisciplinary Research in Accounting, University of Adelaide: Australia.

Wallis, J., \& Dollery, B. (2000) Local government reform in New Zealand. Working paper series in economics, No. 2000-7 - May 2000 (pp. 1-32): University of New England, School of Economic Studies.

Weber, R. (1985). Basic content analysis. California: Sage Publications, Inc.

Webster, A. (2007). We need more focus on service performance reporting standards. Chartered Accountants Journal, November 2007, 34-38.

Wei, T. L., Davy, H., \& Coy, D. (2008). A disclosure index to measure the quality of annual reporting by museums in New Zealand and the UK. Journal of Applied Accounting Research, 9(1), 29-51.

Whitecombe, J. (2008). Contributions and challenges of "New Public Management": New Zealand since 1984. Policy Quarterly, 4(3), 7-13.

Whittred, G., \& Zimmer, I. (1990). A contracting cost framework for the analysis of financial accounting and reporting Financial accounting-incentive effects and economic consequences. Sydney:Holt: Rinehart and Winston.

Williams, S. (2001). Is intellectual capital performance and disclosure practice related? Journal of Intellectual Capital, Bradford: 2001. Vol. 2(3), 192203.

Wilson, V., Salter, J., \& Grierson, S. (2003). A Guide to the Local Government Act 2002. Wellington: Thomson.

Wiseman, J. (1982). An evaluation of environmental disclosures made in corporate annual reports. Accountability, Organizations and Society, 7(1), 53-63.

WorldBook. (2003). The world book encyclopedia. Chicago: World Book, Inc.

Zimmerman, J. (1997). The municipal accounting maze: An analysis of political incentives. Journal of Accounting Research, supplement, 107-144. 


\section{Appendices:}

\section{Appendix A: Local authorities' profile between 2004-2008}

\begin{tabular}{|c|c|c|c|c|c|c|c|c|}
\hline Local authorities & $\begin{array}{l}\text { Area } \\
\left(\mathbf{k m}^{2}\right)\end{array}$ & Pop & $\begin{array}{l}\text { Median } \\
\text { income }\end{array}$ & $\begin{array}{c}\text { No. of } \\
\text { staff }\end{array}$ & $\begin{array}{l}\text { Opert'g } \\
\text { revenue }\end{array}$ & $\begin{array}{l}\text { Opert'g } \\
\text { expense }\end{array}$ & Total assets & $\begin{array}{c}\text { Total } \\
\text { liabilities }\end{array}$ \\
\hline Ashburton DC & 6188.74 & 28700 & $\$ 24,400$ & 117 & 32,540 & $\$ 32,053$ & $\$ 543,124$ & $\$ 21,799$ \\
\hline Auckland CC & 668.53 & 438100 & $\$ 28,100$ & 1666 & 571,493 & $\$ 600,954$ & $\$ 9,633,026$ & $\$ 721,074$ \\
\hline Auckland RC & 16,316 & $1,414,800$ & $\$ 26,800$ & 519 & $\$ 169,374$ & $\$ 113,004$ & $\$ 1,153,166$ & $\$ 127,964$ \\
\hline Bay of Plenty RC & 21,835 & 269,900 & $\$ 22,600$ & 278 & $\$ 59,888$ & $\$ 52,362$ & $\$ 454,763$ & $\$ 81,907$ \\
\hline Buller DC & 7954.94 & 9950 & $\$ 18,000$ & 48 & 19,908 & $\$ 18,327$ & $\$ 300,365$ & $\$ 16,944$ \\
\hline Canterbury RC & 56,788 & 552,800 & $\$ 23,500$ & 529 & $\$ 104,850$ & $\$ 103,389$ & $\$ 600,508$ & $\$ 16,437$ \\
\hline Carterton DC & 1180.04 & 7360 & $\$ 22,200$ & 30 & 8,684 & $\$ 103,389$ & $\$ 138,783$ & $\$ 2,659$ \\
\hline Central Hawke's Bay DC & 3327.95 & 13300 & $\$ 23,500$ & 34 & 21,124 & $\$ 20,015$ & $\$ 674,507$ & $\$ 13,431$ \\
\hline Central Otago DC & 9957.81 & 17700 & $\$ 23,000$ & 58 & 25,984 & $\$ 27,772$ & $\$ 504,394$ & $\$ 4,630$ \\
\hline Chatham Islands CC & & 640 & $\$ 24,900$ & 4 & 4,509 & $\$ 4,038$ & $\$ 41,779$ & $\$ 1,246$ \\
\hline Christchurch CC & 1609.91 & 368900 & $\$ 23,400$ & 1559 & 399,049 & $\$ 387,866$ & $\$ 6,552,658$ & $\$ 223,408$ \\
\hline Clutha DC & 6363.14 & 17350 & $\$ 23,300$ & 68 & 32,100 & $\$ 29,009$ & $\$ 788,681$ & $\$ 5,754$ \\
\hline Dunedin CC & 3341.60 & 122900 & $\$ 19,400$ & 601 & 165,664 & $\$ 179,188$ & $\$ 2,662,121$ & $\$ 191,498$ \\
\hline Far North DC & 7323.84 & 57900 & $\$ 19,200$ & 196 & 84,135 & $\$ 98,395$ & $\$ 1,615,268$ & $\$ 108,819$ \\
\hline Franklin DC & 2187.92 & 63200 & $\$ 27,800$ & 110 & 63,827 & $\$ 61,252$ & $\$ 1,168,439$ & $\$ 74,232$ \\
\hline Gisborne DC & 8355.08 & 45900 & $\$ 20,600$ & 234 & 60,989 & $\$ 64,175$ & $\$ 1,729,782$ & $\$ 36,988$ \\
\hline Gore DC & 1251.59 & 12250 & $\$ 22,400$ & 65 & 15,194 & $\$ 14,386$ & $\$ 314,750$ & $\$ 12,636$ \\
\hline Grey DC & 3516.76 & 13650 & $\$ 21,100$ & 51 & 21,717 & $\$ 20,217$ & $\$ 312,137$ & $\$ 11,962$ \\
\hline Hamilton CC & 98.55 & 138500 & $\$ 24,000$ & 726 & 138,881 & $\$ 164,519$ & $\$ 3,181,858$ & $\$ 246,281$ \\
\hline Hastings DC & 5217.46 & 73800 & $\$ 22,600$ & 360 & 84,534 & $\$ 78,888$ & $\$ 1,302,942$ & $\$ 52,333$ \\
\hline Hauraki DC & 1187.77 & 17750 & $\$ 19,600$ & 106 & 27,326 & $\$ 29,811$ & $\$ 442,602$ & $\$ 12,561$ \\
\hline Hawkes Bay RC & 21,399 & 152,700 & $\$ 22,600$ & 179 & 33,223 & $\$ 29,755$ & $\$ 403,955$ & $\$ 13,894$ \\
\hline Horowhenua DC & 1063.63 & 30600 & $\$ 18,500$ & 58 & 26,543 & $\$ 29,986$ & $\$ 385,894$ & $\$ 24,935$ \\
\hline Hurunui DC & 8660.48 & 10850 & $\$ 23,000$ & 105 & 22,875 & $\$ 23,669$ & $\$ 275,641$ & $\$ 4,788$ \\
\hline Hutt CC & 376.59 & 101600 & $\$ 27,300$ & 303 & 106,104 & $\$ 108,803$ & $\$ 1,082,464$ & $\$ 110,297$ \\
\hline Invercargill CC & 491.32 & 51600 & $\$ 22,000$ & 260 & 63,425 & $\$ 62,173$ & $\$ 651,295$ & $\$ 54,892$ \\
\hline Kaikoura DC & 2046.47 & 3760 & $\$ 21,800$ & 26 & 7,625 & $\$ 6,741$ & $\$ 133,208$ & $\$ 6,076$ \\
\hline Kaipara DC & 3117.19 & 18600 & $\$ 20,100$ & 43 & 33,451 & $\$ 32,510$ & $\$ 442,685$ & $\$ 35,223$ \\
\hline Kapiti Coast DC & 731.31 & 48400 & $\$ 23,000$ & 190 & 45,456 & $\$ 44,490$ & $\$ 744,801$ & $\$ 78,501$ \\
\hline Kawerau DC & 21.95 & 7050 & $\$ 17,100$ & 52 & 7,131 & $\$ 7,735$ & $\$ 53,279$ & $\$ 2,090$ \\
\hline Mackenzie DC & 7439.55 & 3950 & $\$ 22,800$ & 24 & 7,961 & $\$ 8,983$ & $\$ 172,024$ & $\$ 2,564$ \\
\hline Manawatu DC & 2624.13 & 29300 & $\$ 24,200$ & 73 & 33,288 & $\$ 29,912$ & $\$ 537,765$ & $\$ 17,081$ \\
\hline Manawatu Wanganui RC & 25,306 & 229,200 & $\$ 21,600$ & 250 & 42,662 & $\$ 39,648$ & $\$ 308,292$ & $\$ 9,788$ \\
\hline Manukau CC & 682.81 & 362000 & $\$ 24,200$ & 1025 & 291,351 & $\$ 300,732$ & $\$ 6,199,042$ & $\$ 355,081$ \\
\hline Marlborough DC & 12494.05 & 44500 & $\$ 23,300$ & 180 & 75,801 & $\$ 65,562$ & $\$ 972,710$ & $\$ 15,881$ \\
\hline Masterton DC & 2298.80 & 23100 & $\$ 21,700$ & 73 & 23,301 & $\$ 25,809$ & $\$ 588,200$ & $\$ 18,529$ \\
\hline Matamata-Piako DC & 1753.96 & 31400 & $\$ 25,600$ & 150 & 32,816 & $\$ 33,288$ & $\$ 533,907$ & $\$ 30,740$ \\
\hline Napier CC & 105.60 & 56900 & $\$ 22,700$ & 364 & 81,850 & $\$ 71,816$ & $\$ 1,287,915$ & $\$ 27,366$ \\
\hline Nelson CC & 443.31 & 44700 & $\$ 23,100$ & 168 & 68,346 & $\$ 59,893$ & $\$ 1,075,812$ & $\$ 50,115$ \\
\hline New Plymouth DC & 2205.92 & 71800 & $\$ 22,800$ & 430 & 89,153 & $\$ 102,605$ & $\$ 2,188,333$ & $\$ 114,439$ \\
\hline North Shore CC & 129.77 & 223000 & $\$ 29,100$ & 720 & 236,736 & $\$ 238,640$ & $\$ 4,305,541$ & $\$ 327,641$ \\
\hline Northland RC & 30,110 & 154,700 & $\$ 20,900$ & 148 & 21,299 & $\$ 17,251$ & $\$ 132,220$ & $\$ 4,552$ \\
\hline Opotiki DC & 3090.04 & 9060 & $\$ 17,400$ & 43 & 9,513 & $\$ 8,595$ & $\$ 172,719$ & $\$ 5,988$ \\
\hline Otago RC & 38,478 & 154,700 & $\$ 21,600$ & 132 & 31,656 & $\$ 25,079$ & $\$ 435,672$ & $\$ 5,834$ \\
\hline Otorohanga DC & 2063.46 & 9220 & $\$ 24,100$ & 36 & 13,852 & $\$ 12,484$ & $\$ 201,850$ & $\$ 16,068$ \\
\hline Palmerston North CC & 335.55 & 79300 & $\$ 23,100$ & 469 & 81,851 & $\$ 93,101$ & $\$ 1,327,214$ & $\$ 174,700$ \\
\hline Papakura DC & 118.58 & 48300 & $\$ 26,500$ & 126 & 31,616 & $\$ 34,085$ & $\$ 559,085$ & $\$ 49,976$ \\
\hline
\end{tabular}




\begin{tabular}{|c|c|c|c|c|c|c|c|c|}
\hline Local authorities & $\begin{array}{l}\text { Area } \\
\left(\mathbf{k m}^{2}\right)\end{array}$ & Pop & $\begin{array}{l}\text { Median } \\
\text { income }\end{array}$ & $\begin{array}{c}\text { No. of } \\
\text { staff }\end{array}$ & $\begin{array}{l}\text { Opert'g } \\
\text { revenue }\end{array}$ & $\begin{array}{l}\text { Opert'g } \\
\text { expense }\end{array}$ & Total assets & $\begin{array}{c}\text { Total } \\
\text { liabilities }\end{array}$ \\
\hline Porirua CC & 182.42 & 51000 & $\$ 26,300$ & 280 & 52,129 & $\$ 55,234$ & $\$ 1,105,161$ & $\$ 32,156$ \\
\hline Queenstown Lakes DC & 9357.74 & 26400 & $\$ 31,000$ & 52 & 54,920 & $\$ 62,973$ & $\$ 797,302$ & $\$ 75,742$ \\
\hline Rangitikei DC & 4479.46 & 14950 & $\$ 21,700$ & 45 & 25,316 & $\$ 22,712$ & $\$ 472,149$ & $\$ 4,664$ \\
\hline Rodney DC & 2426.98 & 96400 & $\$ 26,600$ & 374 & 121,273 & $\$ 138,719$ & $\$ 1,639,596$ & $\$ 300,598$ \\
\hline Rotorua DC & 2614.88 & 68000 & $\$ 23,900$ & 455 & 87,520 & $\$ 90,820$ & $\$ 882,331$ & $\$ 110,143$ \\
\hline Ruapehu DC & 6730.39 & 13650 & $\$ 21,100$ & 63 & 27,998 & $\$ 26,289$ & $\$ 335,506$ & $\$ 32,481$ \\
\hline Selwyn DC & 6555.47 & 37500 & $\$ 28,100$ & 150 & 36,752 & $\$ 44,938$ & $\$ 836,523$ & $\$ 11,014$ \\
\hline South Taranaki DC & 3575.53 & 26700 & $\$ 24,500$ & 101 & 41,208 & $\$ 39,038$ & $\$ 723,578$ & $\$ 14,168$ \\
\hline South Waikato DC & 1816.94 & 22800 & $\$ 20,900$ & 130 & 24,375 & $\$ 23,185$ & $\$ 342,502$ & $\$ 7,368$ \\
\hline South Wairarapa DC & 2457.20 & 9190 & $\$ 24,100$ & 26 & 12,271 & $\$ 13,240$ & $\$ 348,180$ & $\$ 10,672$ \\
\hline Southland DC & 30979.19 & 29100 & $\$ 25,800$ & 152 & 53,741 & $\$ 52,617$ & $\$ 1,244,596$ & $\$ 15,157$ \\
\hline Southland RC & 55,049 & 93,000 & $\$ 23,200$ & 103 & 15,786 & $\$ 18,728$ & $\$ 70,084$ & $\$ 2,482$ \\
\hline Stratford DC & 2163.35 & 9100 & $\$ 22,400$ & 32 & 12,590 & $\$ 10,364$ & $\$ 266,748$ & $\$ 6,034$ \\
\hline Taranaki RC & 12,700 & 107,500 & $\$ 23,200$ & 109 & 16,189 & $\$ 13,590$ & $\$ 71,914$ & $\$ 3,057$ \\
\hline Tararua DC & 4360.69 & 17750 & $\$ 23,000$ & 62 & 27,819 & $\$ 25,693$ & $\$ 768,202$ & $\$ 14,750$ \\
\hline Tasman DC & 14812.64 & 46500 & $\$ 21,600$ & 150 & 67,229 & $\$ 69,591$ & $\$ 1,086,308$ & $\$ 93,543$ \\
\hline Taupo DC & 6955.11 & 33500 & $\$ 24,500$ & 288 & 68,186 & $\$ 58,115$ & $\$ 1,166,264$ & $\$ 83,721$ \\
\hline Tauranga CC & 168.27 & 110500 & $\$ 23,200$ & 365 & 119,378 & $\$ 117,188$ & $\$ 2,727,647$ & $\$ 269,120$ \\
\hline Thames-Coromandel DC & 2297.25 & 26800 & $\$ 20,300$ & 176 & 60,326 & $\$ 58,669$ & $\$ 1,013,915$ & $\$ 61,107$ \\
\hline Timaru DC & 2735.63 & 43900 & $\$ 21,200$ & 166 & 56,954 & $\$ 54,821$ & $\$ 741,468$ & $\$ 44,848$ \\
\hline Upper Hutt CC & 539.85 & 40200 & $\$ 26,900$ & 140 & 34,078 & $\$ 35,874$ & $\$ 528,111$ & $\$ 25,146$ \\
\hline Waikato DC & 3188.79 & 46800 & $\$ 25,700$ & 156 & 58,134 & $\$ 47,887$ & $\$ 909,247$ & $\$ 22,035$ \\
\hline Waikato RC & 34,711 & 402,200 & $\$ 24,100$ & 368 & 94,262 & $\$ 90,066$ & $\$ 479,528$ & $\$ 15,658$ \\
\hline Waimakariri DC & 2218.82 & 46100 & $\$ 24,000$ & 135 & 50,824 & $\$ 43,609$ & $\$ 953,015$ & $\$ 27,896$ \\
\hline Waimate DC & 3582.25 & 7450 & $\$ 18,900$ & 40 & 9,785 & $\$ 10,011$ & $\$ 327,923$ & $\$ 4,792$ \\
\hline Waipa DC & 1469.24 & 44700 & $\$ 26,500$ & 153 & 45,701 & $\$ 46,642$ & $\$ 958,941$ & $\$ 25,727$ \\
\hline Wairoa DC & 4119.22 & 8480 & $\$ 20,100$ & 32 & 18,082 & $\$ 17,239$ & $\$ 191,471$ & $\$ 3,982$ \\
\hline Waitakere CC & 367.42 & 201400 & $\$ 26,100$ & 765 & 199,983 & $\$ 240,883$ & $\$ 2,580,344$ & $\$ 444,186$ \\
\hline Waitaki DC & 7213.62 & 20700 & $\$ 19,700$ & 16 & 35,834 & $\$ 35,304$ & $\$ 620,221$ & $\$ 9,774$ \\
\hline Waitomo DC & 3546.91 & 9600 & $\$ 23,300$ & 25 & 17,511 & $\$ 20,002$ & $\$ 277,357$ & $\$ 36,597$ \\
\hline Wanganui DC & 2372.66 & 43400 & $\$ 19,800$ & 196 & 56,760 & $\$ 56,129$ & $\$ 826,771$ & $\$ 82,609$ \\
\hline Wellington CC & 290.15 & 192800 & $\$ 32,500$ & 1440 & 325,228 & $\$ 326,270$ & $\$ 6,154,063$ & $\$ 341,003$ \\
\hline Wellington $\mathrm{RC}$ & 15,943 & 473,700 & $\$ 28,000$ & 424 & 162,309 & $\$ 169,195$ & $\$ 703,185$ & $\$ 92,804$ \\
\hline West Coast RC & 36,335 & 32,300 & $\$ 20,400$ & 48 & 15,150 & $\$ 14,751$ & $\$ 57,514$ & $\$ 4,045$ \\
\hline Western Bay of Plenty DC & 2120.78 & 44400 & $\$ 22,600$ & 120 & 52,464 & $\$ 59,473$ & $\$ 985,072$ & $\$ 113,532$ \\
\hline Westland DC & 11880.18 & 8760 & $\$ 22,700$ & 35 & 13,286 & $\$ 13,516$ & $\$ 354,743$ & $\$ 8,974$ \\
\hline Whakatane D C & 4456.78 & 34400 & $\$ 21,700$ & 170 & 43,838 & $\$ 40,588$ & $\$ 565,002$ & $\$ 20,136$ \\
\hline Whangarei DC & 2855.43 & 78200 & $\$ 22,500$ & 230 & 110,284 & $\$ 116,847$ & $\$ 1,254,963$ & $\$ 137,706$ \\
\hline
\end{tabular}

Area $\left(\mathbf{k m}^{2}\right)$ as at July 2006 (The Department of Internal Affairs, 2009a)

Pop (Population estimates) as at July 2008 (Statistics New Zealand, 2009a)

Median income (Median income of population) for the year ended July 2006 (The Department of Internal Affairs, 2009a)

No. of staff (number of council employees) as at July 2004 (The Department of Internal Affairs, 2009a)

Opert'g revenue (Operating revenue) for the year ended July 2008 (Statistics New Zealand, 2009b)

Opert'g expense (Operating expense) for the year ended July 2008 (Statistics New Zealand, 2009b)

Total assets as at July 2008 (Statistics New Zealand, 2009b)

Total liabilities as at July 2008 (Statistics New Zealand, 2009b) 


\section{Appendix B: Examples of prior studies using disclosure indices}

\begin{tabular}{|c|c|c|}
\hline Studies & Types of disclosures & Entities studied \\
\hline $\begin{array}{l}\text { Wiseman } \\
(1982)\end{array}$ & $\begin{array}{l}\text { Voluntary environmental disclosures in annual } \\
\text { reports }\end{array}$ & 26 polluting companies \\
\hline $\begin{array}{l}\text { Hughes, } \\
\text { Anderson and } \\
\text { Gordon (2001) }\end{array}$ & $\begin{array}{l}\text { Voluntary environmental disclosures within } \\
\text { president's letter, management's discussion and } \\
\text { analysis, and financial statement notes section } \\
\text { for their } 1992 \text { and } 1993 \text { annual reports }\end{array}$ & $\begin{array}{l}51 \text { manufacturing firms in } \\
\text { United States }\end{array}$ \\
\hline $\begin{array}{l}\text { Clarkson, P.M., } \\
\text { Li, Y., } \\
\text { Richardson, G., } \\
\text { and Vasvari, F. } \\
(2008)\end{array}$ & $\begin{array}{l}\text { Voluntary environmental disclosures in the } \\
2004 \text { website and social responsibility reports }\end{array}$ & $\begin{array}{l}191 \text { firms from the five } \\
\text { most polluting industries in } \\
\text { United States }\end{array}$ \\
\hline $\begin{array}{l}\text { Bozzolan, S., } \\
\text { O’Regan, P, } \\
\text { Ricceri, F. } \\
\text { (2006) }\end{array}$ & $\begin{array}{l}\text { Voluntary intellectual capital disclosure in } 2001 \\
\text { annual reports }\end{array}$ & $\begin{array}{l}60 \text { listed companies in Italy } \\
\text { and United Kingdom. }\end{array}$ \\
\hline $\begin{array}{l}\text { Schneider and } \\
\text { Samkin (2008) }\end{array}$ & $\begin{array}{l}\text { Voluntary intellectual capital disclosure in } \\
2004 / 2005 \text { annual reports }\end{array}$ & $\begin{array}{l}82 \text { local authorities in New } \\
\text { Zealand. }\end{array}$ \\
\hline $\begin{array}{l}\text { Williams, S. } \\
\text { (2001) }\end{array}$ & $\begin{array}{l}\text { Voluntary intellectual capital disclosure in } \\
1996-2000 \text { annual reports }\end{array}$ & $\begin{array}{l}31 \text { companies in United } \\
\text { Kingdom }\end{array}$ \\
\hline $\begin{array}{l}\text { Buzby, S. } \\
(1975)\end{array}$ & Mandatory disclosures in 1970 annual reports & $\begin{array}{l}88 \text { listed companies in } \\
\text { United States. }\end{array}$ \\
\hline Cooke (1989) & Mandatory disclosures in 1985 annual reports & 90 companies in Sweden \\
\hline $\begin{array}{l}\text { Robbins and } \\
\text { Austin (1986) }\end{array}$ & $\begin{array}{l}\text { Voluntary disclosures in 1981/1982 annual } \\
\text { reports }\end{array}$ & $\begin{array}{l}99 \text { city councils in United } \\
\text { States }\end{array}$ \\
\hline $\begin{array}{l}\text { Stanley, } \\
\text { Jennings and } \\
\text { Mack (2008) }\end{array}$ & $\begin{array}{l}\text { Mandatory disclosures in 2002/03 annual } \\
\text { reports }\end{array}$ & $\begin{array}{l}105 \text { Queensland local } \\
\text { government authorities in } \\
\text { Australia }\end{array}$ \\
\hline $\begin{array}{l}\text { Taylor and } \\
\text { Rosair (2000) }\end{array}$ & Mandatory disclosures in annual reports & $\begin{array}{l}48 \text { governmental } \\
\text { departments in Australia }\end{array}$ \\
\hline $\begin{array}{l}\text { Boyne and Law } \\
\text { (1991) }\end{array}$ & $\begin{array}{l}\text { Voluntary service performance (on } 13 \text { services) } \\
\text { information in } 1981 / 1982-1988 / 1989 \text { annual } \\
\text { reports }\end{array}$ & $\begin{array}{l}37 \text { Welsh district councils } \\
\text { in United Kingdom }\end{array}$ \\
\hline $\begin{array}{l}\text { Ryan, Stanley, } \\
\text { and Nelson } \\
(2002)\end{array}$ & $\begin{array}{l}\text { Mandatory disclosures within 1997-1999 } \\
\text { annual reports }\end{array}$ & $\begin{array}{l}36 \text { Queensland local } \\
\text { government councils in } \\
\text { Australia }\end{array}$ \\
\hline $\begin{array}{l}\text { Smith and Coy } \\
(2000)\end{array}$ & $\begin{array}{l}\text { Mandatory disclosures in 1996/97 - 1997/98 } \\
\text { annual reports }\end{array}$ & $\begin{array}{l}15 \text { local authorities New } \\
\text { Zealand }\end{array}$ \\
\hline $\begin{array}{l}\text { Coy, Tower, } \\
\text { and Dixon } \\
\text { (1994) }\end{array}$ & $\begin{array}{l}\text { Mandatory disclosures in 1990-1992 annual } \\
\text { report }\end{array}$ & $\begin{array}{l}\text { Tertiary education entities } \\
\text { in New Zealand. }\end{array}$ \\
\hline
\end{tabular}




\section{Appendix C: Standardised residual and Cook's Distance values for the}

\section{AR index scores}

\begin{tabular}{|c|c|c|c|}
\hline & Territorial authorities & $\begin{array}{r}\text { Standardised } \\
\text { residual } \\
\end{array}$ & $\begin{array}{r}\text { Cook's } \\
\text { Distance } \\
\end{array}$ \\
\hline 1 & Ashburton DC & 0.2415 & 0.00023 \\
\hline 2 & Auckland CC & -1.1166 & 1.12673 \\
\hline 3 & Buller DC & 0.04322 & 0.00002 \\
\hline 4 & Carterton DC & -0.26151 & 0.00024 \\
\hline 5 & Central Hawk DC & -0.04675 & 0.00002 \\
\hline 6 & Central Otago DC & -1.43106 & 0.00694 \\
\hline 7 & Chatham Island C & -0.88474 & 0.00463 \\
\hline 8 & Christchurch CC & 1.35018 & 0.23548 \\
\hline 9 & Clutha DC & 0.2427 & 0.00034 \\
\hline 10 & Dunedin CC & 0.317 & 0.00189 \\
\hline 11 & Far North DC & 0.44181 & 0.0029 \\
\hline 12 & Franklin DC & 0.40844 & 0.00291 \\
\hline 13 & Gisborne DC & 0.07095 & 0.0001 \\
\hline 14 & Gore DC & -1.08944 & 0.00401 \\
\hline 15 & Grey DC & 1.81761 & 0.01303 \\
\hline 16 & Hamilton CC & 0.91262 & 0.03884 \\
\hline 17 & Hastings DC & -0.06 & 0.00002 \\
\hline 18 & Hauraki DC & 0.35078 & 0.00079 \\
\hline 19 & Horowhenua DC & -0.11557 & 0.00013 \\
\hline 20 & Hurunui DC & -2.18178 & 0.01932 \\
\hline 21 & Hutt CC & 1.15964 & 0.045 \\
\hline 22 & Invercargill DC & 0.00534 & 0 \\
\hline 23 & Kaikoura DC & -0.92953 & 0.00313 \\
\hline 24 & Kaipara DC & -0.04035 & 0.00001 \\
\hline 25 & Kapiti Coast DC & 1.11489 & 0.00496 \\
\hline 26 & Kawerau DC & -1.17776 & 0.02055 \\
\hline 27 & Mackenzie DC & -0.17055 & 0.0001 \\
\hline 28 & Manawatu DC & -0.0644 & 0.00002 \\
\hline 29 & Manukau CC & -2.08122 & 3.14502 \\
\hline 30 & Marlborough DC & 0.60557 & 0.00274 \\
\hline 31 & Masterton DC & 1.22971 & 0.00639 \\
\hline 32 & Matamata-Piako DC & -0.36739 & 0.00089 \\
\hline 33 & Napier CC & 0.08727 & 0.00005 \\
\hline 34 & Nelson CC & 0.95447 & 0.00394 \\
\hline 35 & New Plymouth DC & 1.09448 & 0.02266 \\
\hline 36 & North Shore CC & 0.99601 & 0.02953 \\
\hline
\end{tabular}




\begin{tabular}{|c|c|c|c|}
\hline & Territorial authorities & $\begin{array}{r}\text { Standardised } \\
\text { residual } \\
\end{array}$ & $\begin{array}{r}\text { Cook's } \\
\text { Distance } \\
\end{array}$ \\
\hline 37 & Opotiki DC & -0.24383 & 0.00077 \\
\hline 38 & Otorohanga DC & -0.17127 & 0.00012 \\
\hline 39 & Palmerston North CC & -0.25798 & 0.00122 \\
\hline 40 & Papakura DC & -2.93092 & 0.10713 \\
\hline 41 & Porirua CC & 0.16648 & 0.00029 \\
\hline 42 & Queenstown-Lake DC & -0.44523 & 0.00854 \\
\hline 43 & Rangitikei DC & -0.44895 & 0.00079 \\
\hline 44 & Rodney DC & -0.17447 & 0.00037 \\
\hline 45 & Rotorua DC & 0.48121 & 0.00719 \\
\hline 46 & Ruapehu DC & 0.37936 & 0.00066 \\
\hline 47 & Selwyn DC & -0.06245 & 0.00006 \\
\hline 48 & South Taranaki DC & -0.12123 & 0.00006 \\
\hline 49 & South Waikato DC & -0.36881 & 0.00072 \\
\hline 50 & South Wairarapa DC & 1.25907 & 0.00762 \\
\hline 51 & Southland DC & 1.05853 & 0.01173 \\
\hline 52 & Stratford DC & 0.26712 & 0.00024 \\
\hline 53 & Tararua DC & 0.50417 & 0.00153 \\
\hline 54 & Tasman DC & -0.15686 & 0.00014 \\
\hline 55 & Taupo DC & -1.23586 & 0.01114 \\
\hline 56 & Tauranga CC & 2.29299 & 0.0958 \\
\hline 57 & Thames-Coromandel DC & 1.02859 & 0.00934 \\
\hline 58 & Timaru DC & 0.6143 & 0.00186 \\
\hline 59 & Upper Hutt CC & 0.06071 & 0.00004 \\
\hline 60 & Waikato DC & 0.06562 & 0.00002 \\
\hline 61 & Waimakariri DC & -0.56937 & 0.0012 \\
\hline 62 & Waimate DC & -1.25976 & 0.01381 \\
\hline 63 & Waipa DC & 2.71413 & 0.05992 \\
\hline 64 & Wairoa DC & -0.66089 & 0.00247 \\
\hline 65 & Waitakere CC & 0.36649 & 0.0098 \\
\hline 66 & Waitaki DC & -0.12461 & 0.00016 \\
\hline 67 & Waitomo DC & -1.30643 & 0.00633 \\
\hline 68 & Wanganui DC & -0.86996 & 0.00499 \\
\hline 69 & Wellington CC & -1.21706 & 1.27619 \\
\hline 70 & Western Bay DC & 0.82504 & 0.00268 \\
\hline 71 & Westland DC & -0.29511 & 0.00033 \\
\hline 72 & Whakatane DC & -0.04617 & 0.00001 \\
\hline 73 & Whangarei DC & -0.54213 & 0.00604 \\
\hline
\end{tabular}




\section{Appendix D: Standardised residual and Cook's Distance values for the}

\section{AE index scores}

\begin{tabular}{|c|c|c|c|}
\hline & Territorial authorities & $\begin{array}{r}\text { Standardised } \\
\text { residual } \\
\end{array}$ & $\begin{array}{r}\text { Cook's } \\
\text { Distance }\end{array}$ \\
\hline 1 & Ashburton DC & 0.5085 & 0.001 \\
\hline 2 & Auckland CC & -1.50883 & 2.05733 \\
\hline 3 & Buller DC & 0.90034 & 0.00886 \\
\hline 4 & Carterton DC & -1.19699 & 0.00501 \\
\hline 5 & Central Hawke's Bay DC & 0.29652 & 0.00061 \\
\hline 6 & Central Otago DC & -1.12473 & 0.00429 \\
\hline 7 & Chatham Island C & -1.64749 & 0.01607 \\
\hline 8 & Christchurch CC & 1.03105 & 0.13732 \\
\hline 9 & Clutha DC & 1.09275 & 0.00697 \\
\hline 10 & Dunedin CC & -0.41775 & 0.00327 \\
\hline 11 & Far North DC & 1.12266 & 0.01874 \\
\hline 12 & Franklin DC & 0.74614 & 0.00972 \\
\hline 13 & Gisborne DC & -0.47557 & 0.00448 \\
\hline 14 & Gore DC & -0.78695 & 0.00209 \\
\hline 15 & Grey DC & -0.36936 & 0.00054 \\
\hline 16 & Hamilton CC & 1.71066 & 0.13647 \\
\hline 17 & Hastings DC & 0.41189 & 0.00095 \\
\hline 18 & Hauraki DC & -0.39617 & 0.00101 \\
\hline 19 & Horowhenua DC & -0.78302 & 0.00601 \\
\hline 20 & Hurunui DC & -2.19252 & 0.01951 \\
\hline 21 & Hutt CC & 0.33434 & 0.00374 \\
\hline 22 & Invercargill DC & 0.26169 & 0.00067 \\
\hline 23 & Kaikoura DC & -0.81556 & 0.00241 \\
\hline 24 & Kaipara DC & -1.20409 & 0.01011 \\
\hline 25 & Kapiti Coast DC & 1.40333 & 0.00785 \\
\hline 26 & Kawerau DC & -0.44367 & 0.00292 \\
\hline 27 & Mackenzie DC & 0.9512 & 0.00322 \\
\hline 28 & Manawatu DC & 0.5482 & 0.00125 \\
\hline 29 & Manukau CC & -1.27746 & 1.18491 \\
\hline 30 & Marlborough DC & 0.018 & 0 \\
\hline 31 & Masterton DC & -0.68308 & 0.00197 \\
\hline 32 & Matamata-Piako DC & -0.35557 & 0.00083 \\
\hline 33 & Napier CC & -0.02409 & 0 \\
\hline 34 & Nelson CC & 0.51946 & 0.00117 \\
\hline 35 & New Plymouth DC & -0.54987 & 0.00572 \\
\hline 36 & North Shore CC & 1.46327 & 0.06373 \\
\hline
\end{tabular}




\begin{tabular}{|c|c|c|c|}
\hline & Territorial authorities & $\begin{array}{r}\text { Standardised } \\
\text { residual } \\
\end{array}$ & $\begin{array}{r}\text { Cook's } \\
\text { Distance } \\
\end{array}$ \\
\hline 37 & Opotiki DC & -0.38277 & 0.0019 \\
\hline 38 & Otorohanga DC & 0.93786 & 0.00372 \\
\hline 39 & Palmerston North CC & -0.039 & 0.00003 \\
\hline 40 & Papakura DC & -3.27929 & 0.13412 \\
\hline 41 & Porirua CC & -0.72431 & 0.00555 \\
\hline 42 & Queenstown-Lake DC & 0.19309 & 0.00161 \\
\hline 43 & Rangitikei D & 0.53794 & 0.00114 \\
\hline 44 & Rodney DC & 0.86191 & 0.00892 \\
\hline 45 & Rotorua DC & -1.21984 & 0.04621 \\
\hline 46 & Ruapehu DC & 0.03796 & 0.00001 \\
\hline 47 & Selwyn DC & -1.03624 & 0.01575 \\
\hline 48 & South Taranaki DC & -0.28888 & 0.00035 \\
\hline 49 & South Waikato DC & 0.02458 & 0 \\
\hline 50 & South Wairarapa DC & 0.58036 & 0.00162 \\
\hline 51 & Southland DC & 1.97354 & 0.04076 \\
\hline 52 & Stratford DC & 1.42436 & 0.0069 \\
\hline 53 & Tararua DC & -0.62346 & 0.00234 \\
\hline 54 & Tasman DC & -0.28956 & 0.00046 \\
\hline 55 & Taupo DC & 1.31188 & 0.01255 \\
\hline 56 & Tauranga CC & 1.00067 & 0.01825 \\
\hline 57 & Thames-Coromandel DC & 0.4597 & 0.00187 \\
\hline 58 & Timaru DC & 0.03333 & 0.00001 \\
\hline 59 & Upper Hutt CC & -1.15824 & 0.01498 \\
\hline 60 & Waikato DC & 1.44414 & 0.0118 \\
\hline 61 & Waimakariri DC & -0.66661 & 0.00164 \\
\hline 62 & Waimate DC & 0.53717 & 0.00251 \\
\hline 63 & Waipa DC & 0.65178 & 0.00346 \\
\hline 64 & Wairoa DC & -0.40711 & 0.00094 \\
\hline 65 & Waitakere CC & 1.17353 & 0.1005 \\
\hline 66 & Waitaki DC & 0.19093 & 0.00037 \\
\hline 67 & Waitomo DC & -0.33124 & 0.00041 \\
\hline 68 & Wanganui DC & 0.03551 & 0.00001 \\
\hline 69 & Wellington CC & -0.81098 & 0.56664 \\
\hline 70 & Western Bay of Plenty DC & 0.24328 & 0.00023 \\
\hline 71 & Westland DC & 0.17077 & 0.00011 \\
\hline 72 & Whakatane DC & 0.8409 & 0.00303 \\
\hline 73 & Whangarei DC & -0.47491 & 0.00463 \\
\hline
\end{tabular}


Appendix E: The scatterplot of standardised residuals against standardised predicted value for the AR index

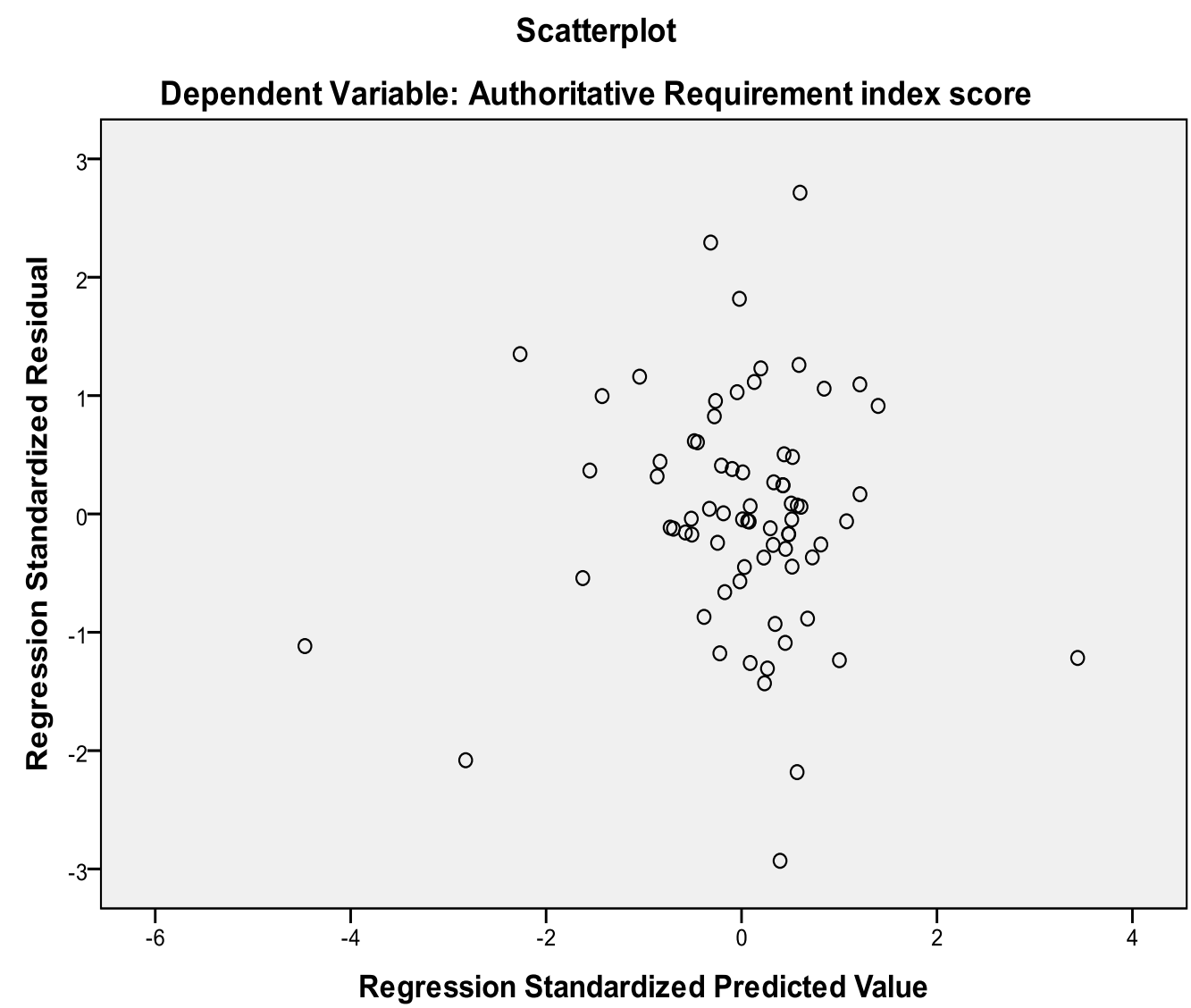


Appendix F: The scatterplot of standardised residuals against standardised predicted value for the $\mathrm{AE}$ index

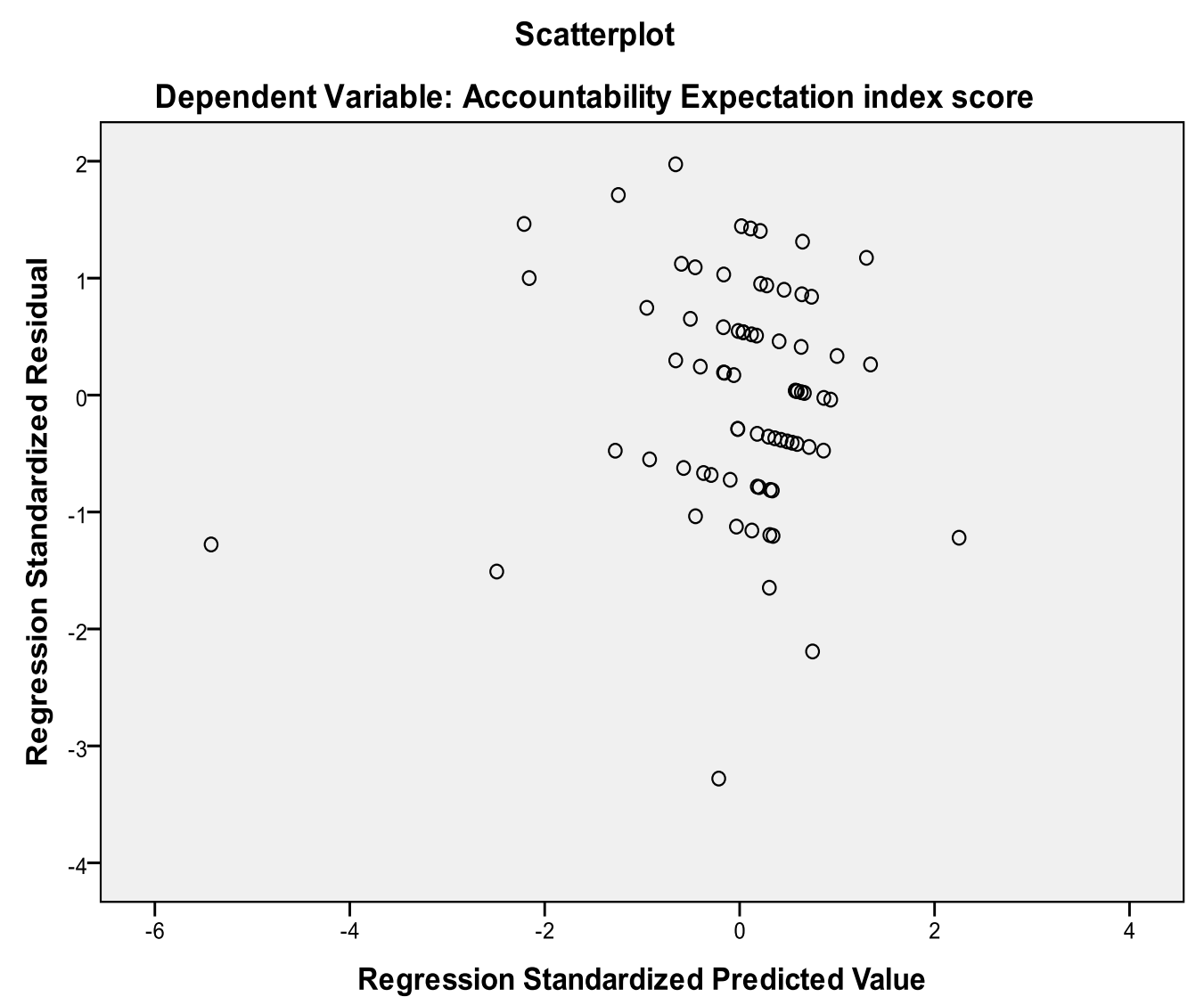


Appendix G: Histogram of standardised residuals for the AR index

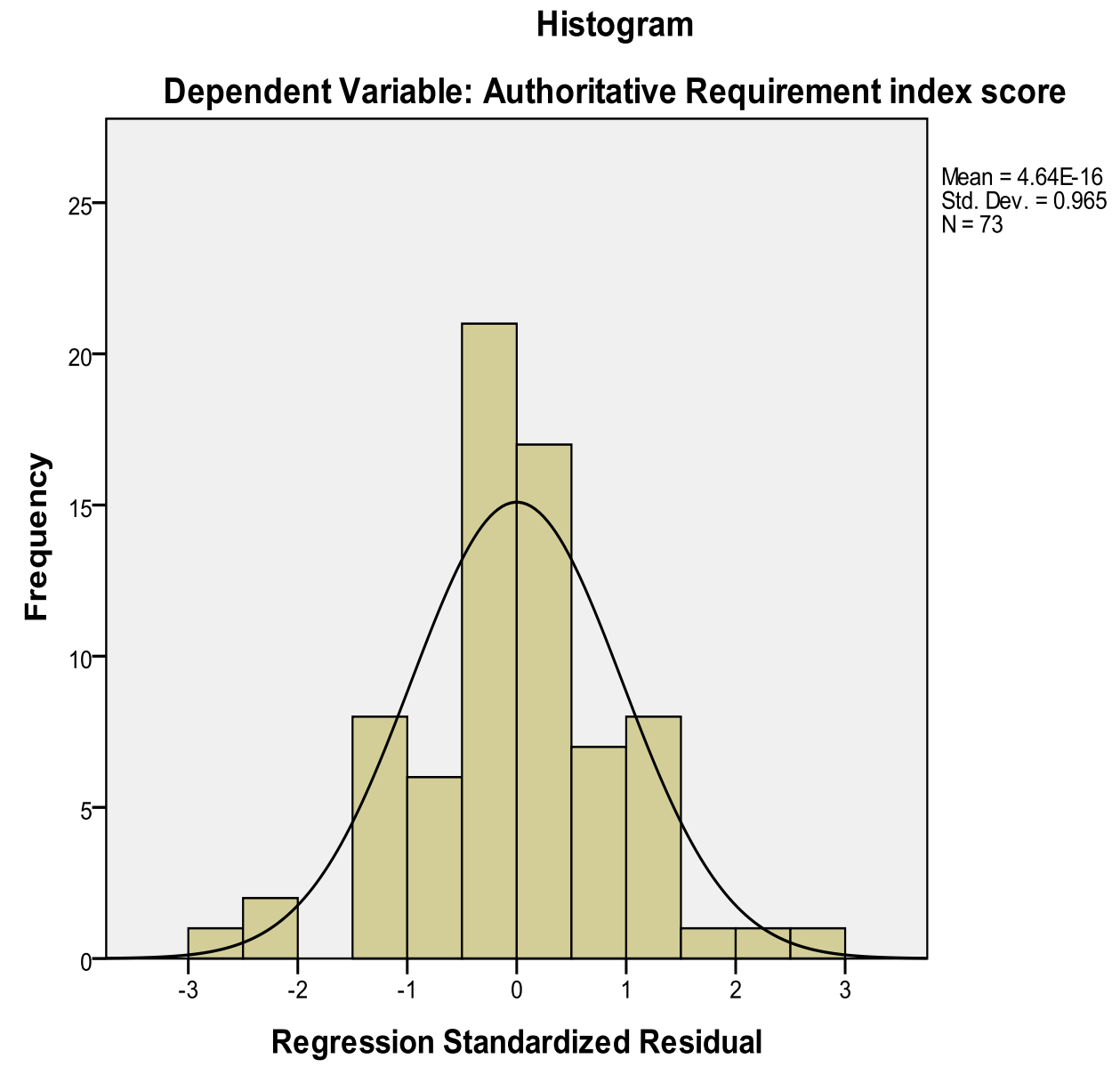


Appendix H: Histogram of standardised residuals for the AE index

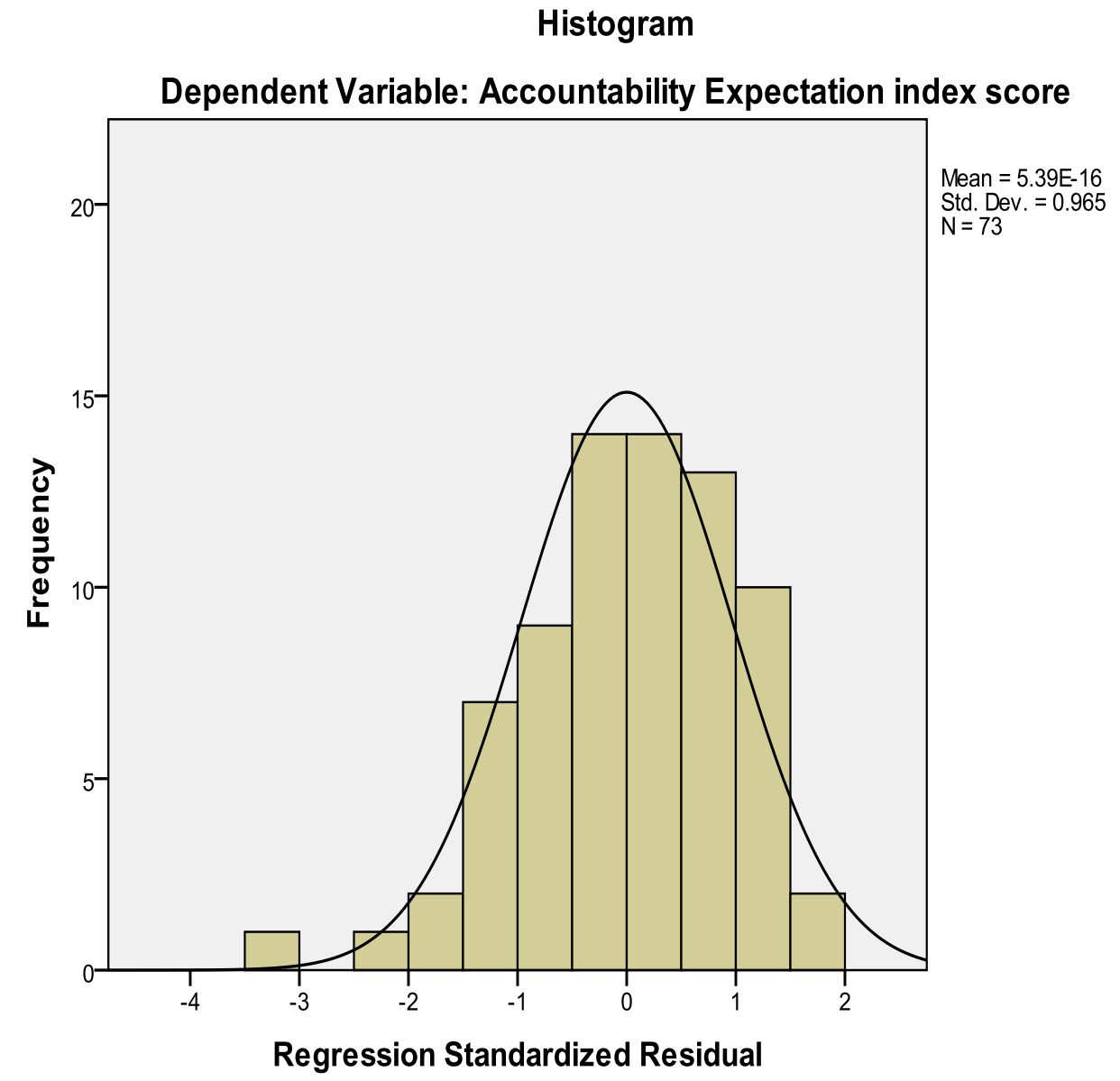


Appendix I: Standardised residual and Cook's Distance value of the logarithmic transformed AR index scores

\begin{tabular}{|c|c|c|c|}
\hline & Territorial authorities & $\begin{array}{r}\text { Standardised } \\
\text { residual } \\
\end{array}$ & $\begin{array}{r}\text { Cook's } \\
\text { distance } \\
\end{array}$ \\
\hline 1 & Ashburton DC & 0.47861 & 0.00118 \\
\hline 2 & Auckland CC & -2.70847 & 0.19337 \\
\hline 3 & Buller DC & 0.04395 & 0.00003 \\
\hline 4 & Carterton DC & 0.12427 & 0.00021 \\
\hline 5 & Central Hawke's Bay DC & -0.15659 & 0.00055 \\
\hline 6 & Central Otago DC & -1.31769 & 0.00731 \\
\hline 7 & Chatham Island C & -0.34689 & 0.02595 \\
\hline 8 & Christchurch CC & 0.60878 & 0.00734 \\
\hline 9 & Clutha DC & 0.14111 & 0.00021 \\
\hline 10 & Dunedin CC & 0.07483 & 0.00013 \\
\hline 11 & Far North DC & 0.10919 & 0.00021 \\
\hline 12 & Franklin DC & 0.44532 & 0.00414 \\
\hline 13 & Gisborne DC & -0.05895 & 0.00007 \\
\hline 14 & Gore DC & -0.84129 & 0.00659 \\
\hline 15 & Grey DC & 1.46716 & 0.01094 \\
\hline 16 & Hamilton CC & 0.87052 & 0.00952 \\
\hline 17 & Hastings DC & 0.11243 & 0.00007 \\
\hline 18 & Hauraki DC & 0.37967 & 0.00126 \\
\hline 19 & Horowhenua D & 0.00115 & 0 \\
\hline 20 & Hurunui DC & -2.01961 & 0.08855 \\
\hline 21 & Hutt CC & 1.12322 & 0.02871 \\
\hline 22 & Invercargill DC & 0.34529 & 0.00148 \\
\hline 23 & Kaikoura DC & -0.66661 & 0.00732 \\
\hline 24 & Kaipara DC & 0.02888 & 0.00001 \\
\hline 25 & Kapiti Coast DC & 1.05809 & 0.00701 \\
\hline 26 & Kawerau DC & -0.53068 & 0.02687 \\
\hline 27 & Mackenzie DC & -0.03657 & 0.00002 \\
\hline 28 & Manawatu DC & 0.17485 & 0.00024 \\
\hline 29 & Manukau CC & -3.80121 & 0.27291 \\
\hline 30 & Marlborough DC & 0.57684 & 0.00236 \\
\hline 31 & Masterton DC & 0.91026 & 0.00925 \\
\hline 32 & Matamata-Piako DC & 0.08729 & 0.00008 \\
\hline 33 & Napier CC & 0.27253 & 0.00057 \\
\hline 34 & Nelson CC & 0.77382 & 0.00238 \\
\hline 35 & New Plymouth DC & 0.88627 & 0.01068 \\
\hline 36 & North Shore CC & 0.55752 & 0.00478 \\
\hline
\end{tabular}




\begin{tabular}{|c|c|c|c|}
\hline & Territorial authorities & $\begin{array}{r}\text { Standardised } \\
\text { residual } \\
\end{array}$ & $\begin{array}{r}\text { Cook's } \\
\text { distance }\end{array}$ \\
\hline 37 & Opotiki DC & -0.11996 & 0.00035 \\
\hline 38 & Otorohanga DC & 0.23324 & 0.00051 \\
\hline 39 & Palmerston North CC & 0.11181 & 0.00011 \\
\hline 40 & Papakura DC & -3.47181 & 0.36817 \\
\hline 41 & Porirua CC & 0.44971 & 0.0024 \\
\hline 42 & Queenstown-Lake DC & -0.0812 & 0.0003 \\
\hline 43 & Rangitikei DC & -0.35667 & 0.00081 \\
\hline 44 & Rodney DC & -0.03861 & 0.00001 \\
\hline 45 & Rotorua DC & 0.86745 & 0.01295 \\
\hline 46 & Ruapehu DC & 0.51624 & 0.00255 \\
\hline 47 & Selwyn DC & 0.25691 & 0.00112 \\
\hline 48 & South Taranake DC & 0.04938 & 0.00001 \\
\hline 49 & South Waikato DC & 0.01157 & 0 \\
\hline 50 & South Wairarapa DC & 0.94431 & 0.01654 \\
\hline 51 & Southland DC & 0.82414 & 0.0086 \\
\hline 52 & Stratford DC & 0.3409 & 0.00095 \\
\hline 53 & Tararua DC & 0.31425 & 0.00115 \\
\hline 54 & Tasman DC & -0.18865 & 0.00021 \\
\hline 55 & Taupo DC & -0.91325 & 0.01526 \\
\hline 56 & Tauranga CC & 1.41753 & 0.01853 \\
\hline 57 & Thames-Coromandel DC & 0.71514 & 0.01003 \\
\hline 58 & Timaru DC & 0.61765 & 0.00238 \\
\hline 59 & Upper Hutt CC & 0.50344 & 0.00475 \\
\hline 60 & Waikato DC & 0.26248 & 0.00036 \\
\hline 61 & Waimakariri DC & -0.4153 & 0.0008 \\
\hline 62 & Waimate DC & -1.44634 & 0.07579 \\
\hline 63 & Waipa DC & 1.93444 & 0.03305 \\
\hline 64 & Wairoa DC & -0.33108 & 0.00177 \\
\hline 65 & Waitakere CC & 0.22864 & 0.00069 \\
\hline 66 & Waitaki DC & -0.23979 & 0.00676 \\
\hline 67 & Waitomo DC & -1.05502 & 0.01171 \\
\hline 68 & Wanganui DC & -0.773 & 0.005 \\
\hline 69 & Wellington CC & -0.30889 & 0.00481 \\
\hline 70 & Western Bay of Plenty DC & 0.64528 & 0.00219 \\
\hline 71 & Westland DC & -0.2481 & 0.00079 \\
\hline 72 & Whakatane DC & 0.22763 & 0.00031 \\
\hline 73 & Whangarei DC & -0.65176 & 0.0056 \\
\hline
\end{tabular}


Appendix J: Standardised residual and Cook's Distance value of the logarithmic transformed AE index scores

\begin{tabular}{|c|c|c|c|}
\hline & Territorial authorities & $\begin{array}{r}\text { Standardised } \\
\text { residual }\end{array}$ & $\begin{array}{r}\text { Cook's } \\
\text { distance }\end{array}$ \\
\hline 1 & Ashburton DC & 0.74896 & 0.00289 \\
\hline 2 & Auckland CC & -2.23479 & 0.13165 \\
\hline 3 & Buller DC & 0.46002 & 0.00337 \\
\hline 4 & Carterton DC & -0.58564 & 0.00476 \\
\hline 5 & Central Hawke's Bay DC & 0.10784 & 0.00026 \\
\hline 6 & Central Otago DC & -0.90996 & 0.00348 \\
\hline 7 & Chatham Island C & -1.60683 & 0.55672 \\
\hline 8 & Christchurch CC & 0.57721 & 0.0066 \\
\hline 9 & Clutha DC & 0.60306 & 0.00381 \\
\hline 10 & Dunedin CC & -0.56579 & 0.00731 \\
\hline 11 & Far North DC & 0.38289 & 0.00258 \\
\hline 12 & Franklin DC & 0.84124 & 0.01478 \\
\hline 13 & Gisborne DC & -0.89273 & 0.01577 \\
\hline 14 & Gore DC & -0.39486 & 0.00145 \\
\hline 15 & Grey DC & -0.14186 & 0.0001 \\
\hline 16 & Hamilton CC & 1.00016 & 0.01257 \\
\hline 17 & Hastings DC & 0.4967 & 0.00133 \\
\hline 18 & Hauraki DC & -0.30688 & 0.00082 \\
\hline 19 & Horowhenua D & -0.43688 & 0.00598 \\
\hline 20 & Hurunui DC & -2.08218 & 0.09413 \\
\hline 21 & Hutt CC & 0.89774 & 0.01834 \\
\hline 22 & Invercargill DC & 0.60796 & 0.00458 \\
\hline 23 & Kaikoura DC & -0.51397 & 0.00435 \\
\hline 24 & Kaipara DC & -1.11324 & 0.02138 \\
\hline 25 & Kapiti Coast DC & 1.28823 & 0.01039 \\
\hline 26 & Kawerau DC & 0.22307 & 0.00475 \\
\hline 27 & Mackenzie DC & 0.81494 & 0.01181 \\
\hline 28 & Manawatu DC & 0.74735 & 0.0044 \\
\hline 29 & Manukau CC & -2.7897 & 0.14699 \\
\hline 30 & Marlborough DC & 0.12995 & 0.00012 \\
\hline 31 & Masterton DC & -0.46539 & 0.00242 \\
\hline 32 & Matamata-Piako DC & 0.22251 & 0.00049 \\
\hline 33 & Napier CC & 0.09982 & 0.00008 \\
\hline 34 & Nelson CC & 0.40655 & 0.00066 \\
\hline 35 & New Plymouth DC & -0.74208 & 0.00748 \\
\hline
\end{tabular}




\begin{tabular}{|c|c|c|c|}
\hline & Territorial authorities & $\begin{array}{r}\text { Standardised } \\
\text { residual } \\
\end{array}$ & $\begin{array}{r}\text { Cook's } \\
\text { distance } \\
\end{array}$ \\
\hline 36 & North Shore CC & 0.93985 & 0.01359 \\
\hline 37 & Opotiki DC & -0.11355 & 0.00031 \\
\hline 38 & Otorohanga DC & 1.07899 & 0.01091 \\
\hline 39 & Palmerston North CC & 0.28879 & 0.0007 \\
\hline 40 & Papakura DC & -4.487 & 0.61496 \\
\hline 41 & Porirua $\mathrm{CC}$ & -0.30437 & 0.0011 \\
\hline 42 & Queenstown-Lake DC & 0.4288 & 0.00832 \\
\hline 43 & Rangitikei DC & 0.39083 & 0.00097 \\
\hline 44 & Rodney DC & 0.94496 & 0.0078 \\
\hline 45 & Rotorua DC & -0.40234 & 0.00279 \\
\hline 46 & Ruapehu DC & 0.09732 & 0.00009 \\
\hline 47 & Selwyn DC & -0.54434 & 0.00504 \\
\hline 48 & South Taranake DC & -0.1054 & 0.00004 \\
\hline 49 & South Waikato DC & 0.39839 & 0.00172 \\
\hline 50 & South Wairarapa DC & 0.647 & 0.00776 \\
\hline 51 & Southland DC & 1.15733 & 0.01696 \\
\hline 52 & Stratford DC & 1.19237 & 0.01162 \\
\hline 53 & Tararua DC & -0.68142 & 0.00542 \\
\hline 54 & Tasman DC & -0.29775 & 0.00052 \\
\hline 55 & Taupo DC & 0.87331 & 0.01396 \\
\hline 56 & Tauranga CC & 0.37474 & 0.00129 \\
\hline 57 & Thames-Coromandel DC & 0.02606 & 0.00001 \\
\hline 58 & Timaru DC & 0.19332 & 0.00023 \\
\hline 59 & Upper Hutt CC & -0.38526 & 0.00278 \\
\hline 60 & Waikato DC & 1.26247 & 0.00823 \\
\hline 61 & Waimakariri DC & -0.41703 & 0.0008 \\
\hline 62 & Waimate DC & 0.31072 & 0.0035 \\
\hline 63 & Waipa DC & 0.77975 & 0.00537 \\
\hline 64 & Wairoa DC & -0.22813 & 0.00084 \\
\hline 65 & Waitakere CC & 1.24461 & 0.02035 \\
\hline 66 & Waitaki DC & -0.05644 & 0.00037 \\
\hline 67 & Waitomo DC & -0.07223 & 0.00005 \\
\hline 68 & Wanganui DC & 0.05996 & 0.00003 \\
\hline 69 & Wellington CC & -0.57425 & 0.01662 \\
\hline 70 & Western Bay of Plenty DC & 0.22471 & 0.00027 \\
\hline 71 & Westland DC & 0.22347 & 0.00064 \\
\hline 72 & Whakatane DC & 0.85981 & 0.00438 \\
\hline 73 & Whangarei DC & -0.20149 & 0.00054 \\
\hline
\end{tabular}

